\title{
DISTRIBUIÇÃO RADICULAR E CONSUMO DE ÁGUA DE GOIABEIRA (Psidium guajava L.) IRRIGADA POR MICROASPERSÃO EM PETROLINA-PE
}

\section{MARCELO DE NOVAES LIMA FERREIRA}

Tese apresentada à Escola Superior de Agricultura "Luiz de Queiroz", Universidade de São Paulo, para obtenção do título de Doutor em Agronomia, Área de concentração: Irrigação e Drenagem

PIR A CICAB A

Estado de São Paulo - Brasil

Janeiro - 2004 


\title{
DISTRIBUIÇÃO RADICULAR E CONSUMO DE ÁGUA DE GOIABEIRA (Psidium guajava L.) IRRIGADA POR MICROASPERSÃO EM PETROLINA-PE
}

\author{
MARCELO DE NOVAES LIMA FERREIRA \\ Engenheiro Agrônomo
}

Orientador: Prof. Dr. RUBENS DUARTE COELHO

Co-Orientador: Dr. LUÍS HENRIQUE BASSOI

\begin{abstract}
Tese apresentada à Escola Superior de Agricultura "Luiz de Queiroz", Universidade de São Paulo, para obtenção do título de Doutor em Agronomia, Área de concentração: Irrigação e Drenagem
\end{abstract}

\author{
PIR A CICAB A \\ Estado de São Paulo - Brasil \\ Janeiro - 2004
}




\section{Dados Internacionais de Catalogação na Publicação (CIP)} DIVISÃO DE BIBLIOTECA E DOCUMENTAÇÃO - ESALQ/USP

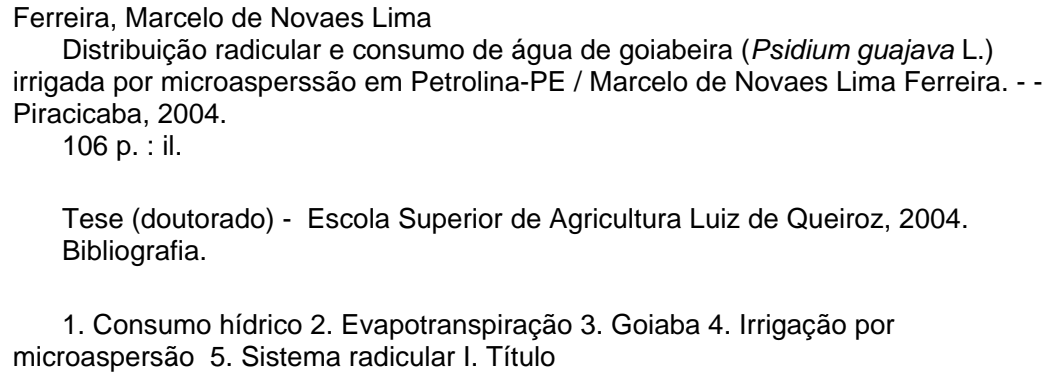

1. Consumo hídrico 2. Evapotranspiração 3. Goiaba 4. Irrigação por microaspersão 5 . Sistema radicular I. Título

CDD 634.421

\section{“Permitida a cópia total ou parcial deste documento, desde que citada a fonte - O autor"}


À minha esposa

Margarida e aos nossos filhos

Rafael e Marcela DEDICO 


\section{AGRADECIMENTOS}

À Universidade do Estado da Bahia (UNEB) e ao Centro Federal de Educação Tecnológica de Petrolina - PE (CEFET).

À Coordenação de Aperfeiçoamento de Pessoal de Nível Superior (CAPES), pela bolsa de estudo fornecida durante o curso.

À Empresa Brasileira de Pesquisa Agropecuária, Embrapa Semi Árido, pela oportunidade de realizar este trabalho em suas dependências.

Ao Prof. Dr. Rubens Duarte Coelho pela orientação e incentivo para a realização deste trabalho.

Ao Dr. Luís Henrique Bassoi, pesquisador da Embrapa Semi Árido e coorientador deste trabalho, pela oportunidade de realizar os trabalhos de campo em Petrolina - PE.

Aos professores do curso de Pós-Graduação em Irrigação e Drenagem da ESALQ - USP: Dr. José Antônio Frizzone, Dr. Sérgio Nascimento Duarte, Dr. Tarlei Arriel Botrel, Dr. Décio Eugênio Cruciani e Dr. Marcus Vinícius Folegatti pelos ensinamentos. Aos professores: Dr. Paulo Cezar Sentelhas e Dr. Quirijn de Jong Van Lier pelas sugestões apresentadas no exame de qualificação.

Ao pesquisador da Embrapa Semi Árido, Antônio Heriberto de Castro Teixeira, aos bolsistas do CNPQ Joselanne Luíza Trajano Maia, José Antonio Moura e Silva, Emanuel Élder Gomes da Silva e ao Técnico Agrícola Valfredo dos Santos pela colaboração na coleta de dados e na condução dos trabalho de campo. 


\section{SUMÁRIO}

Página

LISTA DE FIGURAS........................................................................... vii

LISTA DE TABELAS................................................................................

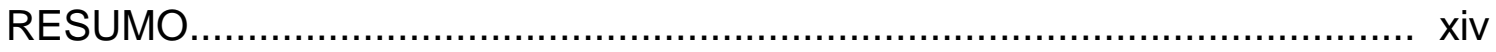

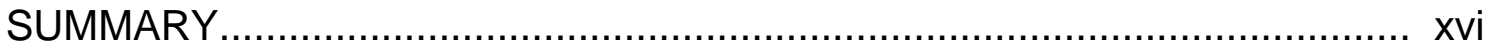

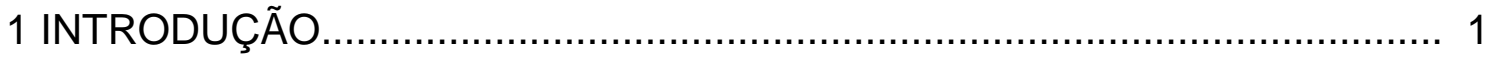

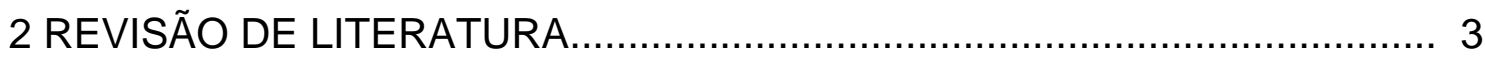

2.1 Considerações sobre a cultura da goiabeira.......................................... 3

2.2 Análise da distribuição radicular......................................................... 7

2.3 Estimativa da evapotranspiração................................................... 12

2.4 Dinâmica da água no solo e balanço hídrico in situ................................ 15

2.5 Métodos de medição de umidade do solo.............................................. 18

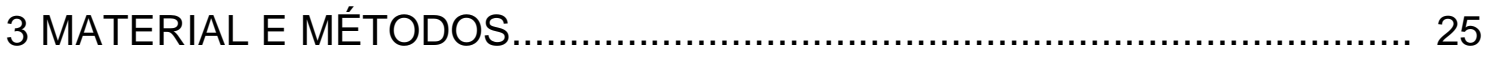

3.1 Localização e caracterização da área experimental................................. 25

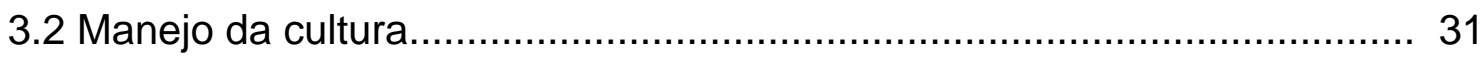

3.3 Evapotranspiração de referência (ETo).............................................. 35

3.4 Balanço hídrico no solo............................................................... 41

3.4.1 Calibração dos equipamentos........................................................ 41

3.4.2 Determinação da evapotranspiração da cultura (ETc)......................... 44

3.5 Análise da distribuição do sistema radicular......................................... 48

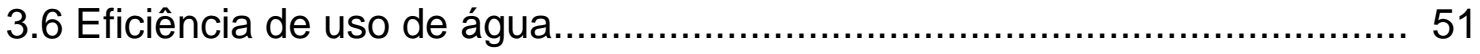




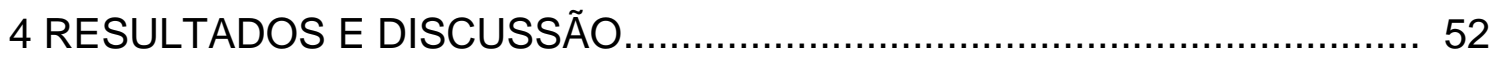

4.1Calibração da sonda de nêutrons e do TDR .................................. 52

4.2 Características do solo................................................................. 53

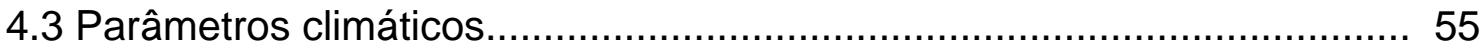

4.4 Distribuição do sistema radicular......................................... 59

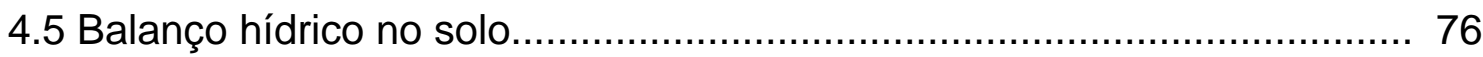

4.6 Eficiência do uso de água....................................................... 84

4.7 Comparações da umidade do solo medida com a SN e com o TDR........ 84

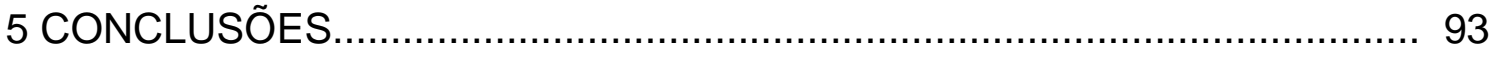

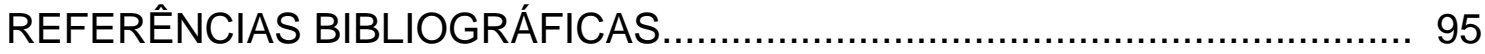




\section{LISTA DE FIGURAS}

Página

1 Planta de situação do projeto Bebedouro............................................ 26

2 Temperatura máxima, média e mínima do ar do período de 1963/99 da estação agrometeorológica de Bebedouro.................................... 27

3 Precipitação pluvial média do período de 1963/99 da estação agrometeorológicade Bebedouro (Petrolina-PE).............................. 27

4 Evaporação do tanque classe A do período de 1963/99 da estação agrometeorológica de Bebedouro (Petrolina-PE)............................

5 Umidade relativa média do ar do período de 1963/99 da estação agrometeorológica de Bebedouro (Petrolina-PE)............................ 28

6 Insolação do período de 1963/99 da estação agrometeorlógica de

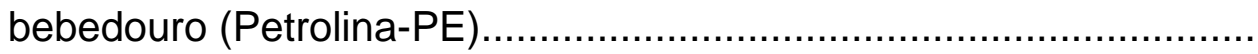

7 Radiação global média do período de 1963/99 da estação agrometeorológica de Bebedouro (Petrolina-PE)............................

8 Velocidade média do vento do período de 1963/99 da estação agrometeorológica de Bebedouro (Petrolina-PE)............................ 30

9 Esquema do pomar de goiabeiras................................................... 32

10 Parcela para a calibração da sonda de nêutrons e do TDR............... 42

11 Detalhe da sonda de nêutrons, do TDR e do tensímetro.................. 45

12 Esquema de instalação dos tensiômetros, dos tubos de acesso da sonda de neutrons e das sondas de TDR........................................

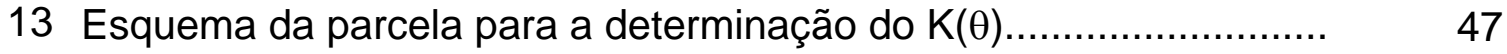

14 Esquema da trincheira para análise de raízes.................................. 49 
15 Quadrado de madeira para delimitar a área a ser fotografada........... 49

16 Equação de calibração do TDR ............................................ 52

17 Equação de calibração da sonda de nêutrons............................... 53

18 Curvas de retenção para três profundidades $(0,2,0,4$ e 0,6 m) do solo estudado

19 Curvas de retenção para três profundidades $(0,8,1,0$ e 1,2 m) do solo estudado.

20 Temperatura média, máxima e mínima da estação agrometeorológica de Bebedouro no período de junho a dezembro de 2001.

21 Precipitação pluviométrica da estação agrometeorológica de Bebedouro no período de junho a dezembro de 2001.

22 Evaporação do tanque classe A da estação agrometeorológica de

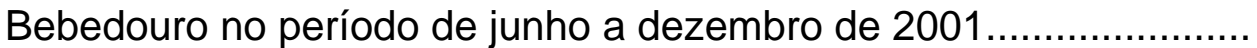

23 Umidade relativa do ar da estação agrometeorológica de

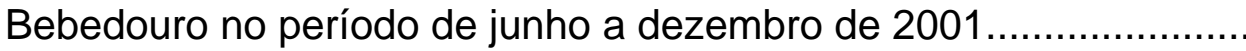

24 Insolação média da estação agrometeorológica de Bebedouro no período de junho a dezembro de 2001.

25 Radiação solar da estação agrometeorológica de Bebedouro no período de junho a dezembro de 2001

26 Velocidade média do vento da estação agrometeorológica de Bebedouro no período de junho a dezembro de 2001.................. 59

27 Perfil de distribuição de raiz a 0,2 m distante do tronco da planta.....

28 Perfil de distribuição de raiz a 2,0 m distante do tronco da planta....

29 Isolinhas de comprimento da raiz do perfil de solo distante $0,2 \mathrm{~m}$ do tronco da planta......

30 Isolinhas de comprimento da raiz do perfil de solo distante $0,4 \mathrm{~m}$ do tronco da planta.

31 Isolinhas de comprimento da raiz do perfil de solo distante 0,6 $\mathrm{m}$ do tronco da planta 
32 Isolinhas de comprimento da raiz do perfil de solo distante $0,8 \mathrm{~m}$ do

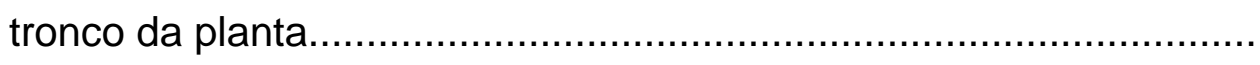

33 Isolinhas de comprimento da raiz do perfil de solo distante 1,0 m do tronco da planta...

34 Isolinhas de comprimento da raiz do perfil de solo distante 1,2 $\mathrm{m}$ do tronco da planta.

35 Isolinhas de comprimento da raiz do perfil de solo distante 1,4 $\mathrm{m}$ do tronco da planta.

36 Isolinhas de comprimento da raiz do perfil de solo distante 1,6 $\mathrm{m}$ do tronco da planta...

37 Isolinhas de comprimento da raiz do perfil de solo distante 1,8 $\mathrm{m}$ do tronco da planta.

38 Isolinhas de comprimento da raiz do perfil de solo distante $2,0 \mathrm{~m}$ do tronco da planta.

39 Isolinhas de comprimento da raiz do perfil de solo distante 2,2 $\mathrm{m}$ do tronco da planta......

40 Isolinhas de comprimento da raiz do perfil de solo distante $2,4 \mathrm{~m}$ do tronco da planta.

41 Isolinhas do comprimento do sistema radicular da goiabeira cv Paluma na direção perpendicular à linha de plantas.

68

42 Distribuição percentual do sistema radicular em função da profundidade do solo...

43 Distribuição percentual do sistema radicular em função da distância do tronco

44 Distribuição percentual do sistema radicular médio dos monolitos coletados a 0,6-0,4 m e 0,4-0,2 m distante do tronco da planta........

45 Distribuição percentual do sistema radicular médio dos monolitos coletados a 0,6-0,4 m e 0,4-0,2 m distante do tronco da planta e diâmetro menor que $2 \mathrm{~mm}$ 
46 Distribuição percentual do sistema radicular médio dos monolitos coletados a 0,6-0,4 $\mathrm{m}$ e 0,4-0,2 $\mathrm{m}$ distante do tronco da planta e

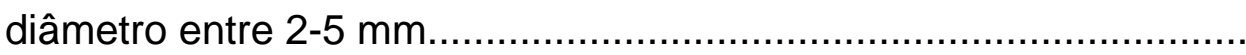

47 Distribuição percentual do sistema radicular médio dos monolitos coletados a 0,6-0,4 m e 0,4-0,2 m distante do tronco da planta e

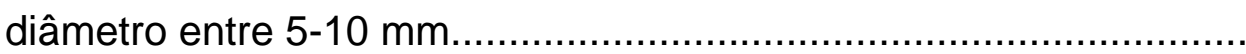

48 Distribuição percentual do sistema radicular médio dos monolitos coletados a 0,6-0,4 m e 0,4-0,2 m distante do tronco da planta e diâmetro maior que $10 \mathrm{~mm}$

49 Correlação dos dados de raízes coletados nos monolitos e nos perfis de solo distante $0,6-0,4 \mathrm{~m}$ e $0,4-0,2 \mathrm{~m}$ do tronco da planta.......

50 Correlação dos dados de raízes coletados nos monolitos e nos perfis de solo acumulados distante 0,6-0,4 m e 0,4-0,2 $\mathrm{m}$ do tronco.

51 Contribuição percentual das camadas de solo na variação da armazenagem da água medida com o TDR

52 Contribuição percentual das camadas de solo na variação da armazenagem da água medida com a sonda de nêutrons.

53 Potencial matricial médio da água no solo a 0,2, 0,4 e 0,6 m de profundidade em função do número de dias após a poda.

54 Potencial matricial médio da água no solo a 0,8, 1,0 e 1,2 m de profundidade em função do número de dias após a poda.................

55 Gradiente do potencial total médio da água no solo a 0,4, 0,6 e 0,8 $\mathrm{m}$ de profundidade em função do número de dias após a poda........

56 Gradiente do potencial total médio da água no solo a 0,8, 1,0 e 1,2 $\mathrm{m}$ de profundidade em função do número de dias após a poda........

57 Diferentes fases fenológicas da cultura da goiabeira cv Paluma......

58 Diâmetro médio da copa das plantas $(\mathrm{m})$ em função do número de dias após a poda.

59 Área média da copa das plantas $\left(\mathrm{m}^{2}\right)$ em função do número de dias após a poda 
60 Comportamento da evapotranspiração de referência por Penmam Monteith FAO e Tanque classe A e da cultura obtida pelo balanço hídrico do solo

61 Comportamento médio dos coeficientes de cultura (Kc) calculados da evapotranspiração de referência por Penman-Monteith FAO e pelo tanque classe $\mathrm{A}$, e da evapotranspiração da cultura pelo balanço hídrico no solo com os dados de umidade do TDR, ao longo das fases fenológicas da goiabeira em Petrolina-PE

62 Comportamento médio dos coeficientes de cultura (Kc) calculados da evapotranspiração de referência por Penman-Monteith FAO e pelo tanque classe $A$, e da evapotranspiração da cultura pelo balanço hídrico no solo com os dados de umidade da sonda de nêutrons, ao longo das fases fenológicas da goiabeira em PetrolinaPE.

63 Lâminas acumuladas do total aplicado (irrigação+precipitação) e evapotranspirado pela cultura da goiabeira em função do número de dias após a poda.

64 Umidade do solo medida com o TDR e a sonda de nêutrons na profundidade de 0-0,15 m em função do número de dias após a poda.

65 Umidade do solo medida com o TDR e a sonda de nêutrons na profundidade de 0,15-0,30 m em função do número de dias após a poda.

66 Umidade do solo medida com o TDR e a sonda de nêutrons na profundidade de 0,30-0,60 m em função do número de dias após a poda.

67 Umidade do solo medida com o TDR e a sonda de nêutrons na profundidade de 0,60-0,90 m em função do número de dias após a poda. 
68 Umidade do solo medida com o TDR e a sonda de nêutrons na profundidade de 0,90-1,2 m em função do número de dias após a poda.

69 Correlação da umidade do solo $\left(\theta, \mathrm{cm}^{3} / \mathrm{cm}^{3}\right)$ medida com o TDR e com a sonda de nêutrons na profundidade 0-0,15 m.

70 Correlação da umidade do solo $\left(\theta, \mathrm{cm}^{3} / \mathrm{cm}^{3}\right)$ medida com o TDR e com a sonda de nêutrons na profundidade $0,15-0,30$ m...................

71 Correlação da umidade do solo $\left(\theta, \mathrm{cm}^{3} / \mathrm{cm}^{3}\right)$ medida com o TDR e com a sonda de nêutrons na profundidade $0,30-0,60$ m...................

72 Correlação da umidade do solo $\left(\theta, \mathrm{cm}^{3} / \mathrm{cm}^{3}\right)$ medida com o TDR e com a sonda de nêutrons na profundidade 0,60-0,90 m

73 Correlação da umidade do solo $\left(\theta, \mathrm{cm}^{3} / \mathrm{cm}^{3}\right)$ medida com o TDR e com a sonda de nêutrons na profundidade 0,90-1,2 m.....................

74 Armazenagem da água no solo a $1,2 \mathrm{~m}$ de profundidade com os dados de umidade da sonda de nêutrons e do TDR em função do

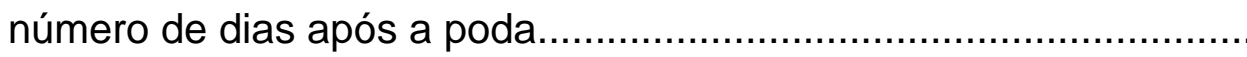

75 Variação da armazenagem $(\Delta \mathrm{A}, \mathrm{mm})$ da água no solo a $1,2 \mathrm{~m}$ de profundidade com os dados de umidade da sonda de nêutrons e do TDR em função do número de dias após a poda...............................

76 Correlação do armazenamento $(\mathrm{A}, \mathrm{mm})$ calculado até $1,2 \mathrm{~m}$ de profundidade com os dados de umidade do TDR e da sonda de nêutrons.

92

77 Correlação da variação do armazenamento $(\Delta \mathrm{A}, \mathrm{mm})$ com os dados de umidade do TDR e da sonda de nêutrons 


\section{LISTA DE TABELAS}

Página

1 Características físicas da área experimental..................................... 31

2 Características químicas da área experimental antes da poda.......... 31

3 Características químicas da área experimental após a colheita........ 54

4 Parâmetros de ajuste da curva de retenção de água no solo............ 54

5 Parâmetros da equação de condutividade hidráulica......................... 55

6 Fases fenológicas da goiabeira cv Paluma após a poda de

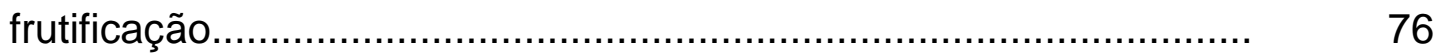

7 Valores do coeficiente de cultura $(\mathrm{Kc})$ para goiabeira irrigada por

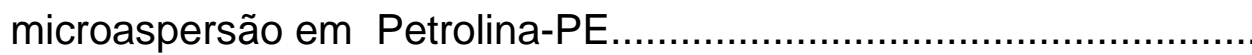

8 Componentes do balanço hídrico com os dados de umidade do solo da sonda de nêutrons e do TDR para todo o ciclo produtivo de

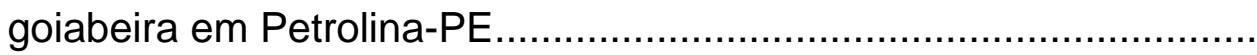




\title{
DISTRIBUIÇÃO RADICULAR E CONSUMO DE ÁGUA DE GOIABEIRA (Psidium guajava L.) IRRIGADA POR MICROASPERSÃO EM PETROLINA-PE
}

\author{
Autor: MARCELO DE NOVAES LIMA FERREIRA \\ Orientador: Prof. Dr. RUBENS DUARTE COELHO \\ Co-Orientador: Dr. LUÍS HENRIQUE BASSOI
}

\section{RESUMO}

O presente trabalho teve como objetivo básico determinar o consumo de água em um pomar de goiabeiras (Psidium guajava L.), cultivar Paluma, com 2,5 anos de idade, plantada no espaçamento de $6 \times 5 \mathrm{~m}$ e irrigada por microaspersão, no Campo Experimental da Empresa Brasileira de Pesquisa Agropecuária, Embrapa Semi-Árido, município de Petrolina - PE, com base na metodologia do balanço hídrico no solo com dados de umidade do solo medidos pela sonda de nêutrons e pelo TDR, e o padrão de distribuição espacial do sistema radicular da cultura de goiabeira. Assumiu-se a hipótese que ambos os métodos de medida de umidade do solo poderiam proporcionar resultados similares, o que levaria à semelhantes estimativas da evapotranspiração de uma cultura. A obtenção do consumo de água ou evapotranspiração de cultivo (ETc) pelo balanço hídrico foi relacionada com a evapotranspiração de referência (ETo) obtida pelos métodos do tanque classe " $A$ " e PenmanMonteith-FAO para determinar os coeficiente de cultura $(\mathrm{Kc})$ da goiabeira para a 
região de Petrolina - PE. Os resultados mostraram que $80 \%$ das raízes encontram-se na profundidade de 0,94 m e numa distância do tronco de 1,23 m, porém foram encontradas raízes até $1,20 \mathrm{~m}$ de profundidade a uma distância de $2,4 \mathrm{~m}$ do tronco da planta. Do total de raízes coletados nos monolitos distantes até $0,6 \mathrm{~m}$ do tronco da planta, $92,1 \%$ das raízes apresentaram diâmetro menor que $2 \mathrm{~mm}, 4,8 \%$ apresentaram diâmetro entre 2-5 mm, 2,7\% entre 5-10 mm e apenas $0,4 \%$ com diâmetro maior que $10 \mathrm{~mm}$. Para o monitoramento da água no solo e aplicações da fertilizantes e matéria orgânica, recomenda-se que seja realizado a uma distância do tronco e profundidade do solo até 0,6 $\mathrm{m}$. O consumo total de água da goiabeira durante o ciclo de 200 dias foi de 691,38 e 679,17 mm determinado pelo balanço hídrico com valores de umidade obtidos pelo TDR e pela sonda de nêutrons, apresentando um valor médio de 3,70 $\mathrm{mm} / \mathrm{dia}$ e 3,63 mm/dia, respectivamente. Os valores médios de $\mathrm{Kc}$ determinados pelo balanço hídrico no solo com dados de umidade do TDR e com valores de ETo segundo o tanque classe A e Penman-Monteith FAO foram de 0,71 e 0,79 , enquanto que com a ETc obtida com resultados de umidade da sonda de nêutrons, os valores foram de 0,70 e 0,78, respectivamente. Para todas as fases fenológicas, ocorreu uma variação nos valores de $\mathrm{Kc}$ de 0,58 a 1,03 , considerando-se todas as combinações de fonte de dados analisadas. Os valores de umidade do solo medidos pela sonda de nêutrons e pelo TDR seguiram a mesma tendência ao longo do ciclo da cultura e, conseqüentemente, proporcionaram estimativas próximas da variação de armazenamento, um dos termos da equação do balanço hídrico no solo. 


\title{
ROOT DISTRIBUITION AND WATER CONSUMPTION OF MICROSPRINKLER IRRIGATED GUAVA (Psidium guajava L.) IN PETROLINA-PE.
}

\author{
Author: MARCELO DE NOVAES LIMA FERREIRA \\ Adviser: Prof. Dr. RUBENS DUARTE COELHO \\ Co-Adviser: Dr. LUÍS HENRIQUE BASSOI
}

\section{SUMMARY}

A field experiment was carried out to estimate the crop water consumption in a guava cv. Paluma orchard, with two and half year-old plants in a $6 \times 5$ grid spacing irrigated by microsprinkler, at the Brazilian Agricultural Research Corporation - Agricultural Research Center of the Semi-Arid Tropic in Petrolina, Pernambuco State, Northeastern Brazil, based on the soil water balance method and the root distribuition pattern in the soil profile (digital image analysis). The soil water content was measured by two methods, the time domain reflectometry (TDR) and the neutron scattering (neutron probe). It was assumed that both soil water measuring methods provide similar values and, consequently, similar estimations of crop evapotranspiration would be obtained. The reference evapotranspiration (ETo) was measured by the class $A$ evaporation pan and by the Penman-Monteith-FAO method. The crop coefficient $(\mathrm{Kc})$ was obtained by the ETc/ETo ratio taking in account the method used to 
estimate the reference water consumption. Around $80 \%$ of total roots were found in the $0.94 \mathrm{~m}$ soil depth and until the 1,23 m distance from the trunk, although roots were observed until $1.2 \mathrm{~m}$ depth and $2.4 \mathrm{~m}$ distance from the plant row. Most of the roots sampled by the monolith method in the 0.2-0.6 m distance from the trunk presented a diameter (d) $\leq 2 \mathrm{~mm}(92,1 \%)$, while 4.8, 2.7 and $0.4 \%$ of roots were within the $2<d \leq 5 \mathrm{~mm}, 5<\mathrm{d} \leq 10 \mathrm{~mm}$, and $\mathrm{d}>10 \mathrm{~mm}$ intervals. Soil water monitoring and application of fertilizer and manure should be performed at a $0.6 \mathrm{~m}$ distance from the trunk and until $0.6 \mathrm{~m}$ depth. Total crop water consumption was $691.38 \mathrm{~mm}$ and $679.17 \mathrm{~mm}$ in a 200 days growing season, using the TDR and neutron probe equipments, which leaded to an average daily water consumption of $3.70 \mathrm{~mm}$ and $3.63 \mathrm{~mm}$, respectively. Using the ETc from soil water content measured by TDR, average $\mathrm{Kc}$ values were 0.71 and 0.79 with ETo from pan and Penman-Monteith-FAO methods, while using the ETc from neutron probe data, average values were 0.70 and 0.78 , respectively. A range from 0.58 to 1.03 was observed in all source of data combinations throughout the phenologic phases. The soil water content measured by TDR and neutron presented close values. Consequently, it was obtained close values of soil water storage changing, which is accounted in the soil water balance method. 


\section{INTRODUÇÃO}

A região do Sub-médio São Francisco do Nordeste brasileiro, principalmente o pólo Petrolina-PE/Juazeiro-BA, caracteriza-se por apresentar condições favoráveis para o desenvolvimento da fruticultura irrigada, pela sua baixa precipitação pluviométrica anual, altas temperaturas, baixa umidade relativa, diminuindo a incidência de pragas e doenças e pela presença marcante do Rio São Francisco como recurso hídrico de grande potencial.

Diversas fruteiras compõem os sistemas de produção atualmente implantados na região, destacando-se entre outras, a mangueira, a bananeira, a videira, o coqueiro e a goiabeira.

A goiabeira cultivada com irrigação e poda de frutificação, além de apresentar altas produtividades, 40 a 50 ton/ha/ano, produz durante todo o ano. Essa característica possibilita ao produtor não só comercializar a fruta in natura em épocas de entressafra nos mercados tradicionais, bem como para a indústria de doces e polpas da região (Gonzaga Neto,1991).

No pólo Petrolina / Juazeiro, são incipientes as pesquisas sobre a distribuição radicular e sobre as necessidades hídricas para a cultura da goiabeira. A necessidade de estudos sobre o consumo hídrico da cultura, nas suas diferentes fases fenológicas torna-se clara quando se percebe que a maioria dos agricultores irrigantes desta região utilizam apenas observações imprecisas para decisão de quando e quanto irrigar, o que quase sempre acarreta em uso excessivo de água. 
Embora o uso de lisímetros seja a ferramenta teórica mais precisa de se quantificar a evapotranspiração de uma cultura, a instalação deste instrumento é sempre difícil e bastante onerosa. Muitos pesquisadores, portanto, têm recorrido a métodos de estimativa, dentre os quais, destaca-se o balanço hídrico no solo, que contabiliza a precipitação e a irrigação, em função da evapotranspiração em um volume de solo compreendido entre a superfície e a profundidade alcançada pelas raízes.

Para um manejo racional da irrigação deve-se considerar além das necessidades hídricas da cultura em cada estádio de desenvolvimento, a distribuição do sistema radicular, com o objetivo de quantificar a lâmina de reposição dos sistemas de irrigação.

Em muitas áreas dos perímetros de irrigação desta região, há a necessidade de instalação de sistemas de drenagem para a manutenção do lençol freático a uma profundidade que permita o desenvolvimento da cultura. $A$ eficiência desses sistemas depende do conhecimento da profundidade efetiva do sistema radicular e da quantidade de água necessária para o desenvolvimento da cultura em questão. A utilização desta técnica contribuirá para a minimização da degradação dos recursos solo e água por meio da salinização.

No pólo de irrigação de Petrolina/Juazeiro, a goiabeira é cultivada principalmente pelos pequenos agricultores, sendo sua produção direcionada para o mercado interno, especialmente para o Nordeste. Neste mercado, a variedade Paluma tem grande aceitação, razão pela qual foi escolhida para o desenvolvimento deste trabalho. 


\section{REVISÃO DE LITERATURA}

\subsection{Considerações sobre a cultura da goiabeira}

A goiabeira (Psidium guajava L.) é uma cultura tropical difundida pela América do Sul e Central, África e Ásia, tendo como principais produtores a Índia, o México, o Brasil e a Malásia. A fruta é pouco conhecida no mercado internacional, onde é considerada exótica, sendo que a preferência é para o consumo das variedades de polpa vermelha para mesa e na forma de polpa ou suco concentrado. A produção brasileira em 2000 foi de cerca de 300 mil toneladas de goiaba, em 13,5 mil ha, tendo como principais produtores os Estados de São Paulo, Pernambuco e Bahia que juntos respondem por mais de $80 \%$ do volume produzido no país. (FrutiSéries, 2001). Segundo a mesma fonte, naquele ano foram destinadas cerca de 130 mil toneladas da fruta para a industrialização e 170 mil toneladas para o consumo in natura.

Segundo dados do Cadastro Frutícola do Vale do São Francisco do Programa de Fruticultura da CODEVASF (2002), o Nordeste do Brasil, juntamente com o Norte de Minas Gerais apresentam uma área plantada de goiaba de $7.850,60$ ha. Deste total, $5.623,00$ ha encontram-se plantados no Vale do São Francisco e $3.225,00$ ha no município de Petrolina, correspondendo a $41 \%$ da área plantada.

Analisando comparativamente a área cultivada com goiaba no Vale do São Francisco no período de janeiro de 1999 a maio de 2001, indica um crescimento significativo da área em produção. Enquanto em 1999 representava 40,8\% do total, em 2001 já significava 99,7\%. Esta evolução 
indica o crescimento do volume de produção destinado ao mercado, da ordem de 120 mil toneladas por safra, dos quais 90\% da variedade Paluma (Frutiséries, 2001).

Gonzaga Neto et al., (1991) relatam que no interior de Pernambuco, a goiabeira irrigada apresenta uma precocidade que permite o início de produção após dois anos do plantio, possibilitando inclusive a obtenção de dois ciclos de produção ao ano. As plantas sob irrigação superam muito a produção das cultivadas sob sequeiro e apresentaram regularidade de produção.

Segundo Gonzaga Neto \& Mattius (1997), a cultura da goiabeira vem se consolidando como uma alternativa de cultivo no pólo Petrolina/Juazeiro, pois o fruto dessa planta agrega valores devido às múltiplas formas de aproveitamento (doce, suco, geléia, polpa, sorvete).

O cultivo irrigado da goiabeira no semi-árido do Nordeste Brasileiro, além de apresentar um nível de produtividade relativamente mais alto que o registrado em outras regiões do país, pode produzir até duas safras por ano, devido principalmente a alta disponibilidade de energia solar, o que permite ao agricultor irrigante comercializar seus frutos em diferentes épocas do ano. No entanto, é necessário o aprimoramento tecnológico da cultura para garantir um padrão de qualidade que só poderá ser alcançado em cultivos racionais, cuja produção será otimizada através do plantio de cultivares selecionados, adoção de técnicas adequadas de manejo, sistema de irrigação eficientes e do conhecimento das reais necessidades hídricas, o que permite regularidade, quantidade e qualidade dos frutos destinados ao mercado consumidor (Gonzaga Neto \& Soares, 1994).

A goiabeira brasileira encontra-se atualmente com perspectiva de conseguir melhor posição na comercialização de frutas e seus derivados, apesar da forte concorrência das frutas estrangeiras. A goiaba é a fruta mais rica em licopeno, o carotenóide que atua na prevenção e combate a diferentes tipos de câncer, é rica em zinco, fibras, niacina, vitamina E, possui 3 a 4 vezes mais vitamina C que a laranja, e teores elevados de selênio, cobre, fósforo, 
magnésio, cálcio, ferro, ácido fólico e vitaminas A, B1, B2 e B6 (Agrianual, 2002). Segundo a mesma fonte, em dezembro de 2001 foi lançado uma nova forma de aproveitamento da goiaba, o Guatchup, novo molho agridoce, 100\% a base de goiaba vermelha, mostrando um novo segmento totalmente aberto, com mercado consumidor a ser desenvolvido tanto no país como internacionalmente.

Apesar de ser nativa da região tropical, a goiabeira vegeta e produz bem desde o nível do mar até a altitude de 1700 metros, sendo, por esta razão, amplamente difundida em várias regiões do país (Gonzaga Neto \& Soares, 1994).

Para o desenvolvimento de cultivos comerciais, a condição climática favorável compreende a temperatura média anual entre $23^{\circ} \mathrm{C}$ e $28^{\circ} \mathrm{C}$. Para o seu cultivo em condições de sequeiro, é necessária precipitação pluviométrica entre 800 e 1000 mm, distribuídos ao longo do ciclo de produção. Seu cultivo em locais onde ocorrem baixas precipitações e elevadas demandas evaporativas, é possível, desde que realizem irrigações complementares. Caso ocorra deficiência hídrica prolongada, pode haver atraso no florescimento e aumento da queda dos frutos. Ventos frios e as geadas são altamente prejudiciais a cultura, causando danos físicos tanto em pomares em formação, como a quebra de ramos novos, quanto naqueles em produção, com a ocorrência de danos mecânicos nos frutos (Souza et al., 1997).

A goiabeira desenvolve-se bem em quase todos os tipos de solos, principalmente naqueles profundos, permeáveis, com pH em torno de 5,0 - 6,0; porém não vegeta bem em solos argilosos ou encharcados. (Zambão \& Bellintani Neto, 1998)

A goiabeira tem origem na América tropical e é cultivada em todos os locais de clima tropical ou subtropical. Por ser uma cultura que se desenvolve em diversas condições climáticas, informações a respeito das necessidades hídricas são poucas. Porém, observações em culturas comerciais irrigadas indicam que grandes aumentos de produtividade em diferentes períodos do 
ano, com excelente qualidade de frutos, podem ser obtidos com irrigação. O conhecimento do ciclo fenológico e a variação do índice de área foliar da cultura ao longo do ciclo de produção (podas sistemáticas) são importantes para se projetar e manejar a irrigação. Culturas podadas intensamente têm redução do volume de copa e consequentemente, menores valores de consumo de água nesse período, devido a redução da área foliar. Porém, a emissão e crescimento de novas brotações e frutificações são altamente dependentes do fornecimento de água (Zanini \& Pavani, 1997).

Para as condições do estado do Rio de Janeiro, a lâmina total de água aplicada influenciou no número de brotos emitidos e no número de ramos estabelecidos na goiabeira, sendo a aplicação de $355 \mathrm{~mm}$ de água a que proporcionou a máxima emissão e a maior quantidade de ramos (Sousa et. al., 1997b).

No período de frutificação da goiabeira o fornecimento de água é um ponto crítico, pois enquanto a falta pode provocar a redução na produção, o excesso diminui a qualidade dos frutos (Maranca, 1978).

Patil \& Patil (1996) denominaram a goiaba de "maçã dos trópicos", sendo uma das frutas mais comuns da Índia, ocupando a quarta posição em termos de área e produção. Relataram também que a goiabeira é uma planta rústica, e a irrigação melhora o crescimento e qualidade dos frutos e que pesquisas sobre requerimento de água são escassas.

Lara Rodrigues \& Borys (1983) relatam que em algumas áreas de produção do México, a goiaba é cultivada sob irrigação e indicam que o requerimento de água é de 35, 50 e 75 litros/planta diários durante o primeiro, segundo e terceiro anos respectivamente. Assinalam também que a água é um fator imprescindível em todas as etapas fenológicas do cultivo: floração, frutificação e desenvolvimento dos frutos e sua ausência em qualquer dessas fases afeta notadamente a produção e qualidade dos frutos.

Patil et al (1993) conduziram experimento sobre o efeito de diferentes regimes de irrigação na produção de goiaba, em um pomar de 17 anos na Índia, 
envolvendo dois fatores: lâminas de irrigação $\left(I_{1}=0,4 ; I_{2}=0,6 ; I_{3}=0,8\right.$ e $I_{4}=1,0$ da evaporação do tanque classe $A$ e desvios da lâmina de irrigação (aumento ou diminuição) de acordo com a fase de desenvolvimento da cultura $\left(D_{0}=\right.$ sem desvio, $D_{1}=$ incremento de 0,2 durante o florescimento e desenvolvimento dos frutos, $D_{2}=$ decréscimo de 0,2 durante a maturação e $D_{3}=$ combinação de $D_{1} e$ $D_{2}$ ) e concluíram que as melhores produções foram obtidas manejando a irrigação com lâminas de $I_{3}=0,8$ até o desenvolvimento dos frutos e com $I_{2}=0,6$ na fase de maturação e colheita.

Gopal (1996) conduziu experimento de irrigação sobre o crescimento e produção da goiaba, na Rajasthan Agricultural University, Índia, com três níveis de dados acumulados do tanque classe $A\left(I_{1}=40 \mathrm{~mm} ; I_{2}=60 \mathrm{~mm} ; I_{3}=80 \mathrm{~mm}\right)$ e três lâminas de irrigação $\left(C_{1}=25 \mathrm{~mm} ; C_{2}=50 \mathrm{~mm} ; C_{3}=75 \mathrm{~mm}\right)$. A melhor performance foi obtida na combinação $\mathrm{I}_{2} \mathrm{C}_{3}$ e os parâmetros medidos foram: data do florescimento, maturação e tamanho (comprimento e diâmetro) dos frutos e produção. Comparando o tratamento $\mathrm{I}_{2} \mathrm{C}_{3}$ com a testemunha, verificouse que houve uma redução de 15 dias no florescimento e 23 dias na maturação dos frutos. O comprimento e o diâmetro dos frutos tiveram um aumento de 2,94 $\mathrm{cm}$ e 2,84 cm, respectivamente, observando um incremento de $28,6 \%$ na produtividade.

\subsection{Análise da distribuição radicular}

Em regiões semi-áridas, o emprego racional da irrigação localizada é primordial para a otimização do uso da água e consequentemente, para a redução do custo de produção, sendo essencial o conhecimento do sistema água-solo-planta-atmosfera para o adequado manejo da irrigação. Nesse contexto, a caracterização da distribuição do sistema radicular e o conhecimento da dinâmica da água no solo são fundamentais para a compreensão dos processos de transferência de água nesse sistema. 
Com relação ao sistema radicular de um pomar adulto de goiabeiras, a presença de raízes secundárias laterais, originadas da raiz principal próximo à superfície do solo, foi verificada por Pereira \& Martinez Jr. (1986).

A quantidade de água a ser aplicada em cada irrigação deve ser aproximadamente aquela necessária para elevar a umidade do solo à capacidade de campo na profundidade efetiva de enraizamento da cultura. Assim, otimiza-se a eficiência de aplicação de água, definida como a relação entre a quantidade de água armazenada na profundidade do sistema radicular e a quantidade de água destinada à área irrigada. Uma irrigação ideal é aquela em que o suprimento de água umedece o solo uniformemente até a capacidade de campo na zona radicular, e essa aplicação de água pode ser verificada, em termos de eficiência, por essa relação. O intervalo de tempo entre as irrigações e a quantidade de água a ser aplicada em cada irrigação para uma cultura depende, entre outros, da capacidade de retenção de água do solo e da profundidade de enraizamento das plantas (Thorne, 1979).

Existem vários métodos para a análise da distribuição radicular das culturas, que são classificados em: método da escavação, método do monolito, método do trado, método do perfil do solo, método da parede ou tubos de vidro, e os métodos indiredos (Bohm, 1979) e mais recentemente o método de análise de imagens digitais (Crestana et al., 1994).

O método da escavação possibilita uma clara visualização de todo ou parte do sistema radicular em sua ocorrência natural, através de abertura de trincheiras e cuidadosa remoção do solo para uma total exposição das raízes. Porém é um método que requer grande trabalho físico e consome muito tempo, sendo mais recomendado para estudos envolvendo árvores e arbustos, por apresentarem raízes lenhosas mais resistentes à quebra (Bohm, 1979).

O método do monolito permite uma análise quantitativa do sistema radicular e consiste na retirada de amostras de solo diretamente no perfil. As raízes são separadas do solo através de lavagem com água e coletadas em peneiras, para uma posterior quantificação. Pequenos monolitos $(10 \times 10 \times 10$ 
$\mathrm{cm}$ ) podem ser coletados com simples ferramentas, como espátulas e pás, porém com o aumento do tamanho do monolito, se faz necessário o uso de guindastes (Bohm, 1979).

O método do trado (manual ou mecânico) consiste na coleta de amostras volumétricas de solo e raiz sem a necessidade de aberturas de trincheiras. Após coletadas, as raízes são separadas do solo por meio de lavagem e posterior quantificação. Permite amostragem rápida sem grandes danos às plantas e, em culturas arbóreas existe a dificuldade de cortar as raízes espessas (Bohm, 1979).

O método do perfil do solo consiste na exposição das raízes em uma trincheira com a ajuda de ferramentas, água ou ar comprimido, permitindo visualizar o número e o comprimento das raízes expostas (Bohm, 1979).

O método da parede ou tubo de vidro (RHIZOTROM) possibilita um estudo contínuo das raízes de uma ou mais plantas, durante todo o ciclo e por muitos anos, e consiste na construção de galerias no subsolo, em cujas paredes instalam-se vidros para a visualização das raízes, sendo uma técnica de alto custo de implantação (Bohm,1979).

Os maiores problemas encontrados nas técnicas de estudo do sistema radicular são o alto consumo de tempo e trabalho requerido e a destruição das raízes. Tais inconvenientes levaram ao desenvolvimento de métodos indiretos, que são baseados na determinação de parâmetros físicos correlatos, como a variação no teor de água no perfil do solo e no deslocamento de traçadores radiativos detectado em sucessivas amostragens. A partir dessas variações, pode-se inferir a distribuição radicular no perfil do solo (Bohm, 1979).

O estudo da distribuição radicular auxiliada pela análise de imagens digitais oferece um número significativo de oportunidades de tratamento e análise, entre as quais avaliar a distribuição de raízes que ocorre em um perfil de solo, em uma trincheira, em substituição a usual quantificação visual, feita mediante quadrados reticulados (método do perfil de solo ou monolito). A determinação da densidade de raízes pode ser obtida por meio de algumas 
etapas de filtragem de imagem e calibração do sistema SIARCS (Sistema Integrado para Análise de Raízes e Cobertura do Solo). Com isso, abrem-se novas perspectivas de estudos mais completos e precisos das interações raizsolo, e da influência de diferentes práticas culturais em condições de campo (Crestana et al., 1994).

A amostragem para obtenção de imagens, através de abertura de trincheiras e preparo do perfil do solo a ser filmado, não é tão simples e é feita de maneira destrutiva. Por outro lado, comparando-se com outros métodos, essa amostragem não é das mais complicadas. O uso de métodos indiretos de determinação da atividade radicular, como a depleção da umidade do solo medida pela técnica de moderação de nêutrons, e a presença de fluxo de água ascendente, baseado no sentido do gradiente do potencial total da água no solo, que por sua vez é estimado a partir do potencial matricial da água no solo obtido por tensiometria, apresentam uma boa concordância com o método de análise de imagens digitais no estudo da distribuição radicular no perfil do solo (Bassoi et al., 1994).

Bassoi et al., (2001a) (2001b) utilizaram o método de análise de imagens digitais na distribuição do sistema radicular para as culturas de bananeira e porta enxertos de videira no Vale do São Francisco mostrando a eficiência do método para esta finalidade.

Estudos conduzidos em um pomar de goiaba com 12 anos de plantio, sem irrigação, em um solo areno-argiloso na Índia, mostraram que a distribuição radicular determinada pela técnica do traçador radioativo (radiotracer) apresentou resultados semelhantes com o método do trado. Tanto na estação chuvosa como no verão, $82 \%$ a $93 \%$ das raízes se encontravam a $60 \mathrm{~cm}$ de profundidade, e $85 \%$ a $92 \%$ das raízes se encontravam até $240 \mathrm{~cm}$ distante do tronco (Purohit \& Mukherjee, 1974).

Ghosh (1974) determinou a distribuição vertical e horizontal de raízes de goiaba em um pomar com 15 anos conduzido sem irrigação em solo silteargiloso na Índia, utilizando a metodologia do monolito, onde as raízes foram 
separadas, lavadas e medidas (diâmetro e comprimento). Os resultados mostraram que $87 \%$ das raízes se encontravam até a profundidade de $75 \mathrm{~cm}$ e $77 \%$ das raízes estavam a $150 \mathrm{~cm}$ de distância do tronco.

Kotur et al (1998) determinaram a distribuição espacial da atividade radicular em um pomar de goiaba conduzido sem irrigação, influenciada pelas estações do ano, utilizando a técnica do traçador radioativo (radiotracer), em um solo argiloso (54,6\% de argila) com baixa taxa de infiltração na Índia. Com relação a distância do tronco, os resultados mostraram que 37\%, 34\%, 19\% e $10 \%$ das raízes se encontravam a $50 \mathrm{~cm}, 100 \mathrm{~cm}, 150 \mathrm{~cm}$ e $200 \mathrm{~cm}$ respectivamente, e 100\% das raízes foram encontradas até $45 \mathrm{~cm}$ de profundidade, devido a presença de camadas adensadas no perfil do solo.

Patil \& Patil (1996) estudaram a atividade radicular de um pomar de goiabeiras com 17 anos, irrigadas por bacias em um Vertisolo na Índia, sob diferentes lâminas de irrigação $\left(I_{1}=0,4 ; I_{2}=0,6 ; I_{3}=0,8\right.$ e $I_{4}=1,0$ da evaporação do tanque classe A) e concluíram que utilizando a lâmina $I_{3}=0,8$ apresentou a melhor produção e que $90 \%$ da umidade do solo foi extraída nos primeiros 60 $\mathrm{cm}$ do solo, indicando que a maior atividade radicular está distribuída até esta profundidade.

Du Preez (1995) determinou o crescimento de raízes de goiaba em um laboratório de raízes (rhizotron) na África do Sul, o qual consiste em tanques com janelas instaladas abaixo do nível do solo. Foram plantadas quatro variedades de goiaba nos tanques e as leituras das raízes (comprimento) foram efetuadas semanalmente. Os resultados mostraram que algumas variedades (Dimple) mostraram maior vigor no crescimento das raízes que outras (Fan Retief), e que as plantas podadas apresentaram atraso de um mês no pico do crescimento das raízes comparando com as plantas não podadas. O autor sugere que a demora do crescimento das raízes observadas nas árvores podadas foi provavelmente devido ao fato de que as reservas foram perdidas durante a poda, e que inicialmente elas produziram ramos, para posteriormente produzirem raízes. 


\subsection{Estimativa da evapotranspiração}

De acordo com Rosemberg et al. (1983), a evaporação é o processo físico no qual um líquido é transferido para o estado gasoso. O termo evapotranspiração (ET) é usado para descrever o processo de transferência de água para a atmosfera resultante da evaporação do solo e da transpiração dos vegetais. Segundo Doorenbos \& Kassan (1979), a evapotranspiração da cultura ou demanda ideal (ETc), refere-se à perda d'água por uma cultura qualquer em condições de nenhuma restrição de água em qualquer estádio de desenvolvimento sob ótimas condições agronômicas e manejo de irrigação.

Quanto à evapotranspiração de referência (ETo), como está apresentado no boletim 56 da FAO, (Allen et al., 1998) o conceito refere-se a uma cultura hipotética, que se assemelha a um gramado, em crescimento ativo e mantida a uma altura uniforme de 0,12 m, sombreando completamente o terreno e sem escassez de água. Representa, portanto, uma extensão da definição original de Penman (1948) de evapotranspiração potencial.

Desde o plantio até a colheita, uma cultura vai progressivamente crescendo e ocupando a área disponível, onde, nessas condições ocorre a evapotranspiração da cultura (ETc). O conhecimento da ETc é fundamental em projetos de irrigação, pois ela representa a quantidade de água que deve ser reposta ao solo para manter o crescimento e a produção em condições ideais. No entanto, a determinação da ETc é difícil, onerosa e requer bastante tempo de pesquisa para sua calibração. Sabe-se que para dar bons resultados, a irrigação deve ser bem quantificada. Irrigações insuficientes repõem a água apenas nas camadas superficiais do solo, não umedecendo a zona das raízes, trazendo prejuízo as plantas. Irrigações excessivas também são contra indicadas, pois acarretam perdas de água e de nutrientes, por percolação abaixo da zona de raízes, além de trazer problemas de encharcamento em áreas com problemas de drenagem. Para contornar essas dificuldades, utilizam-se estimativas da evapotranspiração de referência (ETo), corrigidas por 
um coeficiente de cultura (Kc), e varia com a cultura e seu estádio de desenvolvimento durante o ciclo produtivo (Pereira et al., 1996).

A distribuição do coeficiente de cultura $(\mathrm{Kc})$ durante o ciclo produtivo, é chamada de "curva de cultura", que é obtida experimentalmente, e representa o efeito integrado da mudança na área da folha, da altura da planta, do grau de cobertura, da resistência do dossel da planta e do albedo sobre a ETc em ralação à ETo. Então a estimativa da ETc é obtida pela multiplicação da ETo pelo Kc, que varia com o estádio de crescimento da cultura (Sediyama,1996).

O termo evapotranspiração potencial surgiu primeiramente com Thornthwaite (1948), cuja preocupação principal era explicar as variações sazonais do balanço de água no solo e tentar definir diferenças regionais de clima. A sua equação leva a uma estimativa da evapotranspiração em função apenas da temperatura média do ar, a partir de um índice térmico anual, e da duração do dia para um determinado mês em questão. Penman (1948), preocupado com os processos físicos envolvidos na evaporação, desenvolveu uma fórmula que proporcionou uma estimativa da taxa de evaporação da águalivre, da umidade da superfície do solo ou da vegetação, a partir de elementos climáticos relevantes. Posteriormente, combinou o balanço de energia na superfície com um termo aerodinâmico, cuja equação resultante é conhecida como "equação combinada" (Sediyama, 1996).

Penman, em 1948, não incluiu a função de resistência da superfície para a transferência de vapor d'água na sua equação original. Para aplicações práticas, ele propôs uma equação empírica para a função devida ao vento. Monteith (1965) desenvolveu, com base na equação de Penman, uma equação, que inclui a resistência aerodinâmica e a resistência ao fluxo de vapor pela folha. A equação combinada com os termos de resistência aerodinâmica e da superfície da planta é chamada de equação de Penman-Monteith. Esta equação não somente concilia os aspectos aerodinâmico e termodinâmico, mas também inclui a resistência ao fluxo de calor sensível e vapor d'água no ar (ra), e a resistência da superfície (planta) à transferência de vapor d'água (rc). Esse 
método tem sido usado com sucesso na estimativa da evapotranspiração de culturas e de florestas (Rosemberg et al., 1983).

Existem muitos métodos que determinam a evapotranspiração, segundo Pereira et al., (1997), que pode ser medida em lisímetros e balanço hídrico no solo, ou estimado a partir de uma série de modelos tais como: Thornthwaite (1948), Radiação Solar (Doorembos \& Pruitt (1977), Jensen-Haise (1963), Linacre (1977), Hargreaves (1977), Blaney-Criddle (1977), Monteith (1965), Penmam-Monteith FAO (Allen et al., 1998). Os modelos mais complexos fundamentam-se nos processos físicos de evaporação e evapotranspiração e incluem em suas formulações vários elementos meteorológicos. Os mais empíricos correspondem a equações simples determinadas a partir de correlações entre medidas de ETo e uma ou duas variáveis climáticas, em geral, as mais comumente disponíveis como a temperatura do ar e umidade relativa. Estas necessitam de ajustes as condições locais, pois podem apresentar em determinadas épocas do ano super ou sub estimativas, dependendo das características do clima de cada região. Conhecendo-se as limitações de cada método e os detalhes de seu desenvolvimento, fica mais fácil utilizá-los numa determinada situação.

A estimativa da evapotranspiração de referência (ETo) pelo método do tanque classe A tem sido bastante utilizada no manejo da irrigação, apresentando como vantagem, o fato de integrar todas as variáveis do clima (temperatura do ar, velocidade do vento, umidade relativa, radiação solar, etc) que determinam o processo da evaporação e evapotranspiração, sem que haja necessidade de medir estas variáveis ou estimá-las através de modelos mais complexos (Silva, 2002). 


\subsection{Dinâmica da água no solo e balanço hídrico in situ}

Para o conhecimento da dinâmica da água no solo, é de fundamental importância o conhecimento da umidade do solo e dos potenciais da água do solo. A umidade é apenas um índice que quantifica a água que o solo possui, enquanto que os potenciais da água dizem respeito aos diferentes tipos de energia potencial que atuam no sistema e podem dar indicação de como a água se encontra no solo, se parada ou em movimento (Libardi, 1995).

A infiltração (processo de entrada de água pela superfície do solo, que perdura enquanto houver fornecimento de água), redistribuição (movimento de água no solo após a infiltração), evaporação (passagem da água do estado líquido para o gasoso) e absorção de água pelas plantas (transpiração) envolvem o fluxo de água no solo, e tais processos são interdependentes, e, na maioria das vezes, ocorrem simultaneamente. Para estudar o ciclo da água em uma cultura de maneira geral é necessário considerar-se o balanço hídrico, que é realmente a própria lei da conservação das massas e está intimamente ligado ao balanço de energia, pois os processos envolvidos requerem energia. $O$ balanço de energia por sua vez é a própria lei da conservação da energia. Do ponto de vista agronômico, o balanço hídrico é fundamental, pois ele define as condições hídricas sob as quais uma cultura se desenvolveu (Reichardt, 1996).

Segundo Libardi (1995), o balanço hídrico pode ser estudado em várias escalas, desde uma bacia hidrográfica até uma cultura agrícola. Nesse último caso, pode-se alcançar um maior detalhamento, onde o balanço hídrico pode ser definido como a contabilização das entradas e saídas de água em um dado volume de solo, durante um certo período de tempo. O volume de solo considerado depende da cultura em estudo, pois deve englobar seu sistema radicular. Assim é que se considera como limite superior desse volume a superfície do solo e como limite inferior, a profundidade efetiva do sistema radicular da cultura. Se a quantidade de água que entra neste volume de solo num período de tempo for maior que a quantidade de água que dele sai, haverá 
reposição hídrica, e se sair mais do que entrar, haverá retirada. Esse saldo (positivo ou negativo) de água no solo é obtido pela variação do armazenamento de água do perfil do solo $(\Delta \mathrm{A})$. A quantidade de água que entra é proveniente da precipitação $(P)$ e/ou irrigação (I), e a quantidade de água que sai o faz pelos processos de drenagem profunda (D), evapotranspiração (ET) e do escoamento superficial $(R)$. A drenagem profunda, neste caso, representa a perda de água para fora da zona radicular através do limite inferior do volume de solo considerado. Porém, dependendo das condições, ao invés de sair, a água pode entrar através desse limite, sendo esse processo denominado de ascensão capilar . O escoamento superficial também pode se constituir de uma entrada (positivo) de água ou saída (negativo) no sistema. Assim, a representação matemática do balanço hídrico de uma cultura, na forma integrada, pode ser expressa com mostra a seguir: $P+I \pm D-E T \pm R= \pm \Delta A$. Cada componente do balanço hídrico é de considerável importância dentro de um determinado ramo da ciência onde pode ser estudado com o nível de detalhe de interesse. Para o propósito de obtenção do componente ET, os detalhamentos de estudo de $\mathrm{P}, \mathrm{I}$ e $\mathrm{R}$ são de medida relativamente fácil, em relação à $\Delta \mathrm{A}$ e $\mathrm{D}$.

A precisão do método do balanço hídrico no solo depende da precisão com que são medidos os componentes da equação de conservação de água. A maior dificuldade reside na determinação da drenagem profunda ou ascensão capilar. Uma vantagem desse método quando comparado com outros que utilizam medições agrometeorológicas acima da superfície, é a facilidade de obtenção e processamento dos outros dados (precipitação, irrigação e variação do armazenamento de água no solo). As desvantagens são o menor nível de precisão e as dificuldades de obtenção da evapotranspiração nos períodos chuvosos. Este método não é apropriado para estimativas de evapotranspiração em base diária, porém, se a drenagem for bem avaliada, o método é aceitável para intervalos de dois ou três dias. Quando é aplicado em grandes áreas, o maior problema não é propriamente o método, mas a falta de 
uma boa representatividade devido a variação espacial das chuvas e a falta de homogeneidade na topografia e nos solos.

Diversos pesquisadores realizaram estudos de balanço hídrico no solo para a determinação da evapotranspiração (ETc) e do coeficiente de cultura $(\mathrm{Kc})$, visando a sua aplicabilidade nos cálculos da lâmina de água necessária às culturas (Silva, 2000; Bezerra \& Oliveira, 1999; Ramos, 2001; Lopes, 1999; Moura, 2000; Ávila Neto, 1997). No entanto, a aplicabilidade desses coeficientes é restrita para as condições climáticas e culturais para os quais foram determinados, por isso, há a necessidade de calibração para a sua utilização em lugares diferentes de onde foram concebidos (Allen et al. 1998).

Moura (2000) conduziu experimento em um pomar cultivado com goiabeira, variedade Paluma, no Perímetro de Irrigação Senador Nilo Coelho, Petrolina-PE, e determinou os valores do coeficiente de cultivo $(\mathrm{Kc})$ a partir de médias de 5 dias da evapotranspiração de referência (ETo), obtida pelo método de Penman Montheith FAO e da evapotranspiração da cultura (ETc), obtida pelo método do balanço de energia baseado na razão de Bowen. O Kc médio observado durante todo o ciclo produtivo, conduzido no sistema de poda sobre poda, foi de 0,78 sendo que a maioria dos valores oscilou entre 0,70 e 0,90.

Silva (2000) determinou o coeficiente de cultura para a mangueira irrigada no vale do São Francisco em Petrolina-PE e utilizou para determinação da evapotranspiração da cultura os métodos do balanço hídrico no solo e balanço de energia baseado na razão de Bowen e o método de Penman Monteith FAO para a evapotranspiração de referência.

Bezerra \& Oliveira (1999) determinaram a evapotranspiração e o coeficiente de cultivo para o milho em Fortaleza-CE através do balanço hídrico no solo e o método de Penman Monteith FAO para obtenção da evapotranspiração de referência.

Ramos (2001) estudou a distribuição do sistema radicular e consumo de água da bananeira irrigada por microaspersão em Petrolina-PE. Utilizou o método do balanço hídrico no solo para a determinação da evapotranspiração 
da cultura e o método de Penman Monteith FAO para a evapotranspiração de referência (ETo).

Ávila Neto (1997) determinou o coeficiente de cultivo da videira na Região do submédio São Francisco através da evapotranspiração da cultura (ETc) obtida pelo método do balanço hídrico no solo e a evapotranspiração de referência estimada pelo método de Penman Monteith FAO.

Lopes (1999) determinou a evapotranspiração da mangueira para a região do submédio São Francisco em Petrolina-PE utilizando os métodos do balanço de energia baseado na razão de Bowen e balanço hídrico no solo.

Como pode ser observado nos estudos com a cultura da goiabeira, existe uma grande lacuna no que concerne a determinação de suas necessidades hídricas bem como da avaliação do sistema radicular, principalmente na região do Submédio São Francisco.

\subsection{Métodos de medição da umidade do solo}

Existem vários métodos de determinação do conteúdo de água do solo, podendo ser classificados em métodos diretos e indiretos. Os métodos diretos consistem na medida direta do conteúdo de água de uma amostra, basicamente por evaporação, dividindo-se em: método gravimétrico com secagem em estufa e método gravimétrico com secagem em forno microondas. Os métodos indiretos se baseiam na medida de propriedades físicas ou físico-químicas do solo que sejam proporcionais ao conteúdo de água no solo. São métodos que exigem uma curva de calibração e apresentam a vantagem de serem não destrutivos e proporcionam menor tempo e trabalho na execução das medidas, dividindo-se em: medida da condutividade elétrica/térmica ou capacitância, sonda de nêutrons, atenuação de raios gama, tensiometria e TDR (reflectometria no domínio de tempo) (Tommaselli, 1997). 
Entre os diferentes métodos para a determinação do conteúdo de água do solo, todos apresentam algumas vantagens e limitações: ou são de precisão, ou dispendiosos, ou morosos ou ainda trabalhosos. A opção por um determinado método varia de acordo com a finalidade, os objetivos e as disponibilidades instrumentais existentes (Klar,1991).

No método gravimétrico com secagem em estufa, que é o mais básico e considerado padrão, remove-se a amostra do campo e determina-se as massas úmida e seca com auxílio de uma balança e estufa. Tem como desvantagem de ser demorado e destrutivo. Para se obter a umidade a base de volume por este método é necessário conhecer a densidade do solo (Libardi, 1995).

O método gravimétrico com secagem em forno microondas é rápido, mas tem a desvantagem de ser destrutivo e de difícil padronização, exigindo calibrações do tempo de secagem para cada solo em particular (Tommaselli, 1997).

O método da medida da condutividade elétrica, também conhecido como eletrométrico ou Bouyoucos, consiste em medir a condutividade elétrica de materiais porosos introduzidos no solo que variam de acordo com o conteúdo de água. (Tommaselli, 1997).

Segundo Bacchi \& Reichardt (1990), para efetuar as medições de umidade com a sonda de nêutrons, uma fonte radioativa é colocada na profundidade desejada no perfil do solo através de tubos de acesso de alumínio. As fontes de nêutrons são uma mistura de um emissor alfa (Amerício) e Berílio em pó. As partículas alfa bombardeiam os núcleos de Berílio ocorrendo a seguinte reação nuclear:

$$
{ }_{4}^{2} \alpha+{ }_{4}^{9} B e \Rightarrow{ }_{0}^{1} n+{ }_{6}^{12} c
$$

Eq. 1

Os nêutrons ${ }^{1} \mathrm{n}$, que são o produto da reação, são chamados de nêutrons rápidos, que irão atravessar a parede do tubo e se espalhar pelo solo 
formando uma "nuvem de nêutrons" com diâmetro de 20 a $30 \mathrm{~cm}$ ao redor da fonte, interagindo com os átomos presentes no solo. Ocorrem três processos de interação: absorção de nêutrons por núcleos, espalhamento de nêutrons por colisões, e desintegração de nêutrons.

O espalhamento de nêutrons por colisões (elásticas e inelásticas) é o processo mais importante no qual se baseia o princípio de funcionamento da sonda. Através de colisões, os nêutrons rápidos perdem energia (moderação) e tornam-se lentos ou térmicos. Verificou-se que o hidrogênio é o isótopo alvo mais eficiente na redução da energia do nêutron rápido. Como o hidrogênio é um constituinte da água, esta é um bom moderador de nêutrons; quanto maior o conteúdo de água no solo maior a quantidade de nêutrons lentos presentes.

Os nêutrons lentos são espalhados no sentido do detector, amplificados e enviados para um sistema de contagem, que fornece a leitura obtida no solo. Relacionando esta leitura com a contagem padrão, obtida na blindagem da sonda, para evitar possíveis distorções causadas por efeitos de variações de temperatura e problemas eletrônicos, obtém-se a contagem relativa, e com a curva de calibração do equipamento, obtém-se a umidade $(\theta)$.

Segundo Gomide (2001), a equação de calibração interna da sonda de nêutrons fornecida pelo fabricante, pode ser considerada adequada para muitos casos. Porém, recomenda-se verificar a calibração do equipamento através da umidade gravimétrica do solo a ser manejado. Em caso de grande diferença entre o valor real e estimado, sugere-se a calibração do aparelho em campo ou laboratório.

Os tensiômetros medem o potencial matricial da água no solo, e indiretamente a umidade, através da curva de retenção que relaciona o potencial matricial e o conteúdo da água no solo. São equipamentos constituídos de um tubo geralmente de PVC ou acrílico, com uma cápsula de cerâmica porosa na extremidade inferior conectado a um manômetro capaz de medir pressões negativas inserido no tubo, que pode ser do tipo Bourdon ou de mercúrio (Klar, 1991). Atualmente existem aparelhos digitais, chamados de 
tensímetros, que usam o próprio rebaixamento da água no tubo para medir o potencial.

Toda vez que um solo não estiver saturado, nele existe ar e, portanto existem interfaces água/ar (menisco) que the conferem o estado de tensão (pressão negativa). Assim, a água no solo, via de regra, encontra-se sob tensões. A tensão, chamada de potencial matricial, é resultante da afinidade da água com a matriz do solo, devido as forças adsortivas e de capilaridade oriundas das forças coesivas e adesivas que se desenvolvem no solo (Gomide, 2001).

Na prática, o intervalo de uso do tensiômetro é de $\Psi_{m}=0$ (saturação) e $\Psi_{\mathrm{m}}=80 \mathrm{kPa}$, aproximadamente. Este intervalo de potencial limitado, medido pelo tensiômetro, não é tão limitado como parece. Ele é uma parte pequena do intervalo total de potenciais mas, no campo, cobre o principal intervalo de umidade do solo de importância para irrigação (Reichardt, 1985).

A adaptação da técnica de reflectometria no domínio de tempo (TDR) para medição de umidade foi apresentada por Topp et al (1980), onde a medida do tempo de percurso de uma onda eletromagnética foi relacionada com a umidade do solo $\left(\theta, \mathrm{cm}^{3} \cdot \mathrm{cm}^{-3}\right)$. A medida é feita em um pequeno volume de solo, com relativa facilidade de operação. A propriedade principal que influencia a velocidade de condução de uma onda eletromagnética é a constante dielétrica $(\varepsilon)$, que é uma medida da capacidade de um material não condutor de transmitir ondas ou pulsos eletromagnéticos.

A constante dielétrica é calculada a partir da medida do tempo que um pulso eletromagnético leva para transitar entre dois pontos da sonda (haste) introduzidas no solo. Esse método de medida estabelece que é preciso considerar que o pulso emitido caminhe de um ponto a outro e retorne a posição de partida. Considerando como sendo L o comprimento de percurso do pulso eletromagnético $(\mathrm{m}), \mathrm{t} \mathrm{o}$ tempo de trânsito $(\mathrm{s}), \mathrm{v}$ a velocidade de propagação $(\mathrm{m} / \mathrm{s})$ e C a velocidade da luz no vácuo (Hermann Jr, 2001): 


$$
\begin{aligned}
& V=\frac{C}{\sqrt{\varepsilon}} \\
& t=\frac{2 L}{V}
\end{aligned}
$$

Foi mostrado por Topp et al. (1980), que a constante dielétrica $(\varepsilon)$ relaciona-se com o conteúdo de água ( $\theta$ ) no solo da seguinte forma:

$$
\theta=-0,053+0,0292 \times \varepsilon
$$

Assim, o tempo de percurso do pulso eletromagnético é proporcional a umidade $(\theta)$, devido a proporcionalidade desta com a constante dielétrica $(\varepsilon)$, como foi definido por Fellner-Feldegg (1969)

$$
t=\frac{2 L \sqrt{\varepsilon}}{C}
$$

Souza e Matsura (1995) destacam a técnica do TDR (reflectometria no domínio de tempo) para determinação da umidade do solo em laboratório e em campo, possuindo vantagens quanto ao seu uso, principalmente pela precisão, possibilidade de multiplicação de leituras, repetição sem destruição da amostra de solo e pela segurança. Ressalta ainda que o uso do TDR para estimar a umidade do solo tem sido limitado pelo seu custo.

Dalton et al., (1984) propuseram medidas simultâneas de umidade e salinidade do solo usando o TDR diretamente no campo, sem a necessidade de coletar amostras de solo para análise em laboratório.

A técnica do TDR reúne algumas vantagens importantes como a característica não destrutiva, a rapidez na obtenção dos resultados e a garantia 
de segurança do operador no seu manuseio. O método ainda é caro em função do preço elevado do emissor de pulsos, mas as perspectivas apontam para sistemas bem mais baratos nos próximos anos. Uma das características mais atrativas da técnica do TDR é a sua habilidade de monitorar contínua e simultaneamente o conteúdo de água do solo em vários locais (Tommaselli, 1997).

Para Coelho \& Arruda (2001) a técnica do TDR tem sido usada em manejo de irrigação, na determinação da evapotranspiração de culturas, nos padrões de distribuição de água no volume molhado sob irrigação localizada, em estudos de absorção de água e nutrientes pelo sistema radicular, avaliação do fluxo de água e nutrientes no solo, além do monitoramento do estado da água no solo para definição do momento da irrigação e do quanto de água a aplicar.

Segundo Tommaselli (2001), a técnica do TDR pode ser usada para monitorar o conteúdo de água em materiais tão diversos quanto carvão, minérios, grãos de cereais, lã, madeira e concreto.

Otto, S. R. L. (1998), determinou a curva de retenção de água no solo utilizando TDR e tensiômetro, e os resultados encontrados indicaram que: 1) As leituras de umidade volumétricas realizadas com o TDR, necessitam de correção específica para o tipo de solo estudado; 2) Os valores de umidade volumétrica do solo a um mesmo potencial matricial de água no solo, determinados com o TDR e tensiômetro foram menores que os obtidos com a câmara de pressão de Richards; 3) As curvas de retenção de água no solo obtidas em condições de campo, com a utilização conjunta do TRD e tensiômetro são úteis para o manejo de sistemas de irrigação, pois representam as condições reais.

Souza et al., (2001) avaliaram o material construtivo de TDR para o monitoramento da variação da umidade do solo e na determinação do bulbo molhado em irrigação localizada. Concluíram que hastes de latão podem substituir as de aço inoxidável, promovendo economia financeira na construção 
das sondas de TDR e as leituras de umidade volumétrica não apresentaram diferenças entre as diversas sondas. Os autores recomendam a utilização da técnica de TDR para a determinação das dimensões do bulbo molhado e no monitoramento da frente de molhamento da infiltração da água oriunda de um gotejador.

Segundo Otto (2001), a utilização do TDR na determinação da umidade volumétrica do solo facilita o manejo de irrigação, possibilitando a obtenção instantânea do tempo necessário de funcionamento do sistema de irrigação (localizada e aspersão). O autor recomenda que a equação de calibração do equipamento seja determinada para cada tipo de solo, pois a equação sugerida pelo fabricante subestimou os valores de umidade, em relação aos valores de umidade determinados pela equação específica do solo estudado. 


\section{MATERIAL E MÉTODOS}

\subsection{Localização e caracterização da área experimental}

O experimento foi desenvolvido em um pomar de goiabeiras localizado na Estação Experimental da Empresa Brasileira de Pesquisa Agropecuária, Embrapa Semi-Árido, no Perímetro Irrigado de Bebedouro, município de Petrolina-PE. Encontra-se geograficamente localizada na latitude 09009' S, longitude $40^{\circ} 22^{\prime} \mathrm{W}$, altitude $365,5 \mathrm{~m}$ na região do Submédio São Francisco. O Perímetro Bebedouro está localizado a $35 \mathrm{Km}$ de Petrolina com acesso pela BR 122, Figura 1.

O clima da região que compreende o pólo Petrolina-PE / Juazeiro-BA é do tipo BSwh' semi-árido bastante quente, segundo a classificação de Koeppen. Um dos maiores problemas da região é a irregularidade das chuvas, conjuntamente com a ocorrência de elevadas temperaturas, ocasionando grandes taxas de deficiências hídricas, as quais ocorrem nos meses de verão. O regime hídrico é o mais sério fator limitante do clima para esta região semiárida. O principal período da estação chuvosa estende-se de fevereiro a maio e pode ser influenciado pela temperatura da água dos oceanos e por fatores atmosféricos de escala global e regional. As precipitações mais frequentes ocorrem no período da madrugada, entre zero e três horas tendo seu ponto máximo às duas horas. Dados coletados na Estação Agrometeorológica de Bebedouro de 1963 a 1999 apresentaram temperatura média do ar variando de $24,2^{\circ} \mathrm{C}$ a $28,2^{\circ} \mathrm{C}$ (Figura 2), aonde são apresentados também os dados de temperaturas máxima e mínima do ar (Teixeira, 2002). 


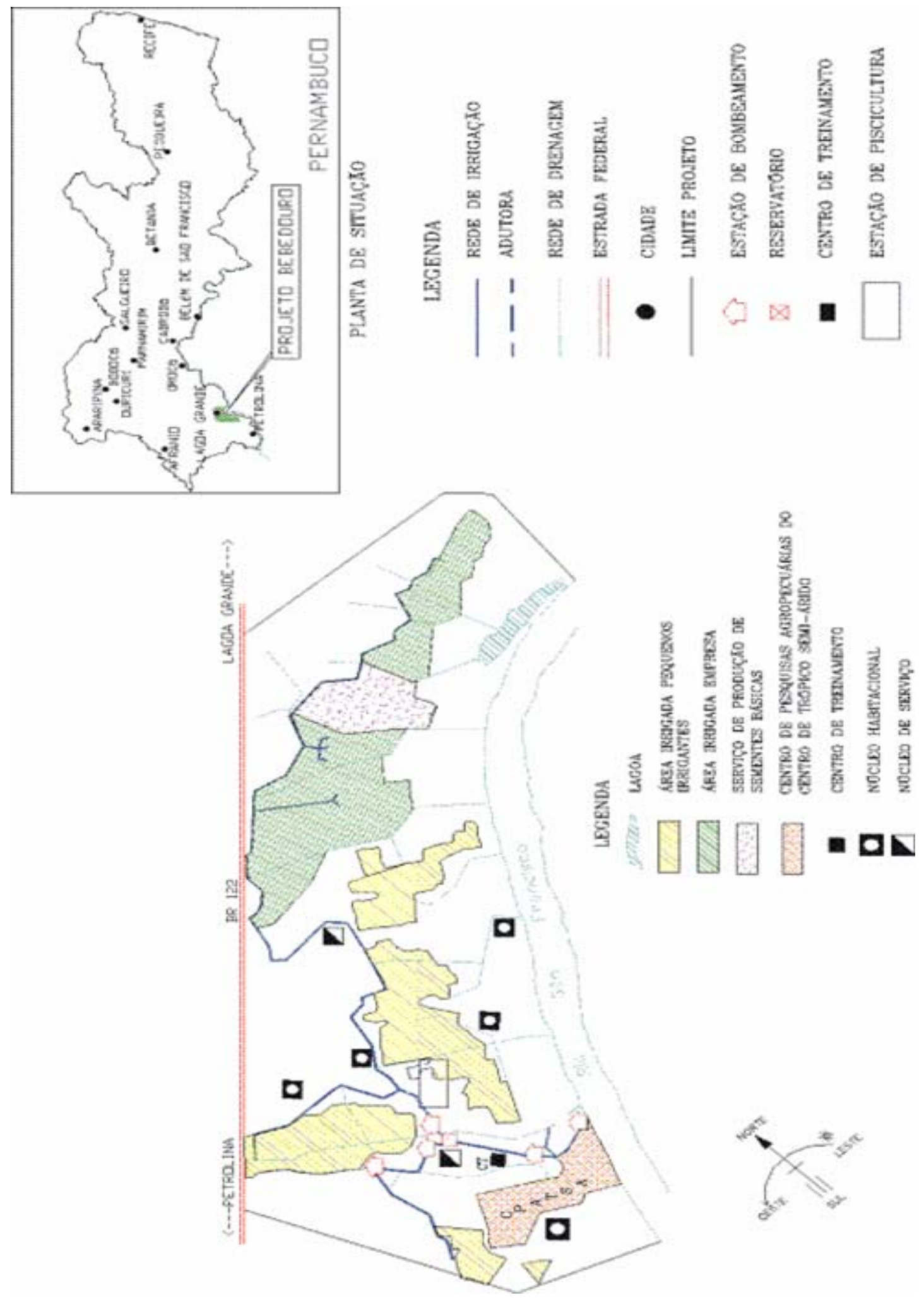

Figura 1 - Planta de situação do projeto Bebedouro (www.codevasf.gov.br) 


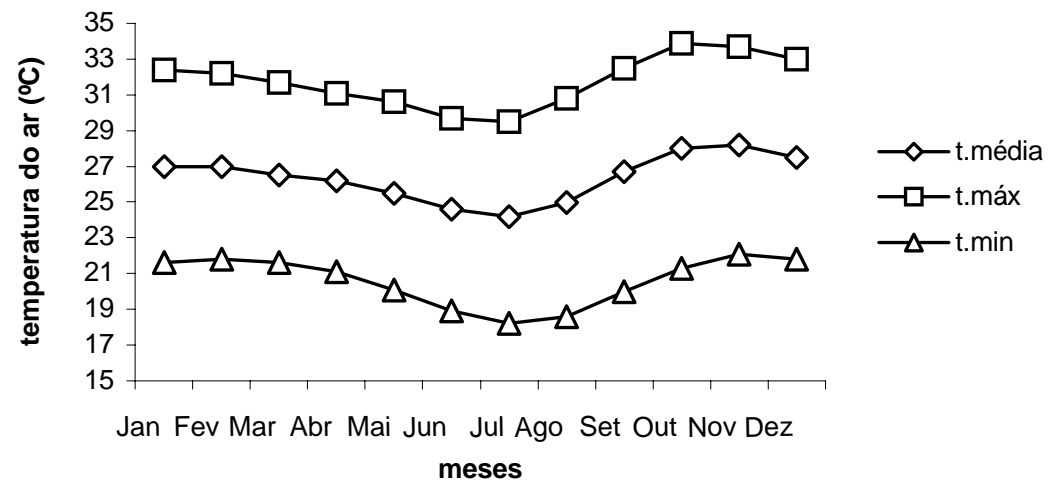

Figura 2 - Temperatura máxima, média e mínima do ar do período de 1963/99 da estação agrometeorológica de Bebedouro (Petrolina-PE)

$\mathrm{Na}$ Figura 3 observa-se a precipitação pluvial nos últimos trinta anos, onde apresentou um total anual médio de $567 \mathrm{~mm}$, concentrando-se entre os meses de novembro e abril, com $90 \%$ do total anual. A quadra chuvosa, de janeiro a abril, contribui com $68 \%$ do total anual, destacando-se o mês de março e o de agosto como o mais e o menos chuvoso, com totais médios de 136,2 $\mathrm{mm}$ e $4,8 \mathrm{~mm}$, respectivamente, (Teixeira, 2002).

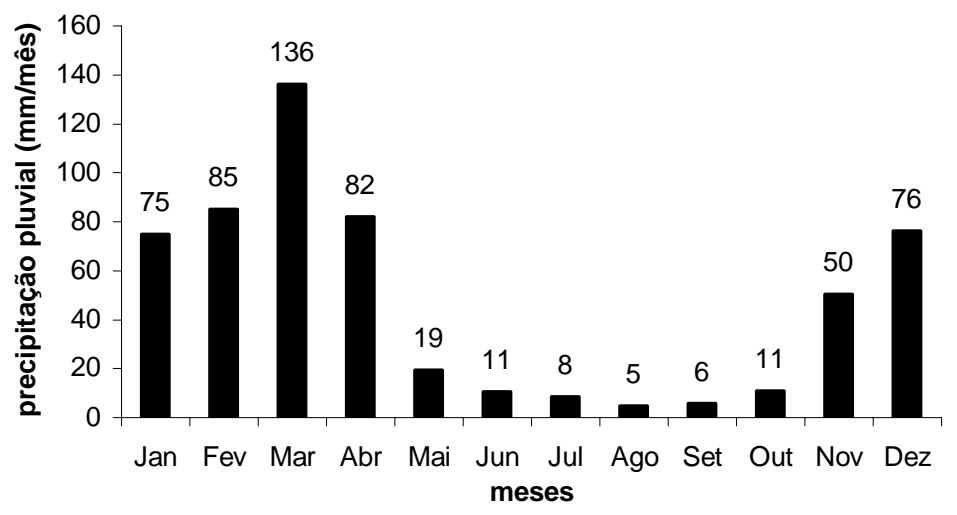

Figura 3 - Precipitação pluvial média do período de 1963/99 da estação agrometeorológica de Bebedouro (Petrolina-PE) 
Dados de evaporação medidos pelo tanque Classe " $\mathrm{A}$ " apresentaram valores médios que variaram de 177 a 298 mm/mês, com os menores valores entre os meses de março a julho, e os maiores valores entre os meses de setembro e outubro, Figura 4 (Teixeira, 2002).

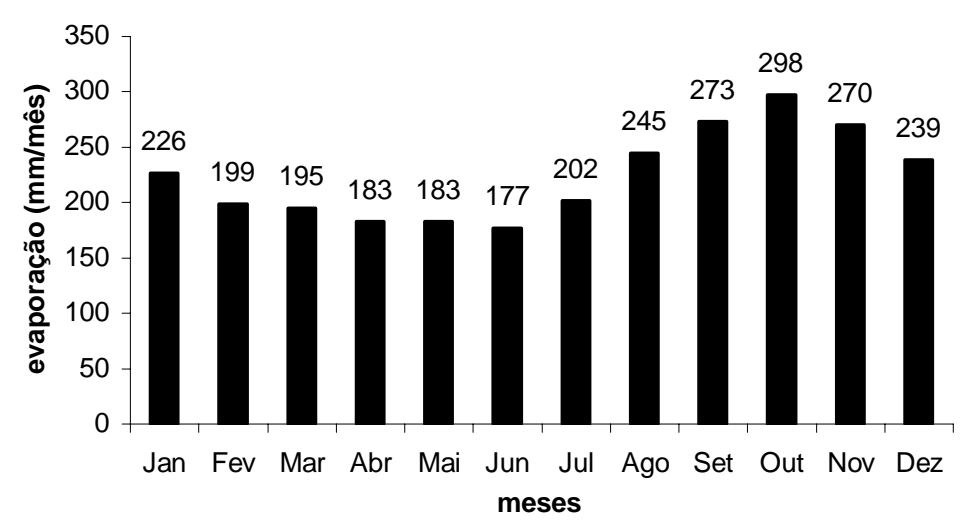

Figura 4 - Evaporação do Tanque Classe A do período de 1963/99 da estação agrometeorológica de Bebedouro (Petrolina-PE)

Com relação a umidade relativa do ar, os meses mais úmidos correspondem àqueles do período chuvoso, variando em média de $66 \%$ a $71,5 \%$, os menores valores acontecem nos meses de setembro e outubro, abaixo de 55\%, como observa-se na Figura 5 (Teixeira, 2002).

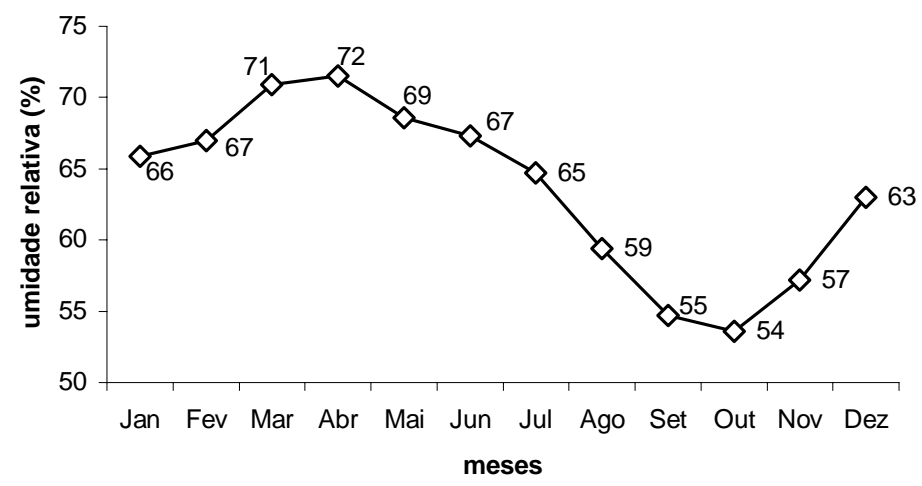

Figura 5 - Umidade Relativa média do ar do período de 1963/99 da estação agrometeorológica de Bebedouro (Petrolina-PE) 
Os meses que apresentam maiores valores de Insolação, correspondem ao período mais seco do ano, entre agosto e novembro, com valor de 266,6 horas/mês em outubro, e o menor valor de 192 horas/mês registrado no mês de julho, apresentando um total médio de 2668,1 horas/ano, Figura 6 (Teixeira, 2002).

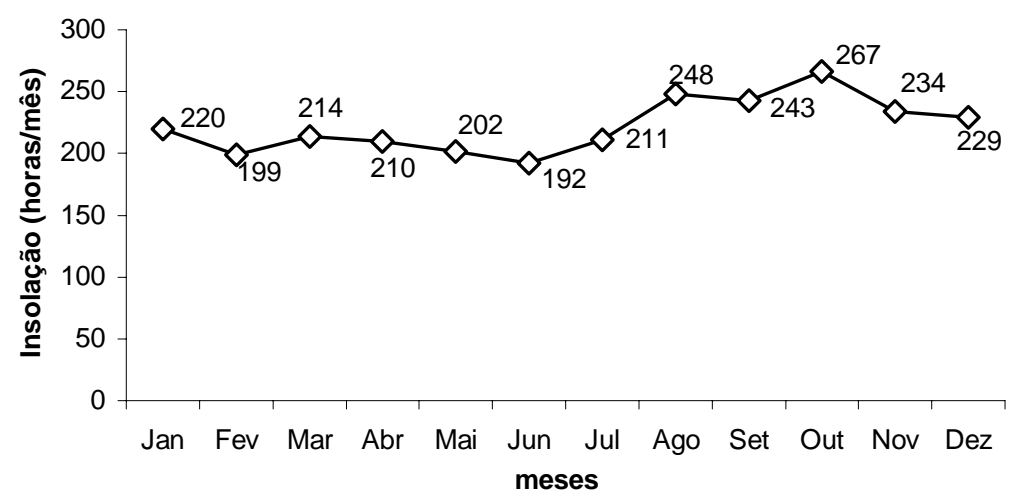

Figura 6 - Insolação do período de 1963/99 da estação agrometeorológica de Bebedouro (Petrolina-PE)

Na Figura 7, observa-se que a radiação global tem um comportamento semelhante ao da insolação, com os maiores valores registrados no mês de outubro, e os menores valores no mês de junho, (Teixeira, 2002).

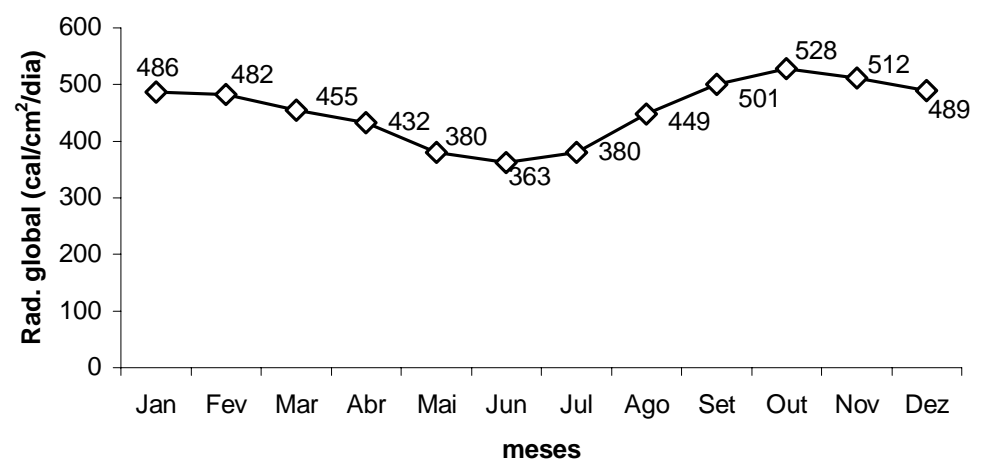

Figura 7 - Radiação global média do período de 1963/99 da estação agrometeorológica de Bebedouro (Petrolina-PE) 
Na Figura 8 observa-se os dados de velocidade do vento a 2,0 m de altura em relação a superfície do solo, onde apresentaram valores mais elevados no período seco, entre os meses de agosto a outubro, chegando a $256 \mathrm{Km} / \mathrm{dia}$, e os menores valores ocorrem no período chuvoso, apresentando valores médios de $139 \mathrm{Km} /$ dia (Teixeira, 2002).

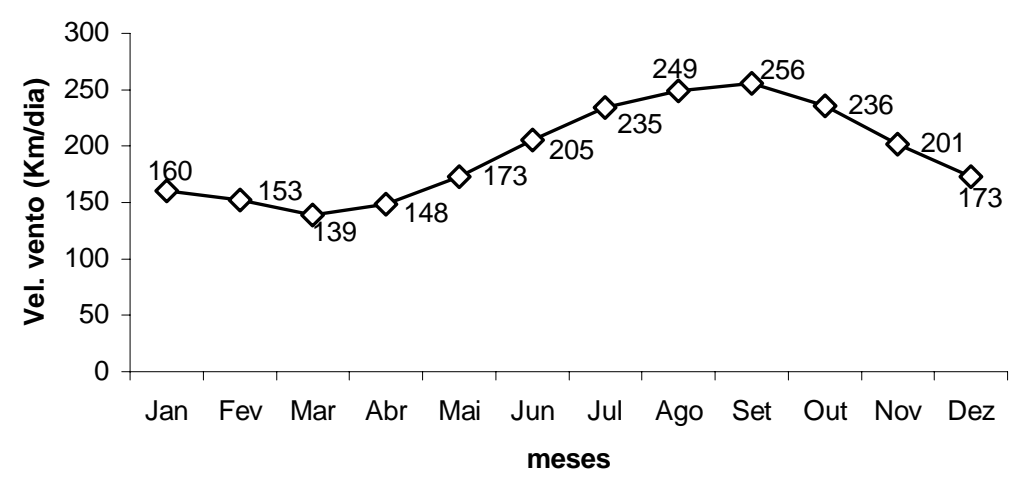

Figura 8 - Velocidade do vento do período de 1963/99 da estação agrometeorológica de Bebedouro (Petrolina-PE)

O solo da área experimental foi classificado como Latossolo Vermelho Amarelo textura média fase caatinga hiperxerófila relevo plano (EMBRAPA, 1999). Pela Tabela 1, observa-se que da superfície a $0,8 \mathrm{~m}$ de profundidade, apresenta textura arenosa e de 0,8 a 1,2 m, textura média. Com o incremento do silte e da argila dentro do perfil do solo, observa-se uma diminuição da densidade do solo e um aumento da umidade nas três tensões apresentadas.

Pela Tabela 2, o solo em questão apresentou baixos níveis de matéria orgânica, característica observada na grande maioria dos solos do Sub-médio São Francisco, acidez média, condutividade elétrica obtida no extrato da pasta de saturação (CE) baixa, fósforo muito alto na primeira camada $(0-0,2 \mathrm{~m})$ e baixo na segunda camada $(0,2-0,4 \mathrm{~m})$, devido ao aporte de fertilizantes de forma localizada. Apresentou também baixas concentrações de cálcio e magnésio, constatando a necessidade de aplicação de calcáreo. Embora a capacidade de troca de cátions seja considerada adequada, para ambas as 
profundidades, a saturação por bases é considerada média para a profundidade de 0-0,2 $\mathrm{m}$ e baixa para profundidade de 0,2-0,4 $\mathrm{m}$, devido a presença de $\mathrm{H}^{+}+\mathrm{Al}^{3+}$.

Tabela 1. Características físicas da área experimental

\begin{tabular}{|c|c|c|c|c|c|c|c|c|}
\hline \multirow[t]{2}{*}{ Prof. } & \multicolumn{3}{|c|}{ Granulometria } & \multicolumn{2}{|c|}{ Densidade } & \multicolumn{3}{|c|}{ Umidade $\left(\mathrm{cm}^{3} / \mathrm{cm}^{3}\right)$} \\
\hline & Areia & Silte & Argila & do solo & partícula & $10 \mathrm{kPa}$ & $30 \mathrm{kPa}$ & $1500 \mathrm{kPa}$ \\
\hline$m$ & \multicolumn{3}{|c|}{ 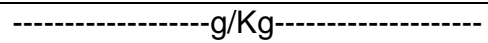 } & \multicolumn{2}{|c|}{----------g/cm } & \multicolumn{3}{|c|}{ 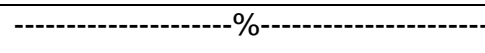 } \\
\hline $0,0-0,2$ & 900 & 10 & 90 & 1,55 & 2,50 & 7,78 & 7,04 & 2,76 \\
\hline $0,2-0,4$ & 890 & 10 & 100 & 1,52 & 2,45 & 9,94 & 6,37 & 3,51 \\
\hline $0,4-0,6$ & 820 & 80 & 100 & 1,52 & 2,48 & 10,51 & 8,73 & 3,88 \\
\hline $0,6-0,8$ & 800 & 90 & 110 & 1,43 & 2,51 & 11,12 & 7,09 & 4,41 \\
\hline $0,8-1,0$ & 760 & 110 & 130 & 1,26 & 2,56 & 12,48 & 7,96 & 4,96 \\
\hline $1,0-1,2$ & 760 & 100 & 140 & 1,30 & 2,55 & 12,58 & 8,56 & 4,86 \\
\hline
\end{tabular}

Tabela 2. Características químicas da área experimental

\begin{tabular}{|c|c|c|c|c|c|c|c|c|c|c|c|c|c|}
\hline Prof. & M.O. & $\mathrm{pH}$ & C.E. & $\mathrm{P}$ & $\mathrm{K}$ & $\mathrm{Ca}$ & $\mathrm{Mg}$ & $\mathrm{Na}$ & $\mathrm{Al}$ & $\mathrm{H}+\mathrm{Al}$ & S & CTC & V \\
\hline$m$ & $\mathrm{~g} / \mathrm{dm}^{3}$ & & $\mathrm{dS} / \mathrm{m}$ & $\mathrm{mg} / \mathrm{dm}^{3}$ & & & $-\cdots$ & $-\mathrm{cmo}$ & $/ \mathrm{dm}^{3}$ & & & & $\%$ \\
\hline $0,0-0,2$ & 7,9 & 5,8 & 0,66 & 46 & 0,94 & 1,3 & 0,6 & 0,03 & 0,10 & 2,14 & 2,87 & 5,01 & 57 \\
\hline $0,2-0,4$ & 5,2 & 5,0 & 0,60 & 8 & 0,87 & 1,2 & 0,6 & 0,03 & 0,20 & 2,80 & 2,20 & 5,00 & 44 \\
\hline
\end{tabular}

\subsection{Manejo da cultura}

A frutífera estudada foi a goiabeira (Psidium guajava L.), cultivar Paluma, plantada em março de 1999, no espaçamento de $6 \times 5 \mathrm{~m}$, sendo as plantas irrigadas por um sistema de microaspersão. A parcela ocupada pelo pomar corresponde a uma área de $2880 \mathrm{~m}^{2}$ com 96 plantas (Figura 9).

Sabe-se que a goiabeira responde à poda de frutificação, independentemente da época do ano, havendo temperatura, luminosidade e irrigação suficientes (Gonzaga Neto, 1991). No pomar estudado, a poda de 
frutificação foi realizada no dia 07/06/2001, correspondendo ao terceiro ciclo da cultura, depois de dois meses de repouso das plantas.

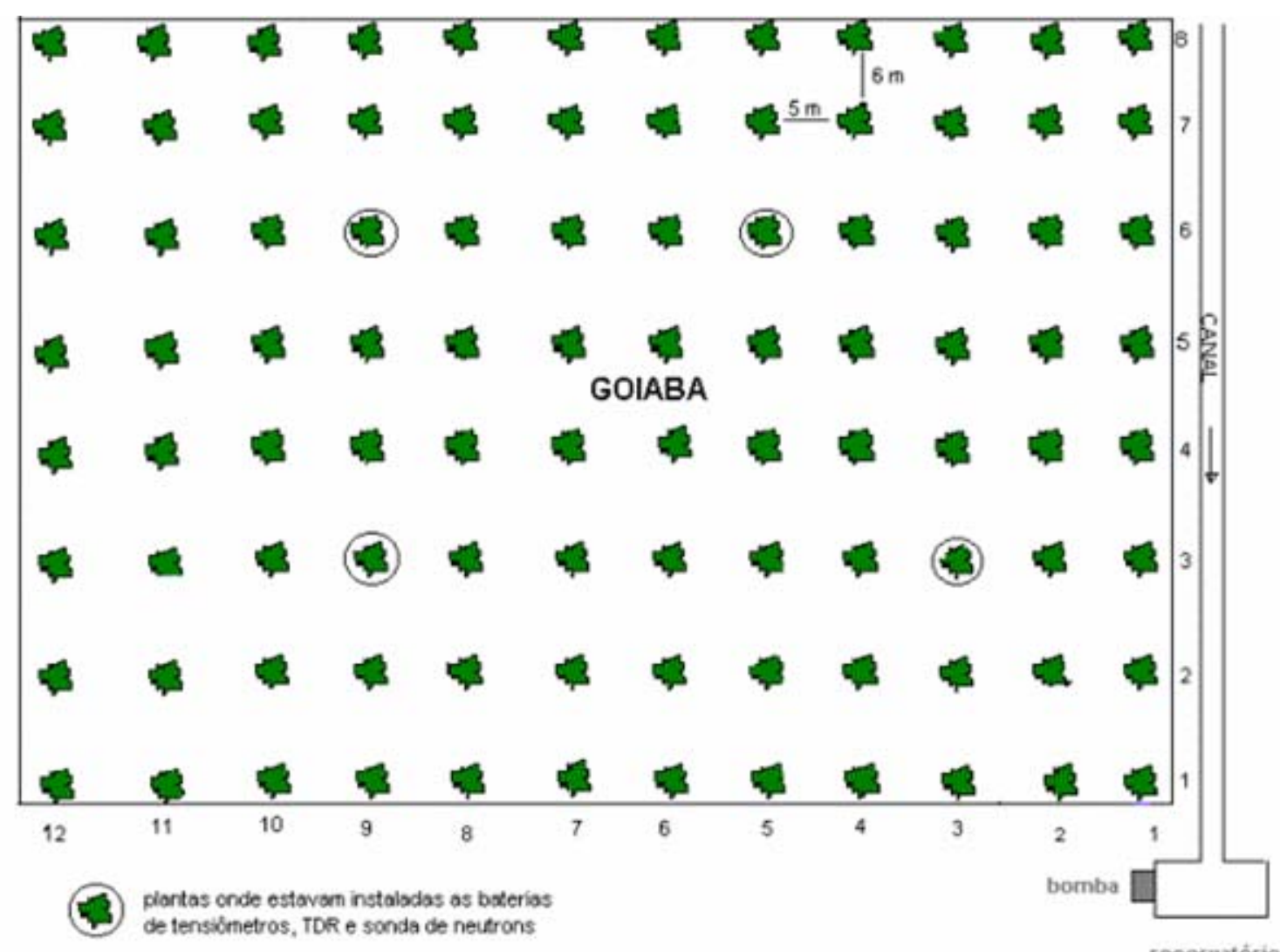

reservatónio

Figura 9 - Esquema do pomar de goiabeiras

As adubações das goiabeiras seguiram as recomendações do laboratório de análise de solo e de plantas da EMBRAPA Semi-Árido, através de amostras coletadas em duas profundidades $(0-20 \mathrm{~cm}$ e $20-40 \mathrm{~cm})$ antes da poda de frutificação. A adubação foi baseada na seguinte recomendação: 20 litros/planta de esterco de curral bem curtido; $250 \mathrm{~g}$ de N/planta, sendo 30\% antes da poda, $40 \%$ após o pegamento dos frutos, $20 \%$ na fase intermediária de crescimento dos frutos e $10 \%$ na fase final de crescimento dos frutos; $70 \mathrm{~g}$ de $\mathrm{P}_{2} \mathrm{O}_{5} /$ planta antes da poda de frutificação; $90 \mathrm{~g}$ de $\mathrm{K}_{2} \mathrm{O} /$ planta, sendo $30 \%$ antes da poda, 15\% após o pegamento dos frutos e 30\% na fase final de 
crescimento dos frutos; 1,15 t/ha de calcário, com o objetivo de elevar a saturação de bases para $80 \%$. Com esta recomendação de adubação, a produtividade esperada é de $25 \mathrm{t} / \mathrm{ha}$. As fontes de adubos minerais utilizados foram uréia, superfosfato simples e sulfato de potássio

Para retirar as folhas remanescentes que ficaram nas plantas após a poda de frutificação, aplicou-se uréia como desfolhante na dosagem de $20 \mathrm{Kg} /$ 200 litros de água, com o objetivo de facilitar a emissão de novas brotações. Foram realizadas pulverizações com inseticidas e fungicidas para o controle de pragas e doenças durante todo o ciclo da cultura, bem como capinas mecanizadas nas ruas do plantio e manual no raio de ação do microaspersor.

A irrigação foi manejada por tensiômetros até a profundidade de 0,60 $\mathrm{m}$, visando a assegurar a condição de umidade do solo para que ocorresse a evapotranspiração máxima da cultura (ETc). Para este objetivo, procurou-se manter o potencial matricial com valores superiores a $-40 \mathrm{kPa}$. O sistema de irrigação constava de um microaspersor por planta, instalado a aproximadamente $0,2 \mathrm{~m}$ do tronco da planta, com vazão média, medida em campo, de 37,8 litros/hora, pressão de serviço de 200 kPa, diâmetro e área molhada de $4 \mathrm{~m}$ e 12,57 $\mathrm{m}^{2}$ respectivamente, apresentando uma intensidade de aplicação de 3,0 mm/hora. Foram instaladas quatro baterias de tensiômetros e as medidas foram realizadas três vezes por semana, às 8:00 horas da manhã. Por meio dessas medidas, estimou-se o potencial matricial da água no solo $\left(\Psi_{\mathrm{m}}\right)$, através da seguinte equação (para os tensiômetros de mercúrio):

$$
\Psi_{m}=-12,6 h(H g)+h_{1}+h_{2} \quad \text { Eq. } 5
$$

onde:

$\mathrm{h}(\mathrm{Hg})$ - altura da coluna de mercúrio, cm;

$\mathrm{h}_{1}$ - altura do reservatório de mercúrio em relação ao solo, cm;

$\mathrm{h}_{2}$ - profundidade de instalação da cápsula, $\mathrm{cm}$. 
Para os tensiômetros digitais utilizou-se a seguinte equação:

$$
\Psi_{m}=L t-h c
$$

onde:

$$
\begin{aligned}
& \text { Lt - leitura do tensímetro (bar) } \\
& \text { hc - altura de coluna de água no tensiômetro (cm) }
\end{aligned}
$$

Utilizou-se o modelo de van Genuchten (1980) para a representação matemática da curva do potencial matricial da água no solo, em função da umidade do solo $\left(\theta, \mathrm{cm}^{3} / \mathrm{cm}^{3}\right)$ :

$$
\theta=\theta_{r}+\frac{\theta_{s}-\theta_{r}}{\left[1+\left|\alpha \Psi_{M}\right|^{n}\right]^{m}}
$$

onde:

$\theta_{\mathrm{r}}$ - umidade residual, $\mathrm{cm}^{3} / \mathrm{cm}^{3}$;

$\theta_{\mathrm{s}}$ - umidade de saturação, $\mathrm{cm}^{3} / \mathrm{cm}^{3}$;

$\Psi_{\mathrm{m}}$ - potencial matricial, cmca;

$\alpha$, - parâmetro dependente do solo, 1/cm;

$\mathrm{n}, \mathrm{m}$ - parâmetros dependentes do solo, adm.

Os parâmetros empíricos da equação 6 foram estimados através do uso do software Curvaret (Dourado Neto e Van Lier, 1993). A lâmina líquida de irrigação $\left(L_{l}, \mathrm{~mm}\right)$ foi determinada pela seguinte equação:

$$
L_{I}=\left(\theta_{c c}-\theta_{p c}\right) \cdot P
$$

onde:

$\theta_{\mathrm{cc}}-$ umidade do solo na capacidade de campo, $\mathrm{cm}^{3} / \mathrm{cm}^{3}$;

$\theta_{\mathrm{pc}}-$ umidade do solo no ponto crítico, $\mathrm{cm}^{3} / \mathrm{cm}^{3}$;

$\mathrm{P}$ - Profundidade de irrigação, $\mathrm{mm}$. 
Os potenciais matriciais do solo utilizados neste trabalho na capacidade de campo e no ponto crítico foram de $-10 \mathrm{kPa}$ e $-40 \mathrm{kPa}$, respectivamente.

Para o cálculo da lâmina bruta de irrigação $\left(L_{b}, m m\right)$ utilizou-se a seguinte equação:

$$
L_{b}=\frac{L_{l}}{E_{f}}
$$

Eq. 8

onde:

$E_{f}$ - eficiência de irrigação, decimal.

O tempo de irrigação $\left(T_{i}\right.$, horas) foi determinado pela seguinte equação:

$$
T_{i}=\frac{L_{b}}{I_{a}}
$$

onde:

$\mathrm{l}_{\mathrm{a}}$ - intensidade de aplicação do microaspersor, $\mathrm{mm} / \mathrm{h}$.

Para facilitar o cálculo do tempo de irrigação da parcela experimental, elaborou-se uma tabela relacionando a leitura do tensiômetro com o tempo de irrigação.

\subsection{Evapotranspiração de referência (ETo)}

Para a estimativa da evapotranspiração de referência (ETo), foram utilizados os métodos de Penman Monteith FAO e o do tanque Classe A (Allen et al 1998). Foram utilizados os dados coletados na estação agrometeorológica de Bebedouro, localizada na margem esquerda do rio São Francisco no 
município de Petrolina-PE. As observações seguiram os padrões internacionais recomendados pela Organização Meteorológica Mundial (OMM) e foram efetuadas nos horários de 12:00, 18:00 e 24:00 horas TMG, (9:00, 15:00 e 21:00 horário local). A estação é composta de uma área gramada de 12 × $18 \mathrm{~m}$, com os seguintes equipamentos e finalidades: 1) Abrigo meteorológico convencional para localização de equipamentos meteorológicos; 2) Psicrômetro, constituído de dois termômetros sendo um de bulbo seco e outro de bulbo úmido para obtenção da temperatura e umidade relativa do ar; 3) Termômetros de máxima e mínima, para obtenção das temperaturas máxima e mínima do ar; 4) Termohigrógrafo, para registro de temperatura e umidade do ar; 5) Pluviômetro Ville de Paris para a obtenção dos totais de chuva; 6) Pluviógrafo Fuess para registro da duração e intensidade de chuva; 7) Tanque classe A para obtenção da evaporação da água; 8) Heliógrafo CampbellStokes, para registro do número de horas de brilho solar (insolação); 9) Actinógrafo bimetálico Fuess para registro da radiação solar global incidente na superfície terrestre; 10) Anemômetros totalizadores de canecas para obtenção da velocidade do vento a $0,5 \mathrm{~m}$ e 2,0 $\mathrm{m}$ de altura.

Para a determinação da ETo através do método Penman Monteith FAO, considerado como padrão, utilizou-se a seguinte equação:

$$
\text { ETo }=\frac{0,408 \Delta(R n-G)+\gamma \frac{900}{T+273} U_{2}\left(e_{S}-e_{a}\right)}{\Delta+\gamma\left(1+0,34 U_{2}\right)}
$$

onde:

ETo - evapotranspiração de referência, $\mathrm{mm} \mathrm{dia}^{-1}$;

$\mathrm{Rn}$ - Saldo de radiação, $\mathrm{MJ} \mathrm{m}^{-2} \mathrm{dia}^{-1}$;

$\mathrm{G}$ - fluxo de calor no solo, $\mathrm{MJ} \mathrm{m}^{-2} \mathrm{dia}^{-1}$;

$\mathrm{T}$ - Temperatura média diária, ${ }^{\circ} \mathrm{C}$;

$\mathrm{U}_{2}$ - Velocidade do vento a $2 \mathrm{~m}$ de altura, $\mathrm{m} \mathrm{s}^{-1}$; 
$\mathrm{e}_{\mathrm{s}}$ - pressão de saturação de vapor, kPa;

$\mathrm{e}_{\mathrm{a}}$ - pressão atual de vapor, $\mathrm{kPa}$;

$\Delta$-- declividade da curva de pressão de vapor, $\mathrm{kPa}{ }^{\circ} \mathrm{C}^{-1}$

$\gamma$-- constante psicrométrica, $\mathrm{kPa}^{\circ} \mathrm{C}^{-1}$.

O saldo de radiação na superfície da cultura foi determinado pela seguinte equação:

$$
\mathrm{Rn}=\mathrm{Rns}-\mathrm{Rnl}
$$

onde:

Rns - saldo de radiação de ondas curtas, $\mathrm{MJ} \mathrm{m}^{-2}$ dia $^{-1}$;

$\mathrm{Rnl}$ - saldo de radiação de ondas longas, $\mathrm{MJ} \mathrm{m}^{-2} \mathrm{dia}^{-1}$.

O saldo de radiação de ondas curtas foi determinado pela seguinte equação:

$$
\text { Rns }=(1-\alpha) \text { Rs }
$$

onde:

$$
\begin{aligned}
& \alpha \text { - albedo para cultura hipotética }(0,23) \text {; } \\
& \text { Rs - radiação solar global, } \mathrm{MJ} \mathrm{m}^{-2} \mathrm{dia}^{-1} \text {. }
\end{aligned}
$$

A radiação solar global (Rs), foi medida na estação agrometeorológica de Bebedouro através do actinógrafo. O saldo de radiação de ondas longas foi determinado pela equação:

$$
R n l=\sigma\left(\frac{T \max , k^{4}+T \min , k^{4}}{2}\right)\left(0,34-0,14 \sqrt{e_{a}}\right)\left(1,35 \frac{R s}{R s o}-0,35\right)
$$

onde: 
$\sigma$ - constante de Stefan-Boltzmann $\left(4,903.10^{-9} \mathrm{MJ} \mathrm{m}^{-2} \mathrm{~d}^{-1} \mathrm{~K}^{-4}\right)$;

$\mathrm{T}_{\mathrm{max}, \mathrm{K}}$ - temperatura máxima diária;

$\mathrm{T}_{\min , \mathrm{K}}$ - temperatura mínima diária;

$\mathrm{e}_{\mathrm{a}}$ - pressão atual de vapor, $\mathrm{kPa}$;

Rso - radiação solar dia limpo, $\mathrm{MJ} \mathrm{m}^{-2} \mathrm{dia}^{-1}$.

A radiação solar em dia limpo foi determinada pela seguinte equação:

$$
\text { Rso }=\left(a_{s}+b_{s}\right) R a
$$

onde:

$a_{s}+b_{s}-$ coeficiente de Angstron, determinado por Teixeira (1999) para o município de Petrolina - PE;

$\mathrm{Ra}$ - radiação no topo da atmosfera, $\mathrm{MJ} \mathrm{m}^{-2} \mathrm{dia}^{-1}$.

A radiação no topo da atmosfera foi determinada pela seguinte equação:

$$
\mathrm{Ra}=37,586 \mathrm{~d}_{\mathrm{r}}\left(\omega_{\mathrm{s}} \operatorname{sen} \varphi \operatorname{sen} \delta+\cos \varphi \cos \delta \operatorname{sen} \omega_{\mathrm{s}}\right)
$$

Eq, 15

onde:

$\mathrm{d}_{\mathrm{r}}$ - distância relativa terra-sol;

$\omega_{\mathrm{s}}$ - ângulo horário do pôr do sol, rad;

$\varphi$ - latitude, rad;

$\delta$ - declinação solar, rad.

A distância relativa Terra-sol foi determinada pela seguinte equação:

$$
d_{r}=1+0,033 \cos \left(\frac{2 \pi}{365} J\right)
$$


onde:

$\mathrm{J}$ - dia juliano.

O ângulo horário do pôr do sol foi determinado pela seguinte equação:

$\omega_{\mathrm{S}}=\operatorname{arc} \cos (-\tan \varphi \tan \delta)$

Eq. 17

A declinação solar foi determinada pela equação:

$$
\delta=0,4093 \operatorname{sen}\left(\frac{2 \pi}{365} J-1,39\right)
$$

A constante psicrométrica foi determinada pela equação:

$$
\gamma=0,001628617 \frac{P}{\lambda}
$$

onde:

$\mathrm{P}$ - pressão atmosférica, $\mathrm{kPa}$;

$\lambda$ - calor latente de evaporação, $\mathrm{MJ} \mathrm{Kg}^{-1}$.

A pressão atmosférica foi determinada pela equação:

$$
P=101,3\left(\frac{293-0,0065}{293} Z\right)^{5,26}
$$

onde:

Z - altitude, $\mathrm{m}$.

O calor latente de evaporação foi determinada pela equação:

$$
\lambda=2,501-\left(2,361.10^{-3}\right) T
$$


onde:

$\mathrm{T}$ - temperatura média, ${ }^{\circ} \mathrm{C}$.

O fluxo de calor no solo (G) foi considerado igual a zero, pois segundo Allen et al (1998), a magnitude de fluxo de calor no solo para períodos diários ou dez dias, é relativamente pequeno, podendo ser ignorado, e a velocidade do vento a $2 \mathrm{~m}$ de altura foi medida na estação agrometeorológica de Bebedouro. A pressão de saturação de vapor foi determinada pela seguinte equação:

$$
e_{s}=\frac{e^{0}(T \max )+e^{0}(T \min )}{2}
$$

onde:

$\mathrm{e}^{0}$ - pressão de saturação de vapor em função da temperatura, kPa.

A pressão de saturação de vapor $\left(e^{0}\right)$ em função da temperatura foi determinada pela seguinte equação:

$$
e^{0}=0,6108 \exp \left(\frac{17,27 \times T}{T+237,3}\right)
$$

onde:

$\mathrm{T}-$ Temperatura do ar, ${ }^{\circ} \mathrm{C}$.

A pressão atual de vapor $\left(e_{a}\right)$ foi determinada pela seguinte equação:

$$
e_{a}=\frac{R H \times e_{s}}{100}
$$

onde:

$\mathrm{RH}$-umidade relativa média, \%. 
A declividade da curva de pressão de vapor foi determinada pela seguinte equação:

$$
\Delta=\frac{4098 \times e^{0}}{(T+237,3)^{2}}
$$

Para estimativa da evapotranspiração de referência (ETo) pelo método do tanque classe A, instalado na estação agrometeorológica de Bebedouro, em uma área gramada de aproximadamente $10 \mathrm{~m}$ de bordadura, onde as leituras foram efetuadas diariamente às 9:00 horas, foi utilizada a seguinte equação:

$$
\begin{array}{ll}
E T o=K p \times \text { Epan } & \text { Eq. } 26
\end{array}
$$

onde:

$\mathrm{Kp}$ - coeficiente do tanque;

Epan - evaporação do tanque, $\mathrm{mm}$ dia $^{-1}$.

Para a determinação do coeficiente do tanque (Kp), foi utilizada a seguinte equação:

Eq. 27

$$
K p=0,108-0,0286 U_{2}+0,0422 \ln (F E T)+0,1434 \ln (R H)-0,000631 \ln (F E T)^{2} \ln (R H)
$$

onde:

FET - distância da área gramada ao redor do tanque, m.

\subsection{Balanço hídrico no solo}

\subsubsection{Calibração dos equipamentos}

A calibração da sonda de nêutrons e do TDR (reflectometria no domínio de tempo) consistiu em se obter uma relação entre as leituras dos aparelhos e a 
umidade do solo $\theta\left(\mathrm{cm}^{3} / \mathrm{cm}^{3}\right)$. Os dados para a calibração dos equipamentos foram coletados em duas parcelas de 3,0 x 3,0 m (Figura 10) em uma área próxima ao experimento, contendo cada uma cinco tubos de acesso de alumínio para a sonda de nêutrons e doze sondas de TDR até a profundidade de $1,20 \mathrm{~m}$.

Foram coletados, inicialmente, os dados em condição de solo com baixo teor de umidade, considerada parcela seca, e posteriormente em condição de saturação, obtidos com o umedecimento do perfil (considerada parcela umedecida), apresentando uma ampla faixa de variação de umidade. Foram obtidas leituras de umidade do solo com ambos os equipamentos e em seguida coletadas amostras indeformadas de solo foram com anéis de volume conhecido para determinação da umidade gravimétrica e da densidade do solo.
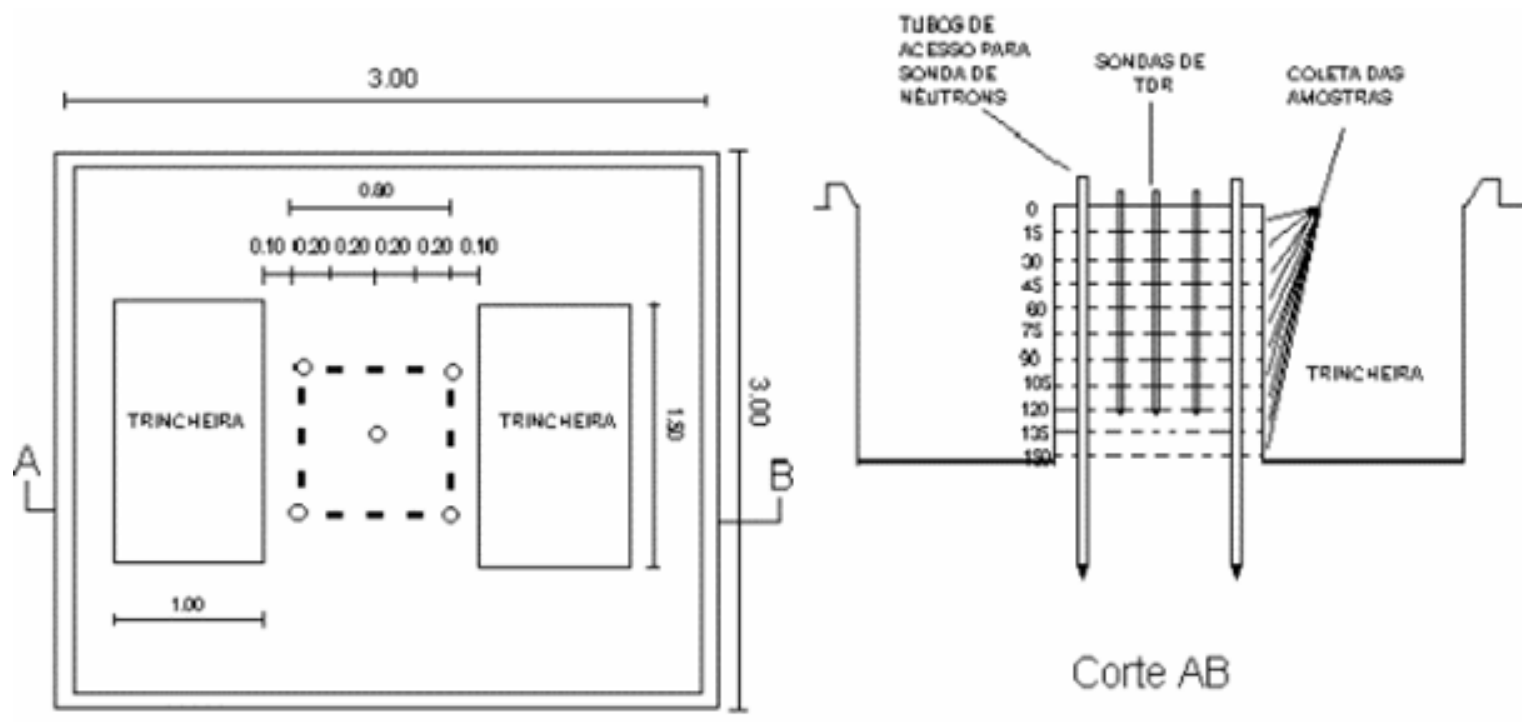

Vista de cima

Corte $\mathrm{AB}$

Figura 10 - Parcela para a calibração da sonda de nêutrons e do TDR 
Trabalhou-se com a leitura relativa (Lr) para os dois equipamentos, e não diretamente com as leituras obtidas no solo, utilizando a blindagem de proteção da sonda de nêutrons como leitura padrão, e no caso do TDR, utilizouse o ar como leitura padrão obtida em laboratório, através da seguinte equação:

$$
L r=\frac{L s}{L p}
$$

onde:

$$
\begin{aligned}
& \text { Lr - Leitura relativa; } \\
& \text { Ls - Leitura obtida no solo; } \\
& \text { Lp - Leitura padrão. }
\end{aligned}
$$

A umidade $\theta\left(\mathrm{cm}^{3} / \mathrm{cm}^{3}\right)$ foi determinada pela seguinte equação de regressão linear:

$$
\theta=b \times L r+a
$$

onde:

$\theta$ - Umidade do solo, $\mathrm{cm}^{3} / \mathrm{cm}^{3}$;

$\mathrm{Lr}$ - Leitura relativa;

$a, b$ - coeficientes linear e angular.

Para utilização dos tensiômetros, tanto os de coluna de mercúrio como os digitais, determinou-se curvas de retenção da água no solo representativa da parcela experimental, através de amostras de solo extraídas com um trado nas profundidades de 20, 40, 60, 80, 100 e $120 \mathrm{~cm}$. Essas amostras foram colocadas na câmara de Richards para obtenção da quantidade de água retida no solo nas pressões de 10, 30, 50, 70, 100, 500 e $1500 \mathrm{kPa}$, realizado no laboratório de solos da Embrapa Semi-Árido. 


\subsubsection{Determinação da evapotranspiração da cultura (ETc)}

O consumo de água da goiabeira foi estimado entre os dias 07/06/2001 (poda de frutificação) até o dia 24/12/2001 (final da colheita), correspondendo a $3^{a}$ poda do pomar e um total de 200 dias. Este período de produção foi dividido em quatro sub-períodos, assim denominados: $F_{1}$ - brotação e crescimento vegetativo, $F_{2}$ - floração e queda fisiológica dos frutos, $F_{3}$ - crescimento dos frutos, $\quad F_{4}-$ maturação e colheita. A evapotranspiração (ETc) foi estimada nestas fases da cultura, por serem as mais representativas e de fácil visualização no campo.

Realizou-se o balanço hídrico no solo por meio da contabilização da precipitação pluvial $(P)$, da irrigação (I), da variação do armazenamento da água no solo $(\Delta \mathrm{A})$, da drenagem profunda ou ascensão capilar (D), e da evapotranspiração (ET), através da seguinte equação:

$$
\mathrm{P}+\mathrm{I} \pm \mathrm{D} \pm \Delta \mathrm{A} \pm \mathrm{R}=\mathrm{ET}
$$

Eq. 30

Devido a topografia da área experimental ser plana, o componente escoamento superficial $(R)$, foi desconsiderado. Os dados de precipitação pluvial foram obtidos através de pluviômetro instalado na estação agrometeorológica de Bebedouro. A lâmina de irrigação foi calculada pela seguinte equação, derivada da equação 9:

$$
\mathrm{L}=\mathrm{T}_{\mathrm{i}} \times \mathrm{I}_{\mathrm{a}}
$$

onde:

$$
\begin{aligned}
& L \text { - lâmina de irrigação, mm; } \\
& T_{i} \text { - tempo de irrigação, horas; } \\
& \mathrm{l}_{a} \text { - intensidade de aplicação do microaspersor, mm/hora. }
\end{aligned}
$$


O armazenamento da água no solo foi determinada a partir dos valores de umidade obtidos da sonda de nêutrons, do TDR e dos tensiômetros (Figura 11). Foram instalados quatro baterias para leitura da sonda de nêutrons, quatro baterias dos tensiômetros e duas baterias para leitura do TDR conforme esquema mostrado na Figura 12.
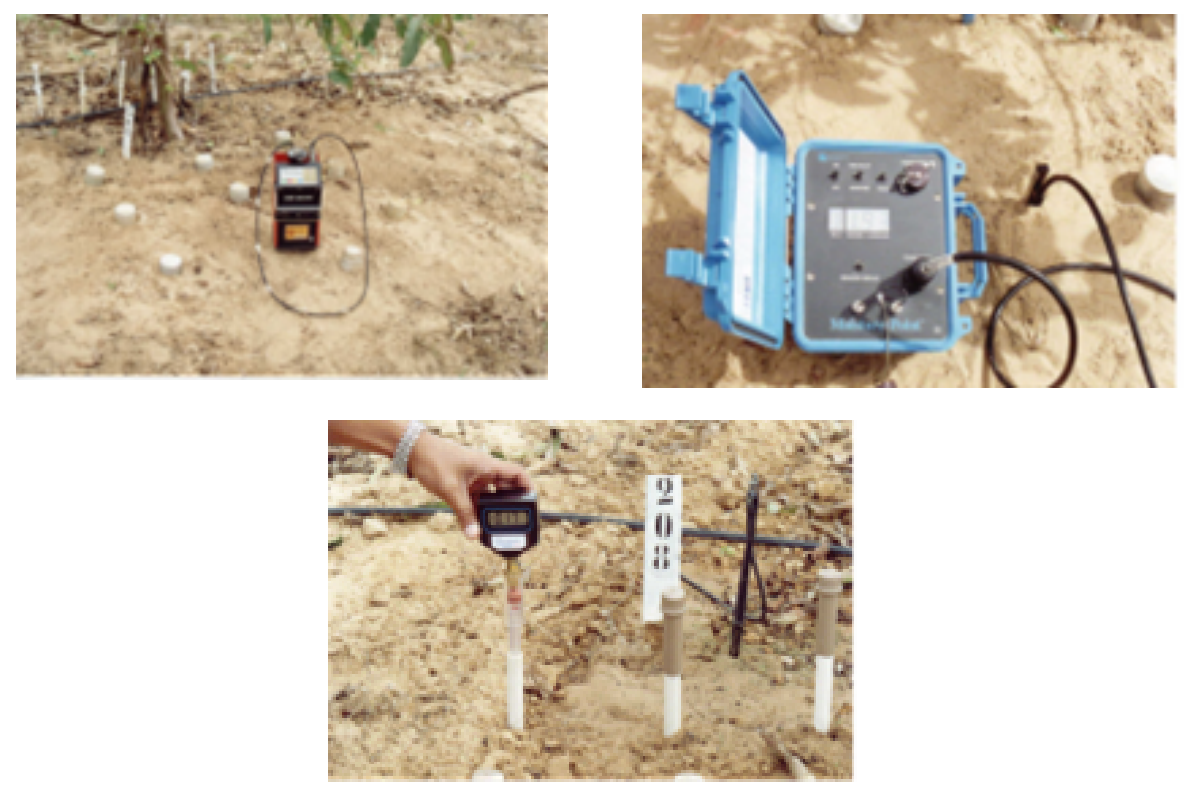

Figura 11 - Detalhe da sonda de nêutrons, do TDR e do tensímetro

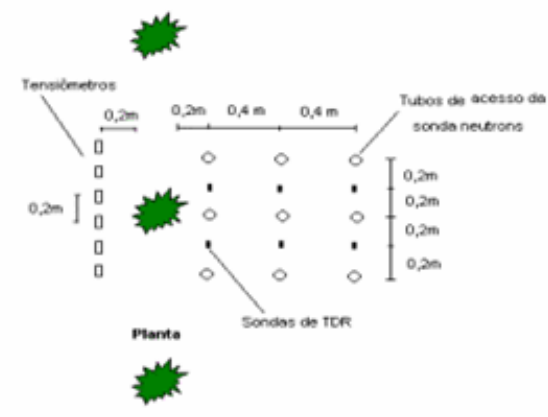

Figura 12 - Esquema de instalação dos tensiômetros, dos tubos de acesso da sonda de nêutrons e das sondas de TDR.

O armazenamento foi calculado até a profundidade de 1,2 $\mathrm{m}$ através da regra do trapézio, como mostra a seguir (Libardi,1995): 


$$
A=\int_{0}^{L} \theta(z) d z \cong\left[1,5 \theta\left(z_{1}\right)+\sum \theta\left(z_{i}\right)+0,5\left(z_{n}\right)\right] \Delta z
$$

onde:

A - armazenamento de água do perfil z, $\mathrm{mm}$;

$\theta$ - umidade volumétrica, $\mathrm{cm}^{3} / \mathrm{cm}^{3}$;

$\mathrm{Z}_{1}$ - umidade da primeira camada, $\mathrm{cm}^{3} / \mathrm{cm}^{3}$;

$z_{i}$ - umidade das camadas intermediárias, $\mathrm{cm}^{3} / \mathrm{cm}^{3}$;

$\mathrm{Z}_{\mathrm{n}}$ - umidade da última camada, $\mathrm{cm}^{3} / \mathrm{cm}^{3}$;

$\Delta \mathrm{z}$ - largura da camada, $\mathrm{mm}$.

A variação do armazenamento da água no solo $(\Delta \mathrm{A}, \mathrm{mm})$ foi calculada durante os períodos de tempo considerado, pela seguinte equação:

$$
\Delta A=A_{f}-A_{i}
$$

onde:

$A_{f}$ - armazenamento no tempo final, $\mathrm{mm}$;

$A_{i}$ - armazenamento no tempo inicial, $\mathrm{mm}$.

Para a determinação da drenagem profunda ou ascensão capilar (fluxo descendente ou ascendente) no limite inferior do volume de solo considerado ( $z=1,2 \mathrm{~m}$ ) utilizou-se a equação de Darcy - Buckingham, como mostra a seguir:

$$
q=-K(\theta) \frac{\partial \Psi_{t}}{\partial z}
$$

onde:

q - fluxo de água no solo, $\mathrm{mm} \mathrm{dia}^{-1}$;

$\mathrm{K}(\theta)$ - condutividade hidráulica, $\mathrm{mm} \mathrm{dia}^{-1}$;

$\frac{\partial \Psi_{t}}{\partial z}$ - gradiente do potencial total;

$\Psi_{\mathrm{t}}$ - potencial total da água no solo, cm;

z - coordenada vertical de posição, $\mathrm{cm}$. 
A determinação da condutividade hidráulica não saturada do solo (K⿻) foi feita pelo método da umidade proposto por Libardi (1995), de acordo com o modelo:

$$
K(\theta)=K_{0} e^{\gamma\left(\theta-\theta_{0}\right)}
$$

onde:

$\mathrm{K}_{0}$ - condutividade hidráulica saturada, $\mathrm{mm} \mathrm{dia}^{-1}$;

$\gamma$ - constante dependente do solo;

$\theta$ - umidade do solo, $\mathrm{cm}^{3} / \mathrm{cm}^{3}$;

$\theta_{0}$ - umidade do solo saturado, $\mathrm{cm}^{3} / \mathrm{cm}^{3}$.

Para isso, foi saturada uma parcela de solo de $25 \mathrm{~m}^{2}(5 \times 5 \mathrm{~m})$ próxima a área experimental, de maneira que os processos em seu centro não fossem afetados pelos seus limites. Na região central da parcela foram instalados três tubos de acesso de alumínio para a medida da umidade do solo com a sonda de nêutrons nas profundidades de 0,15; 0,30;0,45;0,60;0,75;0,90; 1,05 e $1,20 \mathrm{~m}$, como mostra a figura 13.
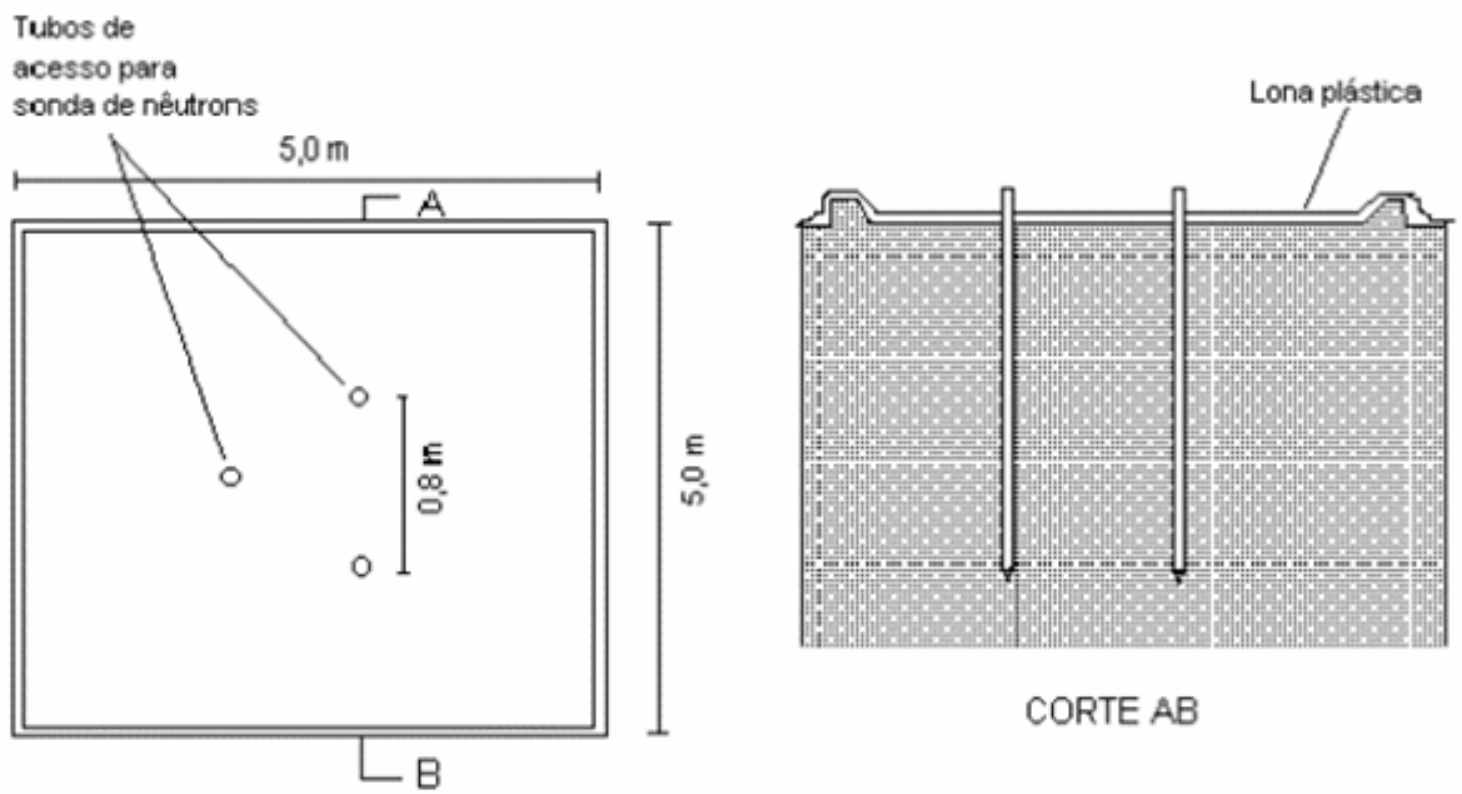

Figura 13 - Esquema da parcela para determinação do $K(\theta)$ 
Colocou-se água na superfície da parcela para umedecimento do perfil do solo, e depois da constatação de umidade constante com o tempo, a parcela foi coberta com uma lona plástica para evitar a evaporação direta e a entrada de água através da superfície. Durante o processo de redistribuição da água no perfil do solo, foram efetuadas medidas periódicas de umidade com a sonda de nêutrons nas profundidades pré-estabelecidas.

Determinou-se o coeficiente de cultura $(\mathrm{Kc})$ através da equação 34 , sendo utilizados os valores de ETo estimados pelo modelo de PenmanMonteith-FAO e pelo método do tanque classe $A$.

$$
K c=\frac{E T c}{E T o}
$$

onde:

$$
\begin{aligned}
& \text { Kc - coeficiente de cultura; } \\
& \text { Etc - Evapotranspiração da cultura, mm; } \\
& \text { ETo - Evapotranspiração de referência, mm. }
\end{aligned}
$$

\subsection{Análise da distribuição do sistema radicular}

Para a análise da distribuição do sistema radicular da goiabeira, foram abertas trincheiras paralelas à linha de duas plantas, com 1,20 m de profundidade e 5,0 $\mathrm{m}$ de comprimento (Figura 14). $\mathrm{O}$ trabalho foi realizado em janeiro de 2002, após a colheita.

O preparo do primeiro perfil do solo foi realizado a $2,4 \mathrm{~m}$ da planta e consistiu na escarificação da parede da trincheira para retirada de $2 \mathrm{~cm}$ de solo com o objetivo de melhorar a visualização das raízes. Em seguida, foi realizada a pintura das raízes com tinta látex branca, a fim de realçar o contraste destas com o solo. 


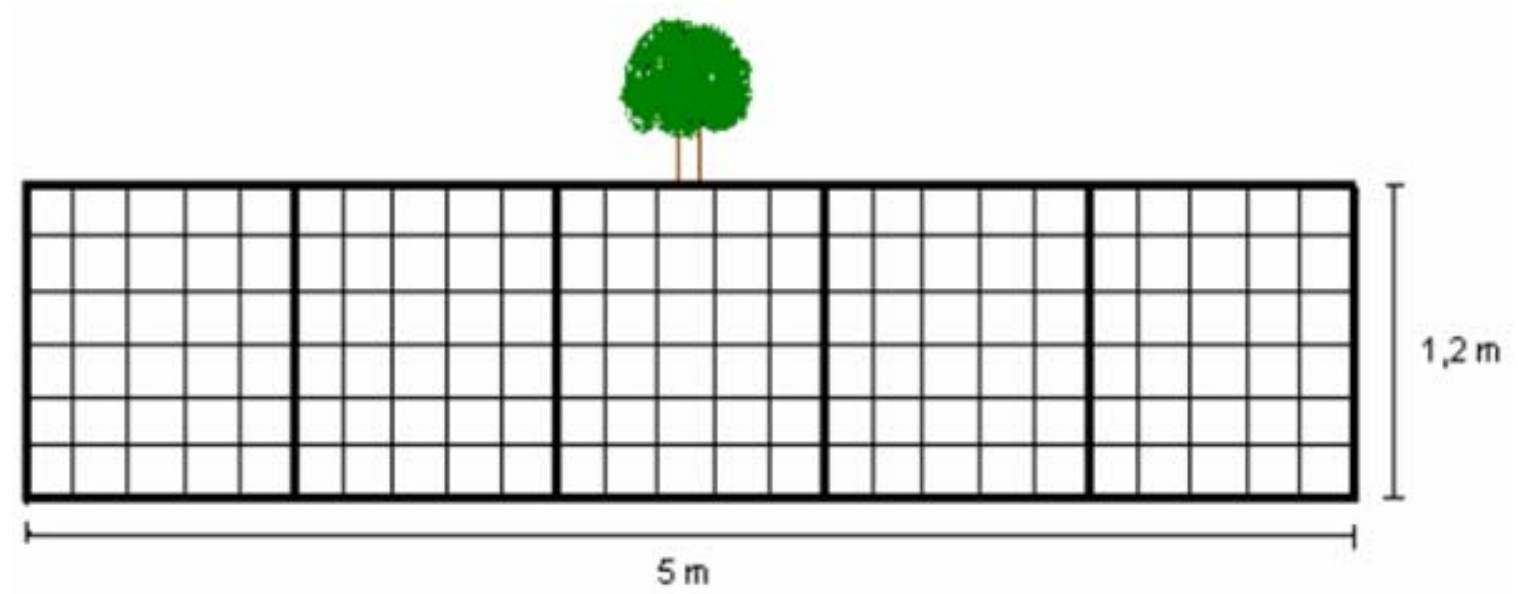

Figura 14 - Esquema da trincheira para análise das raízes

Para delimitar a área a ser fotografada, utilizou-se um quadrado de madeira de $1 \times 1 \mathrm{~m}$, subdividido em pequenos quadrados de 0,2 x 0,2 m (Figura 15). Cada um dos quadrados foi identificado segundo o perfil e sua localização horizontal e vertical. A imagem de cada um dos quadrados foi obtida com uma câmara fotográfica digital.

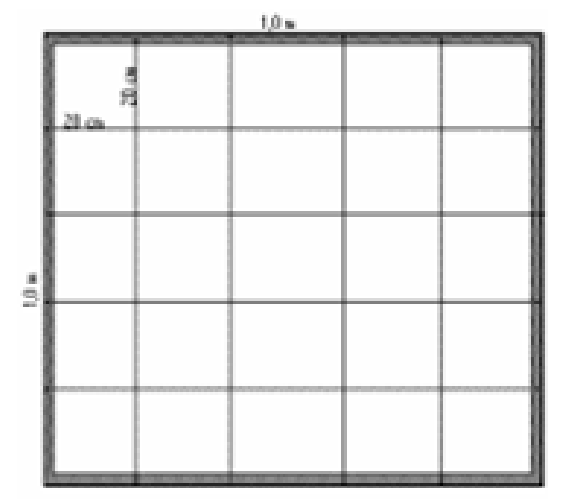

Figura 15 - Quadrado de madeira para delimitar a área a ser fotografada 
Para aquisição de fotos de um segundo perfil, retirou-se uma camada de solo de 0,2 $\mathrm{m}$ de espessura, onde o novo perfil foi preparado e em seguida fotografado. Este procedimento foi repetido até a distância de $0,2 \mathrm{~m}$ da planta.

As imagens das raízes foram analisadas pelo SIARCS 3.0 (Sistema Integrado para Análise de Raízes e Cobertura do Solo), onde foram medidos a área $\left(\mathrm{cm}^{2}\right)$ e o comprimento $(\mathrm{cm})$ das raízes expostas em cada quadrado de $0,2 \times 0,2 \mathrm{~m}$. Os valores desses parâmetros foram integralizados em cada perfil e sua distribuição percentual foi obtida nas direções vertical e horizontal.

Nos perfis de 0,4 e 0,6 m de distância da planta, utilizou-se a metodologia do monolito com o objetivo de comparar este método com o método de imagem digitais fotografado nos perfis de solo, citado anteriormente. Ambos os métodos permitem análise quantitativa do sistema radicular.

$\mathrm{Na}$ parte central da parede da trincheira (abaixo do tronco) foram coletadas amostras de solo (monolitos) de $20 \times 20 \times 20 \mathrm{~cm}$ em uma das plantas analisadas. O solo foi separado das raízes por peneiramento no campo, e em laboratório, as raízes foram lavadas, secas ao ar e divididas por diâmetro (d) ( $d<2 \mathrm{~mm}, 2<\mathrm{d}<5 \mathrm{~mm}, 5<\mathrm{d}<10 \mathrm{~mm}, \mathrm{~d}>10 \mathrm{~mm}$ ). Posteriormente, foram obtidas imagens digitais das raízes separadas por diâmetro em um fundo de cor contrastante com dimensões de $20 \times 20 \mathrm{~cm}$ e analisadas pelo SIARCS 3.0 para quantificação da área $\left(\mathrm{cm}^{2}\right)$ e do comprimento $(\mathrm{cm})$.

As imagens coletadas diretamente no campo, e nas mesmas posições dos monolitos foram correlacionados em termos de comprimento $(\mathrm{cm})$ e percentagem de raízes.

Para inferir a distribuição do sistema radicular no solo, utilizou-se o método indireto da variação da armazenagem da água no perfil do solo. As medidas de umidade utilizadas para esta estimativa, foram coletadas através da sonda de nêutrons e do TDR, e os resultados desta estimativa foram correlacionados com a distribuição percentual de raízes obtidas das imagens coletadas diretamente no campo e analisadas pelo SIARCS 3.0. 


\subsection{Eficiência de uso de água}

A eficiência de uso de água foi determinada pela relação entre a produtividade total dos frutos e a quantidade de água aplicada através da irrigação (Equação 37), conforme descrito por Doorenbos e Kassan (1994):

$$
E U A=\frac{P t}{W}
$$

onde:

$$
\begin{aligned}
& \text { EUA - eficiência do uso da água, } \mathrm{Kg} \mathrm{m}^{-3} \text {; } \\
& \mathrm{Pt} \text { - produtividade total, } \mathrm{Kg} \mathrm{ha}^{-1} ; \\
& \mathrm{W} \text { - volume de água aplicado, } \mathrm{m}^{3} \mathrm{ha}^{-1} \text {. }
\end{aligned}
$$




\section{RESULTADOS E DISCUSSÃO}

\subsection{Calibração da sonda de nêutrons e do TDR}

As calibrações dos equipamentos de sonda de nêutrons e TDR foram realizadas em uma área próxima (50 m) à parcela experimental, sendo possível a obtenção de uma única equação de calibração até a profundidade de 1,2 m, como observa-se nas Figuras 16 e 17. As calibrações do dois equipamentos apresentaram alta correlação, porém, aparentemente a sonda de nêutrons é mais precisa na estimativa de $\theta$, principalmente para maiores valores de umidade do solo.

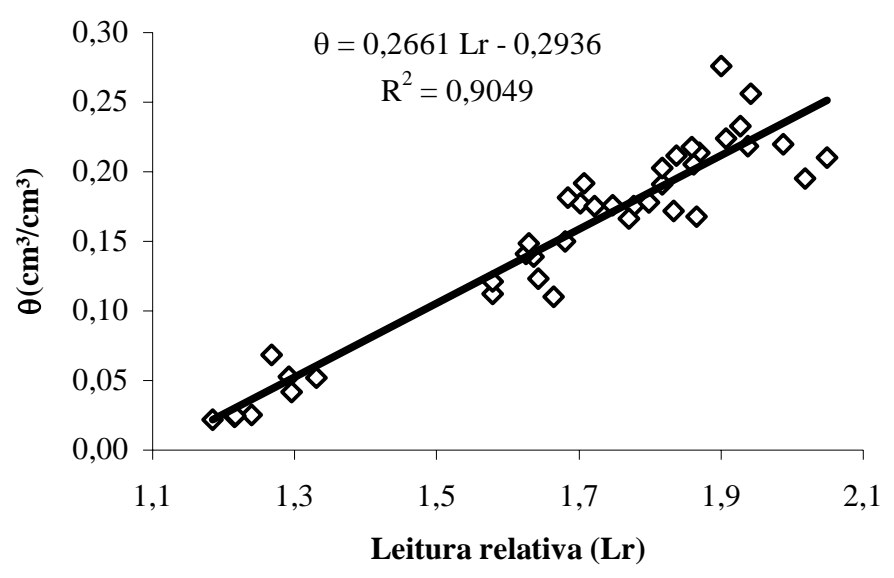

Figura 16 - Equação de calibração do TDR 


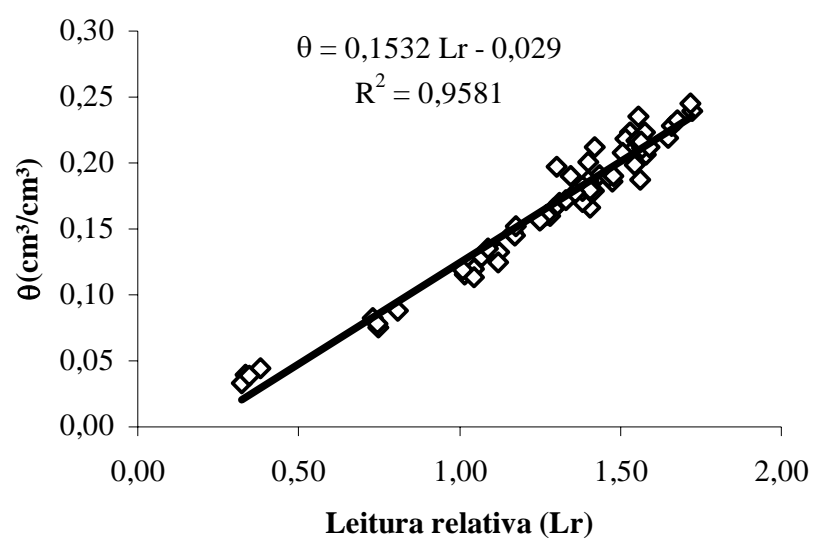

Figura 17 - Equação de calibração da sonda de nêutrons

\subsection{Características do solo}

A Tabela 3 apresenta as características químicas de amostras de solo coletadas após a colheita, nas trincheiras abertas para o estudo de raízes. Observa-se que o solo apresenta um baixo teor de matéria orgânica, que diminui com a profundidade; uma acidez média até $0,6 \mathrm{~m}$ de profundidade e elevada em maiores profundidades; valores de condutividade elétrica aumentando com a profundidade, mas sem indicar a condição de solo salino; teores de fósforo reduzindo em profundidade, sendo os mesmos considerados altos até $0,8 \mathrm{~m}$; altos teores de potássio em todas as camadas do solo, com um aumento em profundidade, provavelmente em função da lixiviação desse cátion; baixos e médios teores de cálcio e magnésio, respectivamente, que diminuíram com a profundidade; baixos teores de sódio; teores baixos de alumínio até 0,6 m e médios abaixo dessa profundidade; e média capacidade de troca de cátions e saturação de bases.

Na Tabela 4 encontram-se os parâmetros de ajuste da equação de van Genuchten (1980), obtidos do software Curvaret (Dourado Neto \& Van Lier). As curvas de retenção com melhor ajuste para cada profundidade de solo, constituem as Figuras 3 e 4, que correspondem as profundidades de 0,2, 0,4, $0,6 \mathrm{~m}$ e 0,8, 1,0,1,2 $\mathrm{m}$ respectivamente. 
Tabela 3. Características químicas da área experimental

\begin{tabular}{|c|c|c|c|c|c|c|c|c|c|c|c|c|}
\hline Prof. & M.O. & $\mathrm{pH}$ & C.E. & $P$ & $\mathrm{~K}$ & $\mathrm{Ca}$ & $\mathrm{Mg}$ & $\mathrm{Na}$ & $\overline{\mathrm{Al}}$ & $\mathrm{H}+\mathrm{Al}$ & CTC & V \\
\hline$m$ & $\mathrm{~g} / \mathrm{dm}^{3}$ & & $\mathrm{dS} / \mathrm{m}$ & $\mathrm{mg} / \mathrm{dm}^{3}$ & -- & & 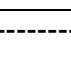 & $---\mathrm{cmo}$ & $/ \mathrm{dm}^{3}--$ & -י---י- & ------ & $\%$ \\
\hline $0,0-0,2$ & 11,0 & 5,3 & 0,16 & 64 & 0,28 & 1,4 & 1,1 & 0,02 & 0,20 & 2,97 & 5,77 & 49 \\
\hline $0,2-0,4$ & 9,6 & 4,9 & 0,21 & 60 & 0,33 & 1,3 & 1,1 & 0,02 & 0,25 & 2,97 & 5,72 & 48 \\
\hline $0,4-0,6$ & 5,8 & 5,0 & 0,28 & 43 & 0,74 & 1,1 & 1,2 & 0,03 & 0,25 & 2,47 & 5,54 & 55 \\
\hline $0,6-0,8$ & 5,6 & 4,4 & 1,25 & 33 & 1,16 & 0,7 & 1,0 & 0,03 & 0,60 & 2,64 & 5,53 & 52 \\
\hline $0,8-1,0$ & 3,2 & 4,0 & 2,23 & 6 & 1,24 & 0,6 & 0,9 & 0,13 & 0,90 & 2,64 & 5,51 & 52 \\
\hline $1,0-1,2$ & 2,7 & 3,9 & 2,34 & 1 & 1,12 & 0,7 & 0,9 & 0,15 & 1,15 & 2,97 & 5,84 & 49 \\
\hline
\end{tabular}

Tabela 4. Parâmetros de ajuste da curva de retenção de água no solo

\begin{tabular}{llllll}
\hline prof. $(\mathrm{cm})$ & $\alpha$ & $\mathrm{m}$ & $\mathrm{n}$ & $\theta_{\mathrm{r}}\left(\mathrm{cm}^{3} / \mathrm{cm}^{3}\right)$ & $\theta_{\mathrm{s}}\left(\mathrm{cm}^{3} / \mathrm{cm}^{3}\right)$ \\
\hline $0-20$ & 0,0023 & 0,6962 & 3,2911 & 0,045 & 0,126 \\
$20-40$ & 0,0049 & 0,5131 & 2,0538 & 0,055 & 0,157 \\
$40-60$ & 0,0029 & 0,6359 & 2,7462 & 0,061 & 0,164 \\
$60-80$ & 0,0048 & 0,5714 & 2,3333 & 0,066 & 0,166 \\
$80-100$ & 0,0045 & 0,5326 & 2,1397 & 0,078 & 0,181 \\
$100-120$ & 0,0044 & 0,5452 & 2,1989 & 0,075 & 0,192 \\
\hline
\end{tabular}

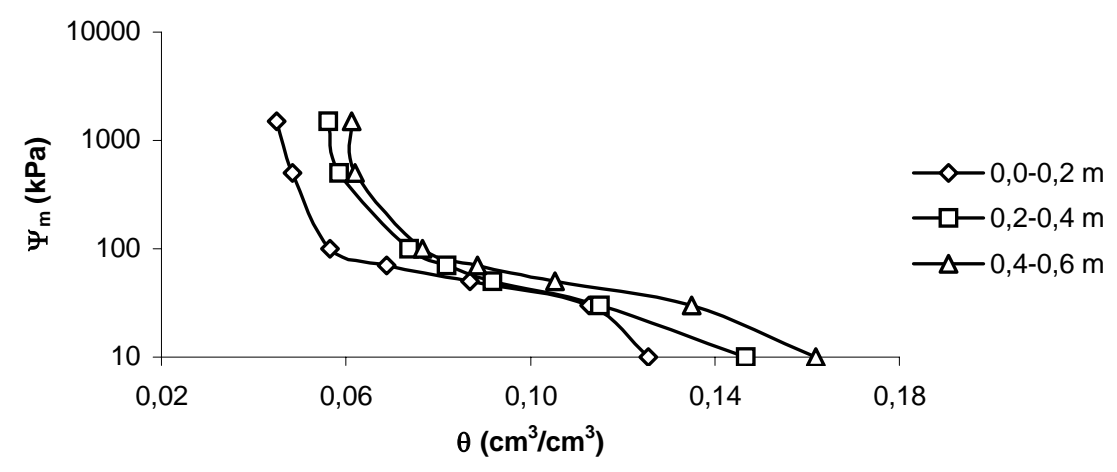

Figura 18 - Curvas de retenção de água no solo para as profundidades de 0,2 , 0,4 e $0,6 \mathrm{~m}$ 


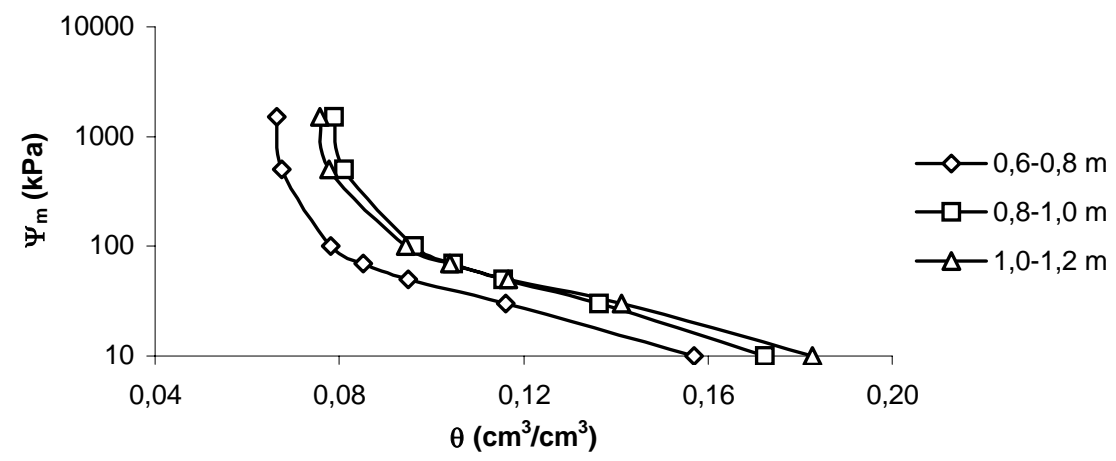

Figura 19 - Curva de retenção de água no solo para as profundidades de 0,8 , 1,0 e $1,2 \mathrm{~m}$

A Tabela 5 mostra os parâmetros das equações de condutividade hidráulica determinadas para quatro profundidades segundo Libardi et al (1995).

Tabela 5. Parâmetros da equação de condutividade hidráulica

\begin{tabular}{llll}
\hline Prof. $(\mathrm{cm})$ & Ko $(\mathrm{mm} /$ dia $)$ & $\gamma$ & $\theta_{0}\left(\mathrm{~cm}^{3} / \mathrm{cm}^{3}\right)$ \\
\hline 30 & 13,295 & 56,1204 & 0,245 \\
60 & 22,355 & 76,4584 & 0,232 \\
90 & 32,076 & 87,0266 & 0,230 \\
120 & 26,841 & 85,6256 & 0,243 \\
\hline
\end{tabular}

\subsection{Parâmetros climáticos}

Na Figura 20 observa-se as temperaturas média, máxima e mínima, coletadas na estação agrometeorológica do Campo Experimental de Bebedouro, durante os meses de junho a dezembro de 2001, correspondendo ao período de realização do experimento. 


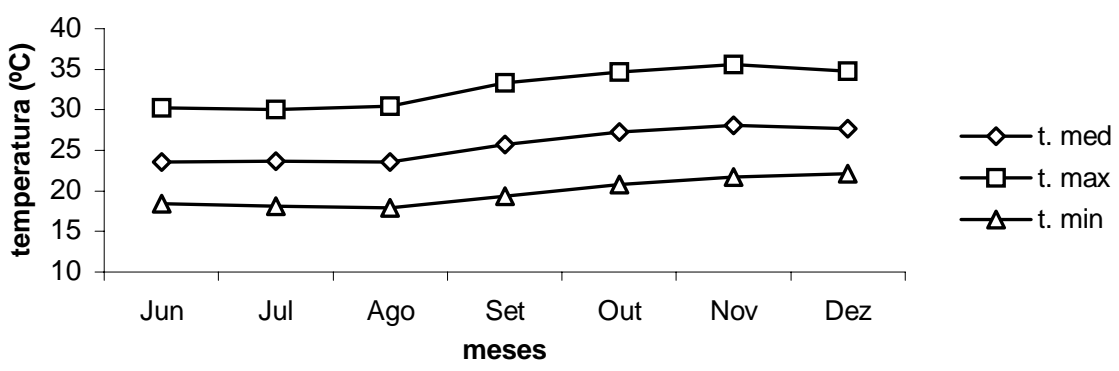

Figura 20 - Temperatura média, máxima e mínima da estação agrometeorológica do Campo Experimental de Bebedouro no período de junho a dezembro de 2001

Na Figura 21 estão os valores de precipitação, onde no mês de junho de 2001 apresentou 27,4 mm e no mês de outubro apenas 0,6 mm, com um total de $51 \mathrm{~mm}$ no período estudado.

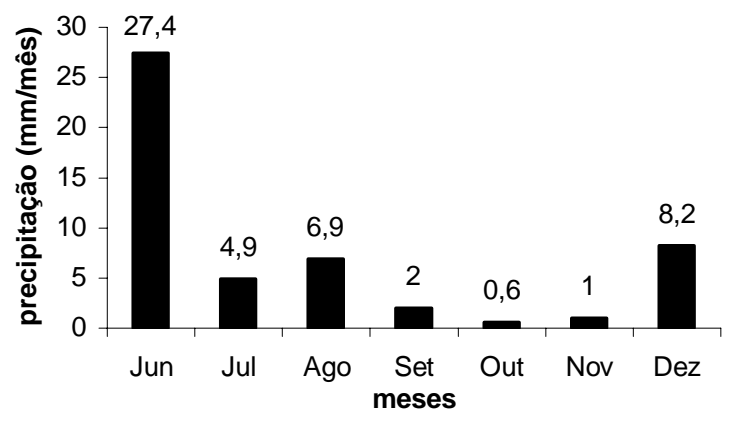

Figura 21 - Precipitação pluvial da estação agrometeorológica do Campo Experimental de Bebedouro no período de junho a dezembro de 2001 
Na Figura 22 pode-se observar os valores de evaporação do tanque classe A, havendo um incremento de 162 mm no mês de junho de 2001 para $261 \mathrm{~mm}$ no mês de novembro de 2001, apresentando um total de $1522 \mathrm{~mm}$ no período estudado.

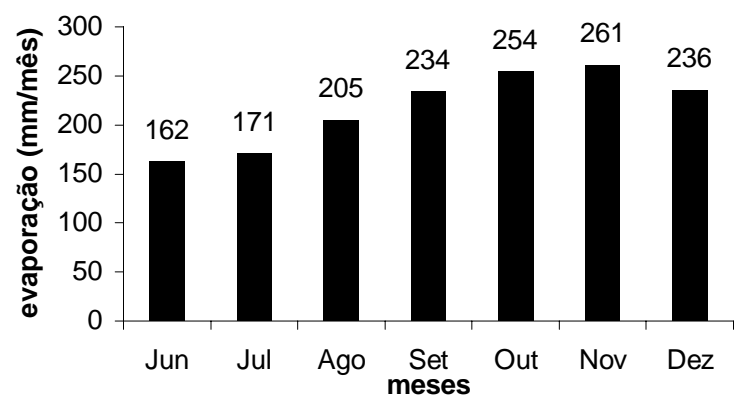

Figura 22 - Evaporação do tanque classe A da estação agrometeorológica do Campo Experimental de Bebedouro no período de junho a dezembro de 2001

Na Figura 23 observa-se os dados de umidade relativa, onde apresenta o maior valor no mês de junho, correspondendo a $69 \%$ e o menor valor no mês de outubro, correspondendo a 56\%, e na Figura 24 observa-se os valores de insolação, apresentando um total de 1709 horas no período estudado. As Figuras 25 e 26 apresentam os valores de radiação solar e velocidade do vento, onde os menores valores são, respectivamente, de $249 \mathrm{cal} / \mathrm{cm}^{2}$.dia e de 198,6 $\mathrm{Km} /$ dia no mês de junho. Estes parâmetros climáticos foram utilizados na determinação diária da evapotranspiração de referência (ETo) pelos métodos de Penman-Monteith e do tanque Classe A, durante o período estudado. 


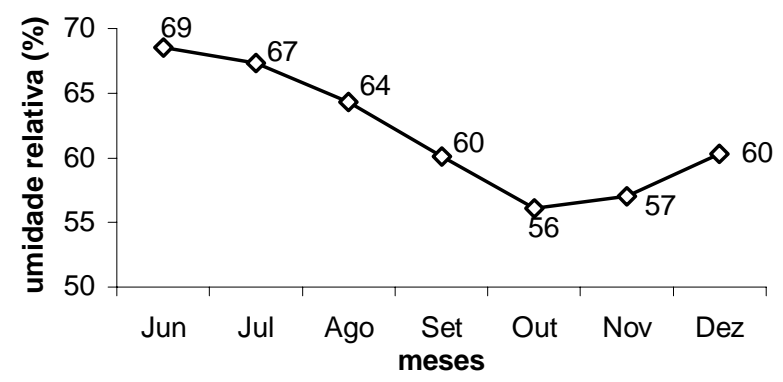

Figura 23 - Umidade relativa da estação agrometeorológica do Campo Experimental de Bebedouro no período de junho a dezembro de 2001

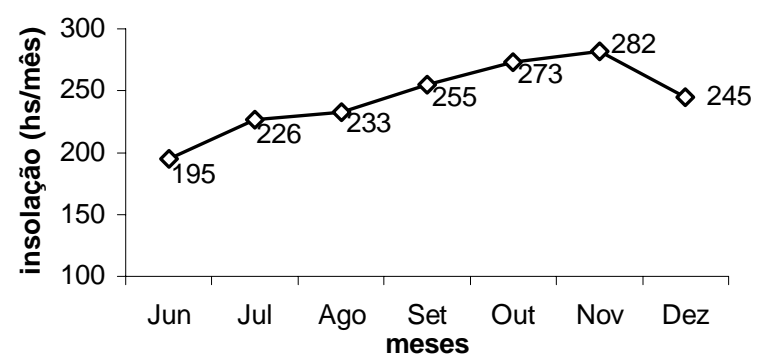

Figura 24 - Insolação da estação agrometeorológica de Bebedouro no período de junho a dezembro de 2001

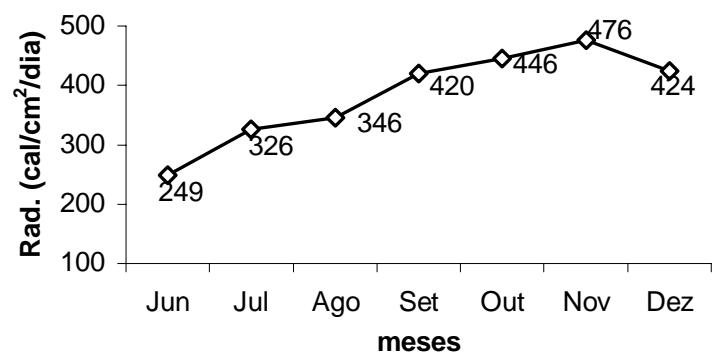

Figura 25 - Radiação solar da estação agrometeorológica de Bebedouro no período de junho a dezembro de 2001 


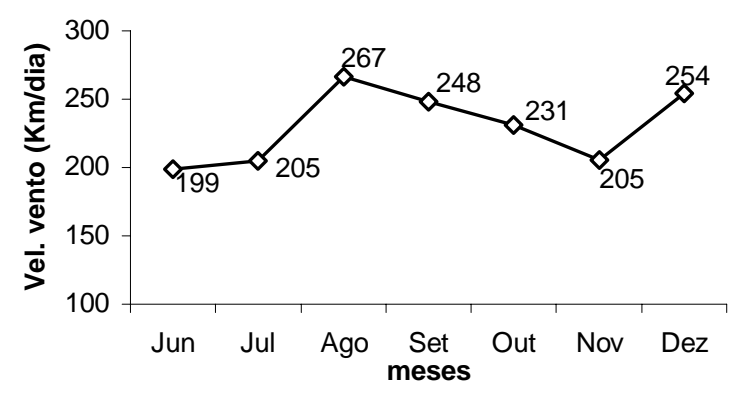

Figura 26 - Velocidade do vento a 2 m de altura da estação agrometeorológica do Campo Experimental de Bebedouro no período de junho a dezembro de 2001

\subsection{Distribuição do sistema radicular}

Nas Figuras 27 e 28 observa-se, respectivamente, os perfis a 0,2 e 2,0 $\mathrm{m}$ de distância da planta, com as raízes pintadas com tinta látex branca, para aumentar o contraste das mesmas com o solo.

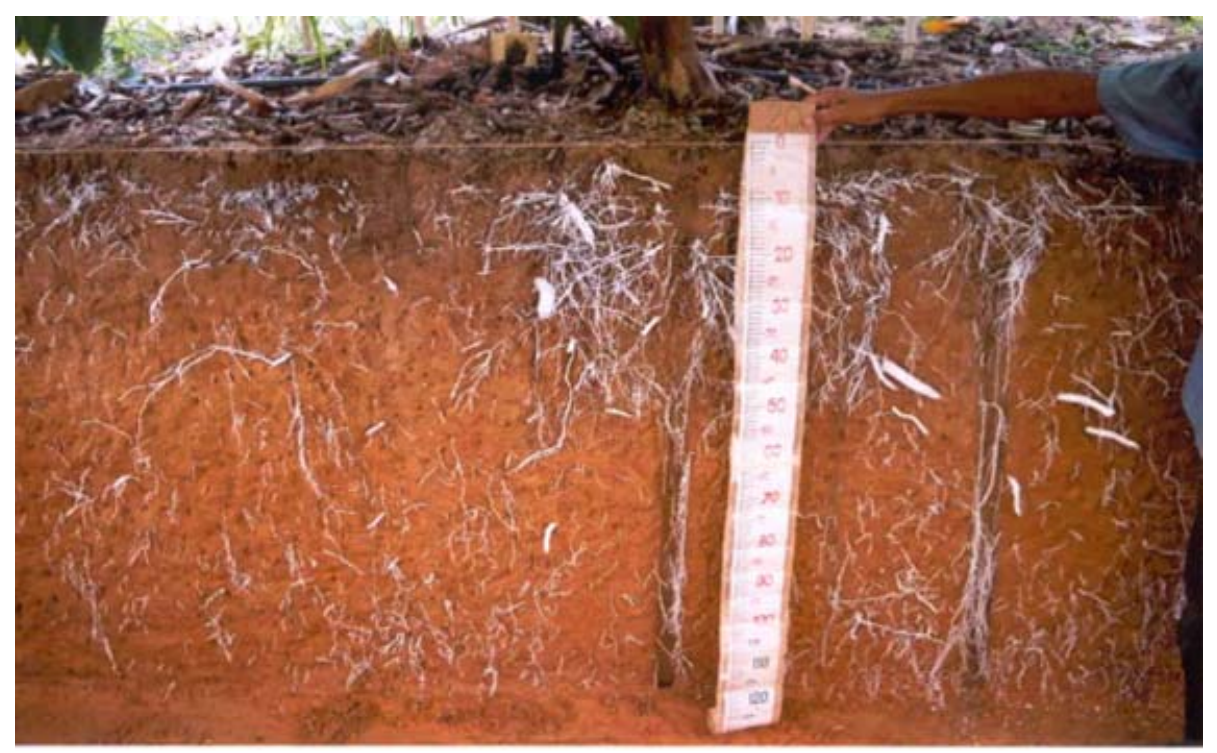

Figura 27 - Perfil de solo a 0,2 m de distância do tronco da planta 


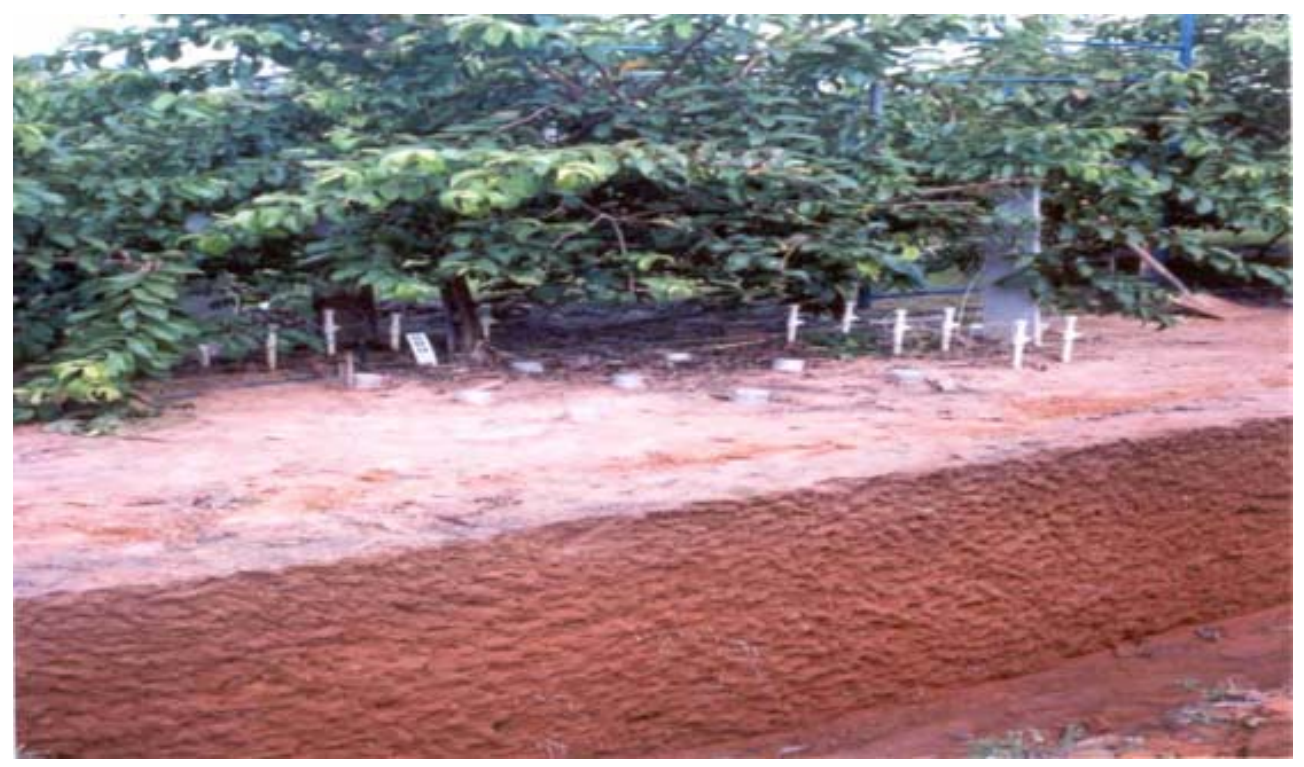

Figura 28 - Perfil de solo a 2,0 m distante do tronco da planta

Nas Figuras 29 a 40 observa-se a distribuição radicular em todas as distâncias estudadas da planta, respectivamente 0,$2 ; 0,4 ; 0,6 ; 0,8 ; 1,0 ; 1,2 ; 1,4$; 1,6; 1,8; 2,0; 2,2 e 2,4 $\mathrm{m}$ do tronco. O perfil a 0,2 m (Figura 29) distante do tronco apresenta uma maior quantidade de raízes, devido à proximidade do tronco, bem como a aplicação de matéria orgânica (esterco curtido) e fertilizantes. A medida que aumenta da distância do tronco, verifica-se uma redução gradual da quantidade de raízes (comprimento), porém em todos os perfis as raízes atingiram a profundidade de 1,2 m, apesar da redução do $\mathrm{pH}$, da matéria orgânica, do fósforo, cálcio e magnésio, e do aumento da condutividade elétrica e dos teores de sódio e alumínio com a profundidade do solo (Tabela 3). Apesar do microaspersor utilizado no experimento ter apresentado um raio de molhamento de 2,0 m, pôde-se observar no perfil com 2,4 m distante do tronco (Figura 40) a presença de raízes, principalmente a partir de 0,4 m de profundidade. Baseado nos atributos do solo e nas características do sistema de irrigação utilizado, pode-se considerar o sistema radicular da goiabeira tolerante à certas condições químicas do solo adversas ao seu desenvolvimento. 


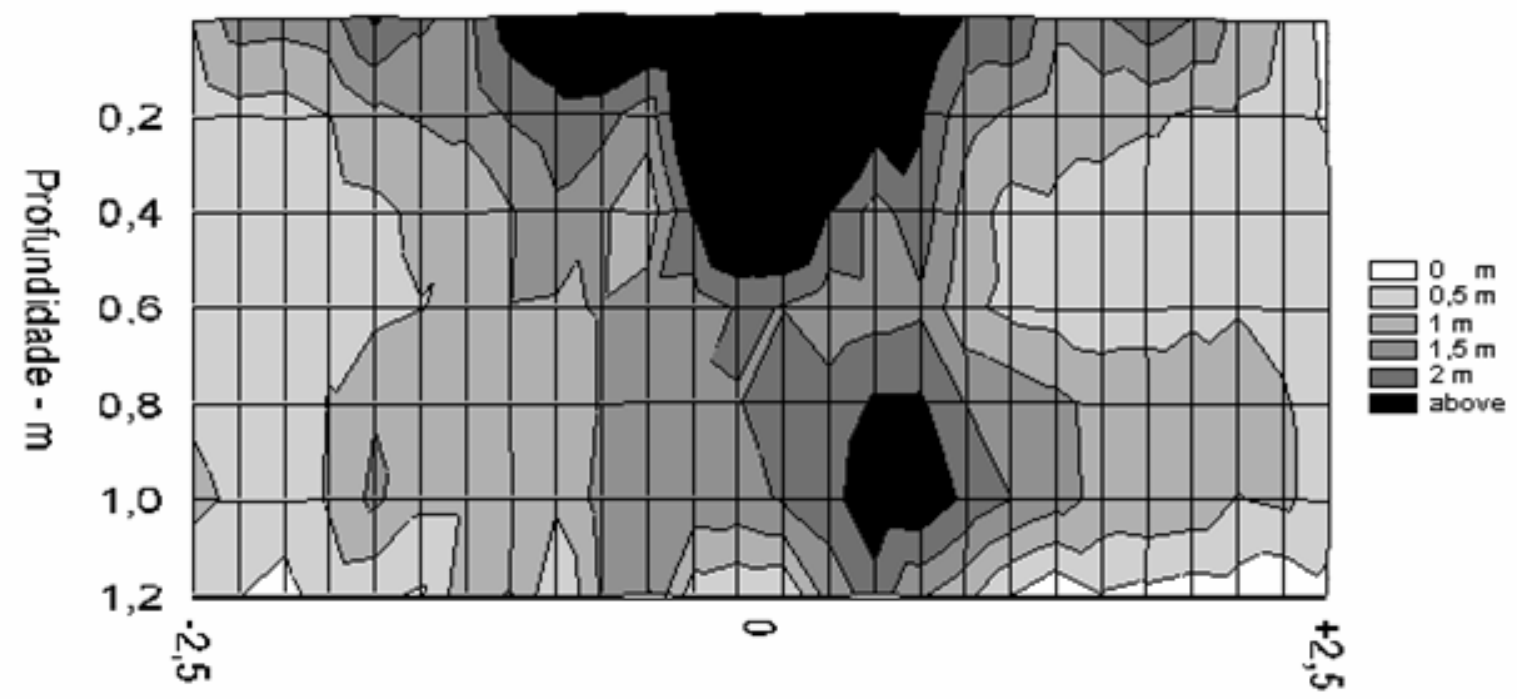

Distânçia do tronco - m

Figura 29 - Isolinhas de comprimento de raízes no perfil de solo distante $0,2 \mathrm{~m}$ do tronco da goiabeira

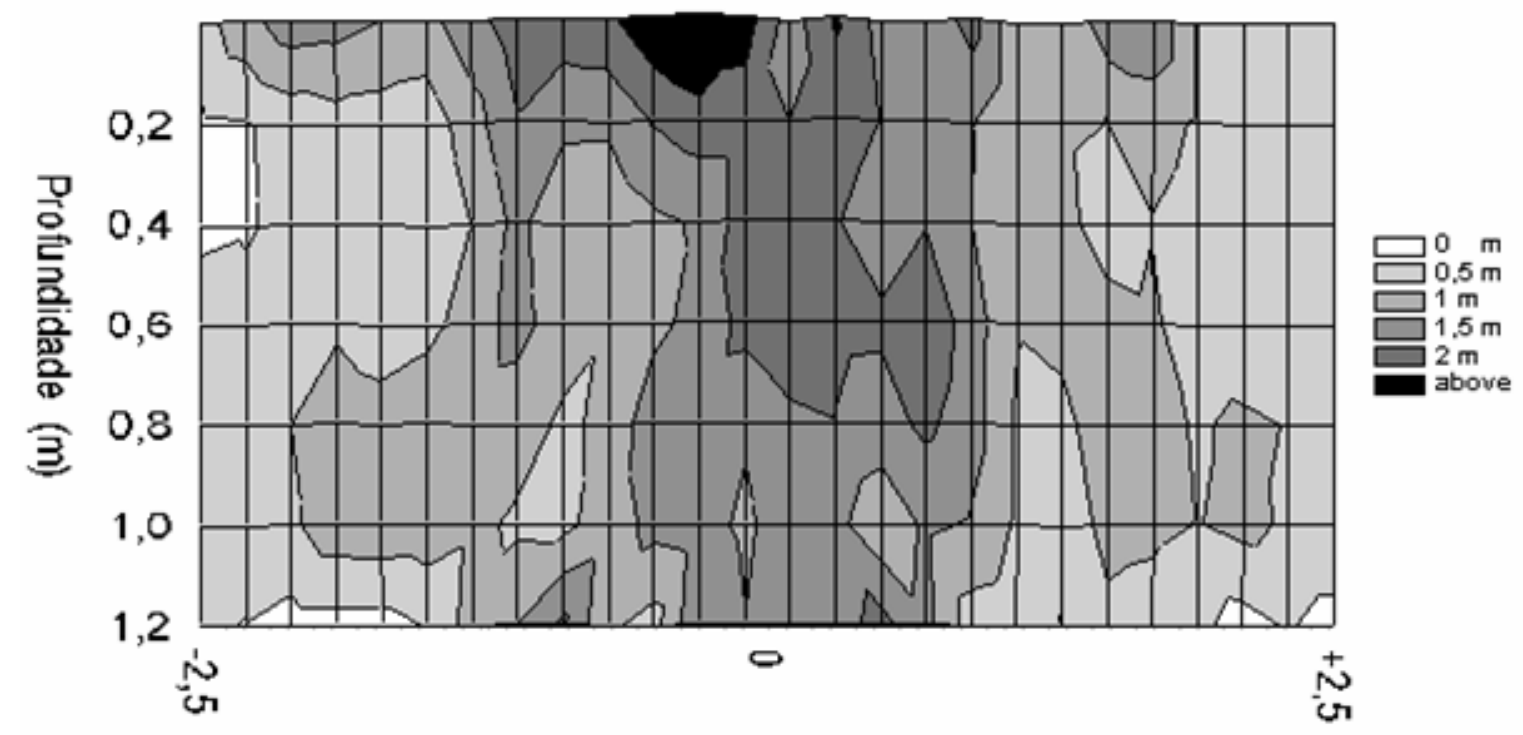

Diståncia do tronco (m)

Figura 30 - Isolinhas de comprimento de raízes no perfil de solo distante $0,4 \mathrm{~m}$ do tronco da goiabeira 


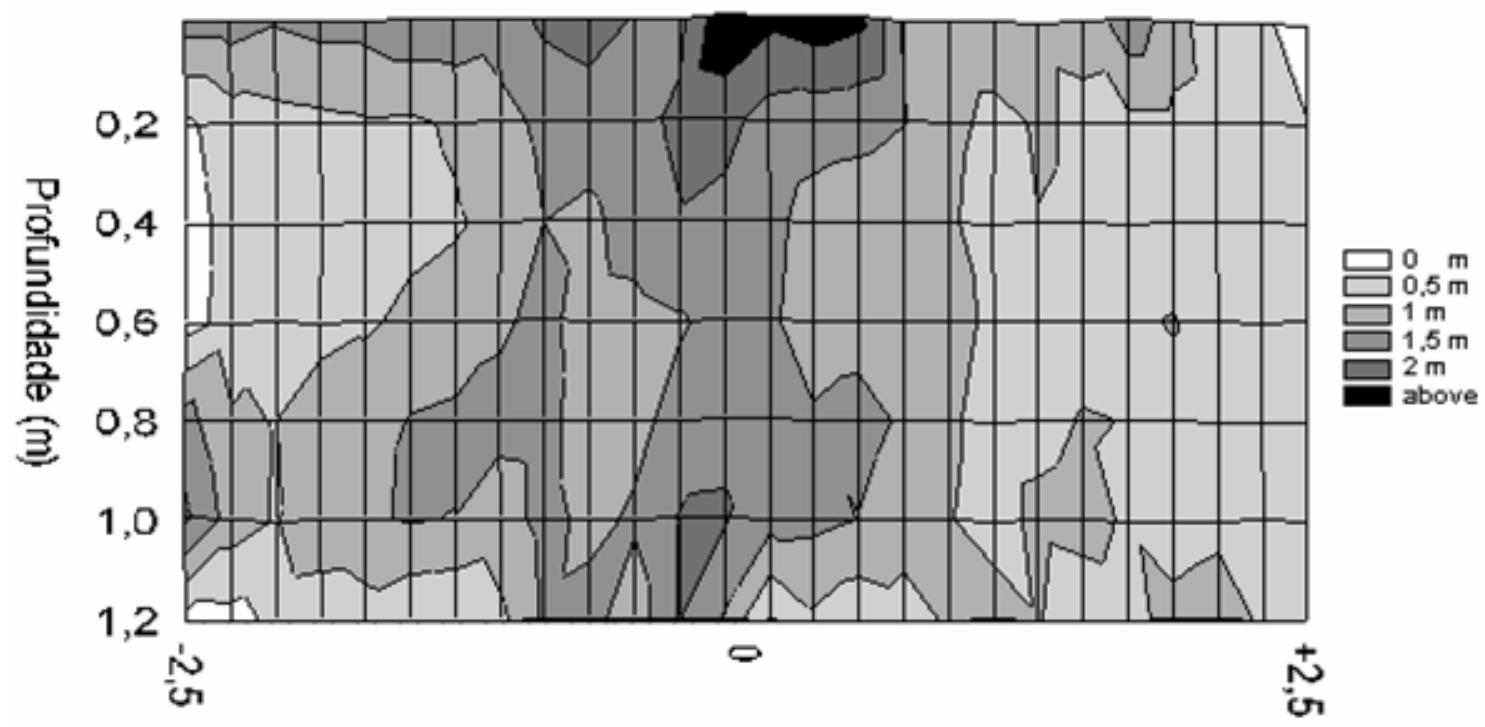

Diståncia do tronco (m)

Figura 31 - Isolinhas de comprimento de raízes no perfil de solo distante 0,6 m do tronco da goiabeira

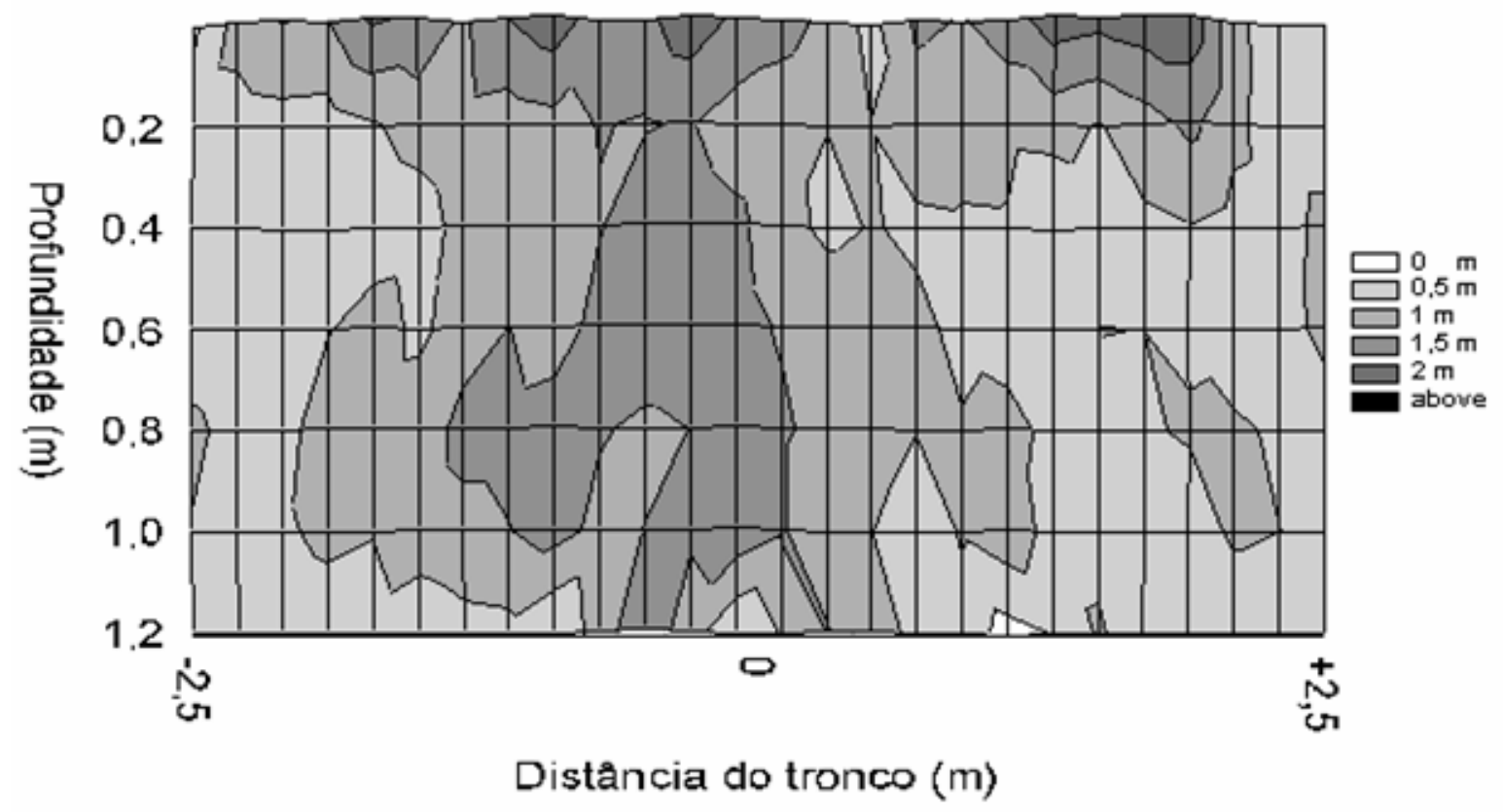

Figura 32 - Isolinhas de comprimento de raízes no perfil de solo distante 0,8 m do tronco da goiabeira 


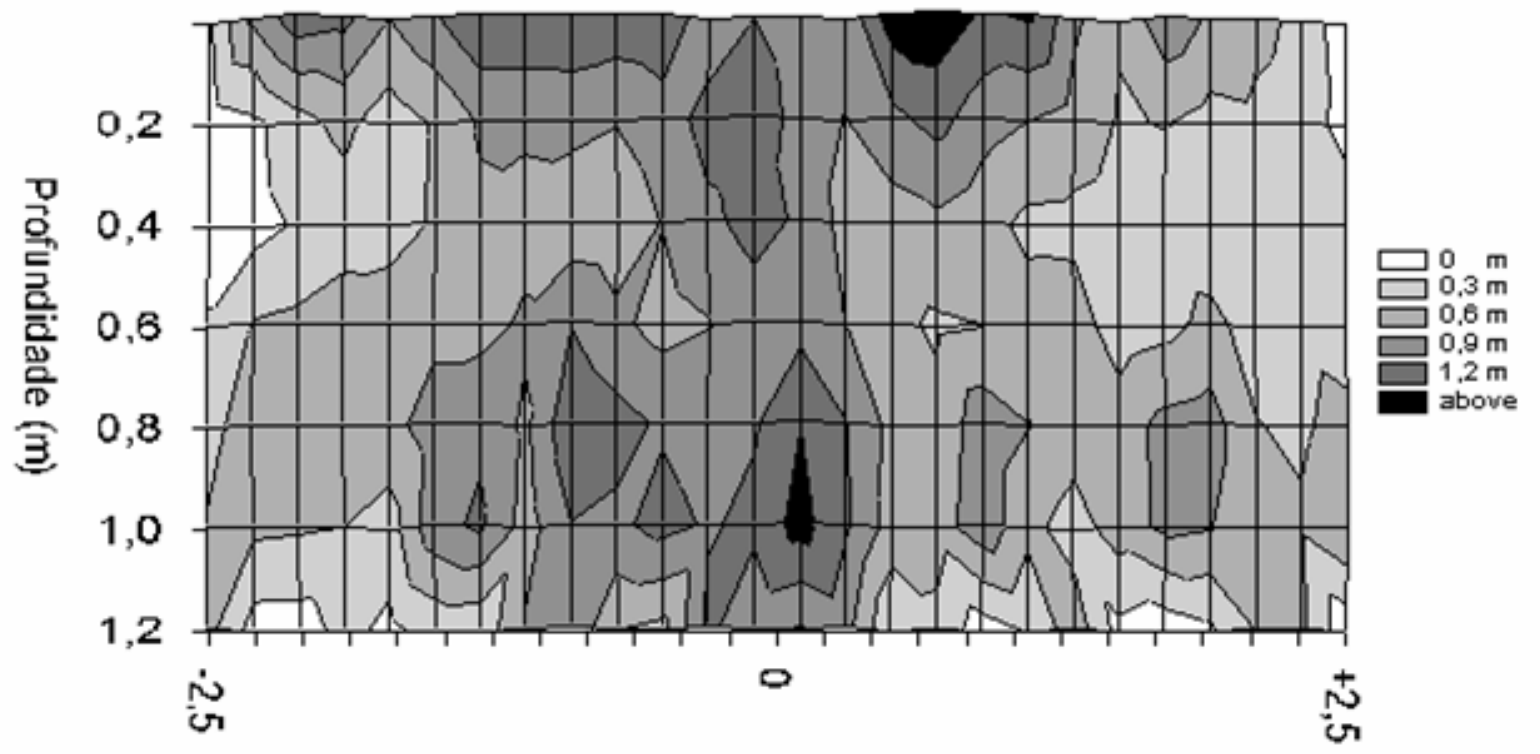

Distância do tronco (m)

Figura 33 - Isolinhas de comprimento de raízes no perfil de solo distante 1,0 m do tronco da goiabeira

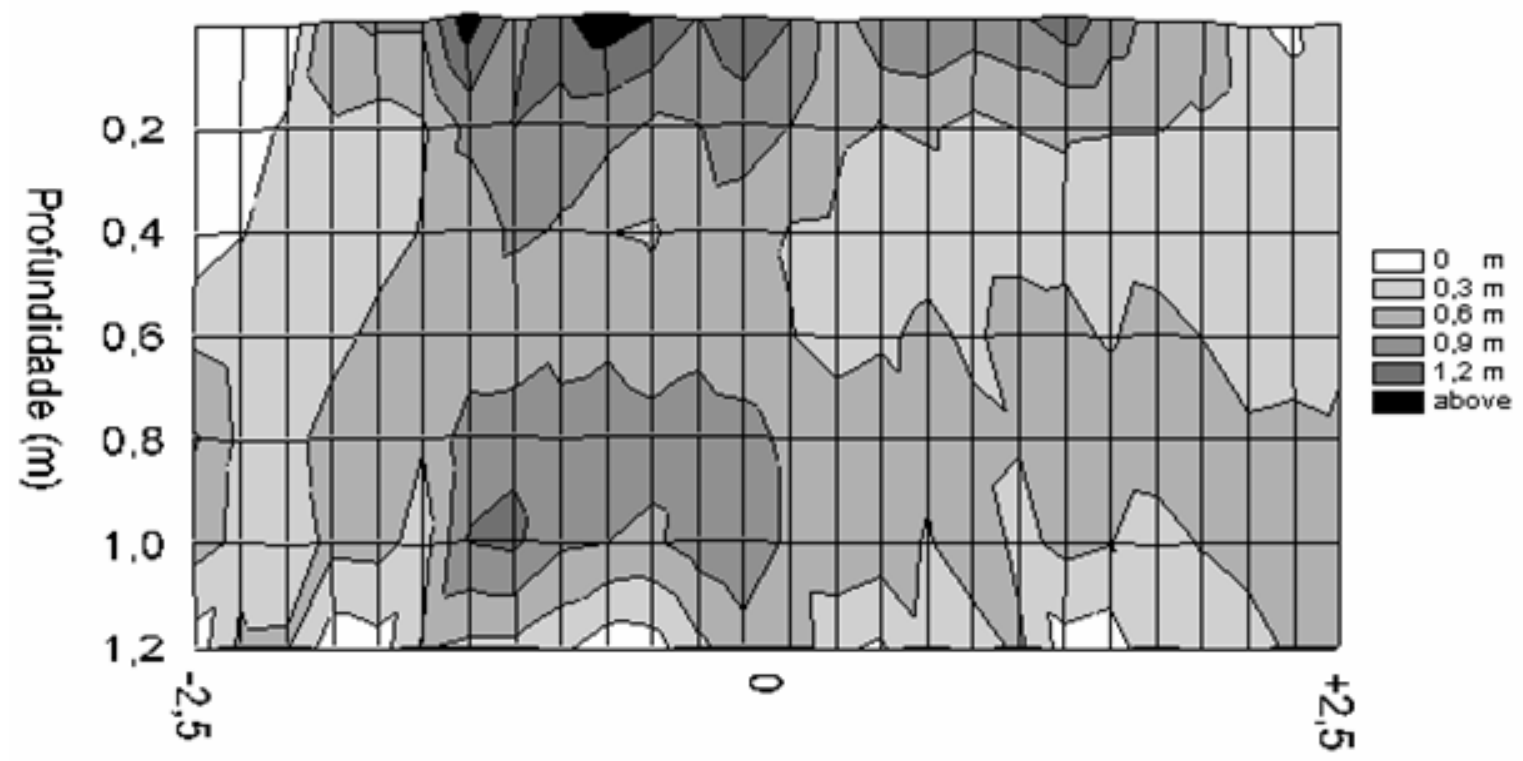

Distância do tronco (m)

Figura 34 - Isolinhas de comprimento de raízes no perfil de solo distante 1,2 m do tronco da goiabeira 


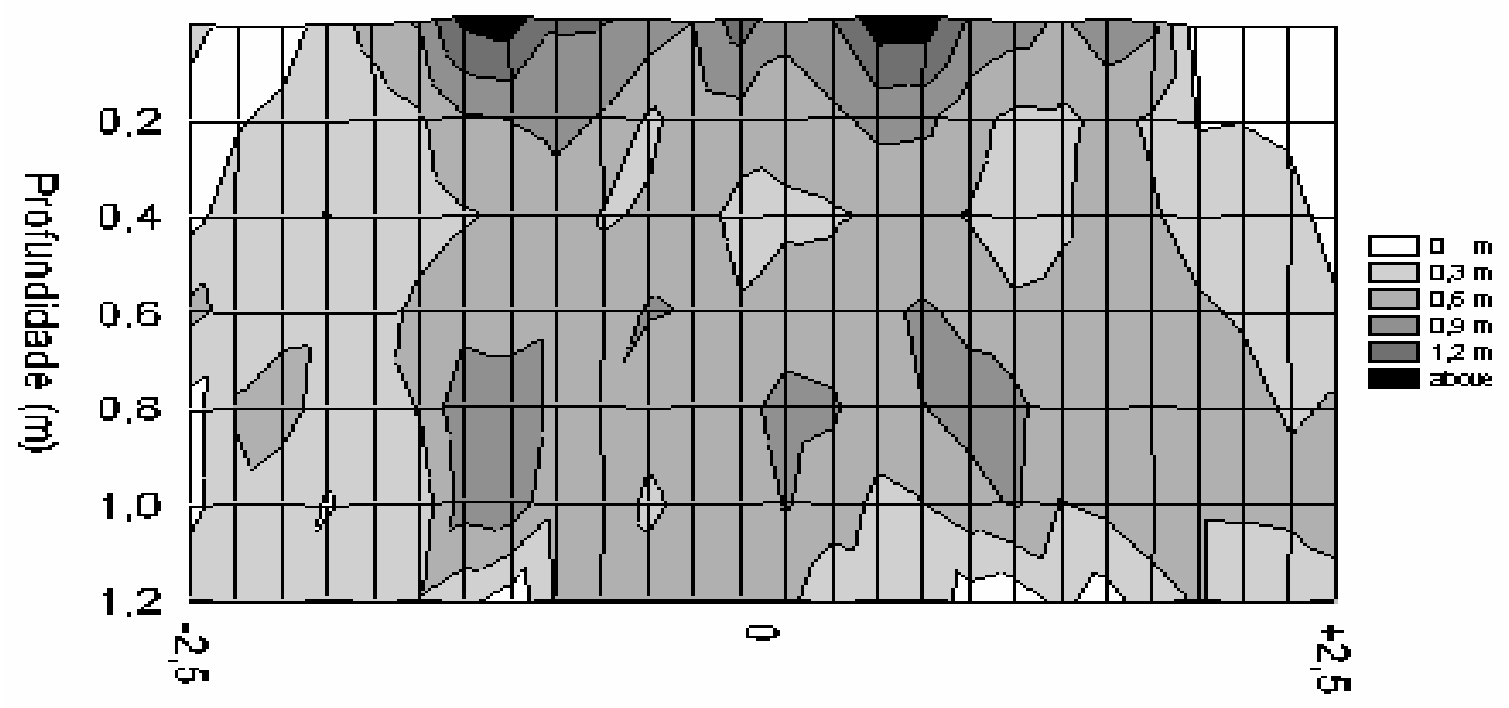

Distancia do tronco(m)

Figura 35 - Isolinhas de comprimento de raízes no perfil de solo distante 1,4 m do tronco da goiabeira

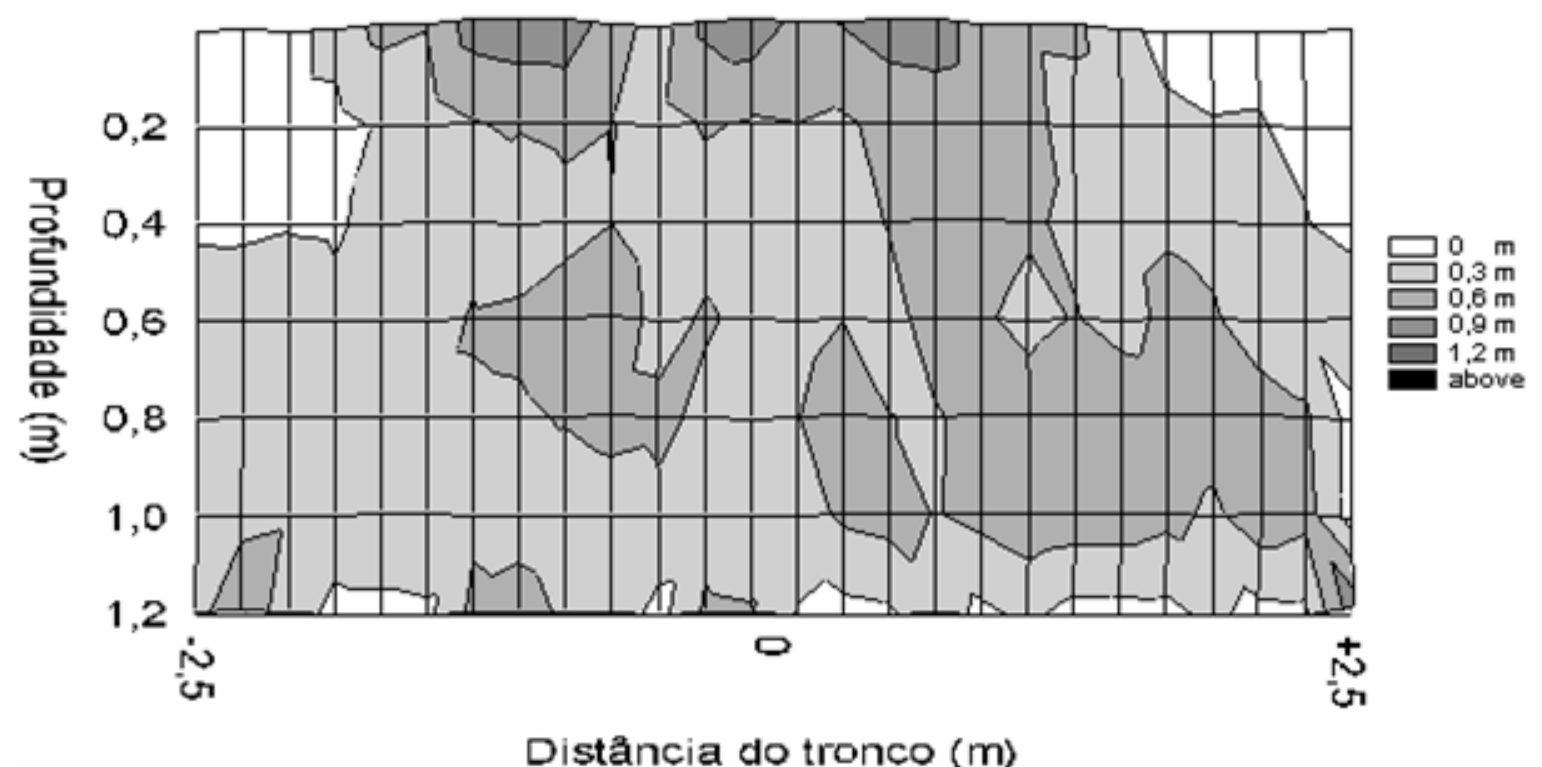

Figura 36 - Isolinhas de comprimento de raízes no perfil de solo distante 1,6 m do tronco da goiabeira 


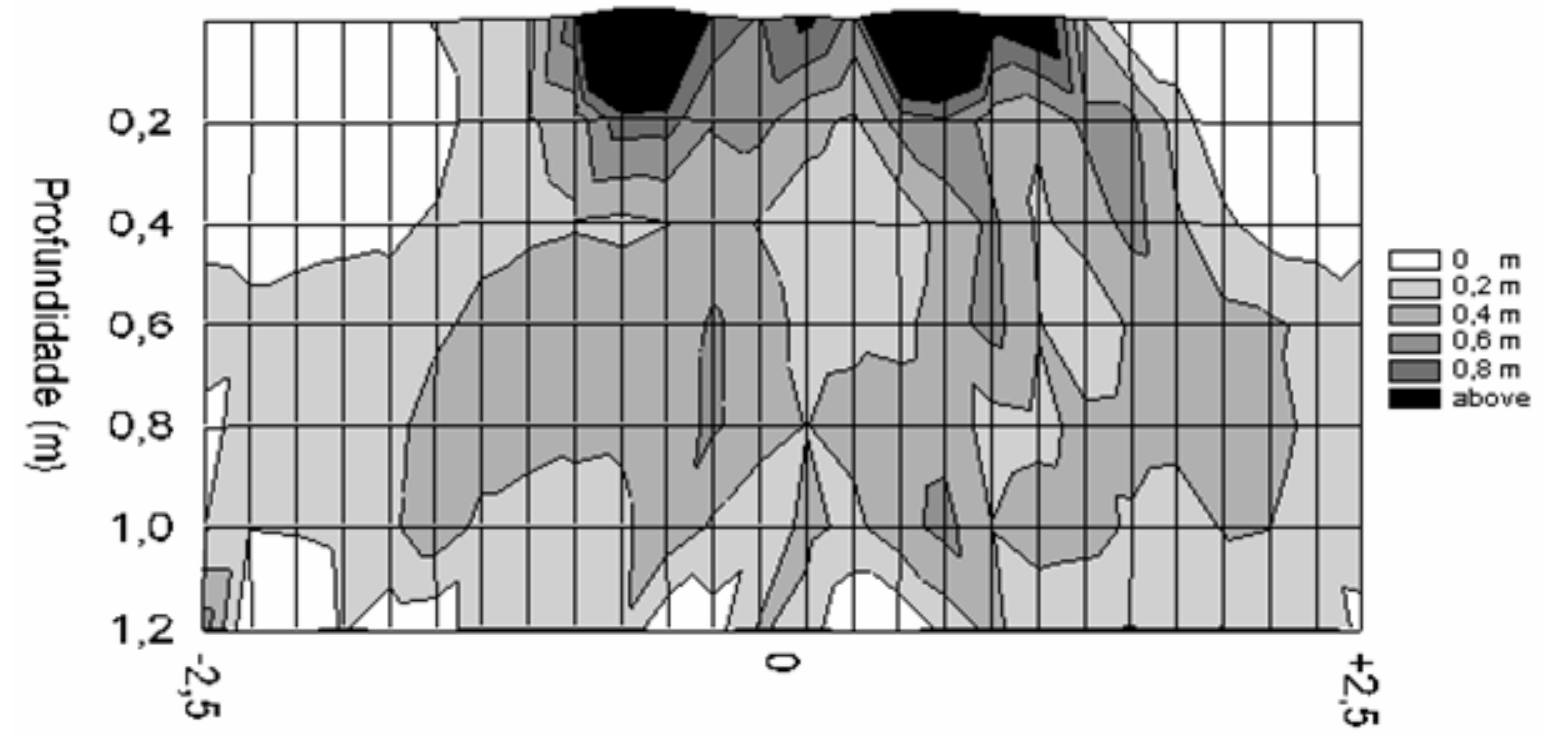

Distảncia do tronco $(\mathrm{m})$

Figura 37 - Isolinhas de comprimento de raízes no perfil de solo distante 1,8 m do tronco da goiabeira

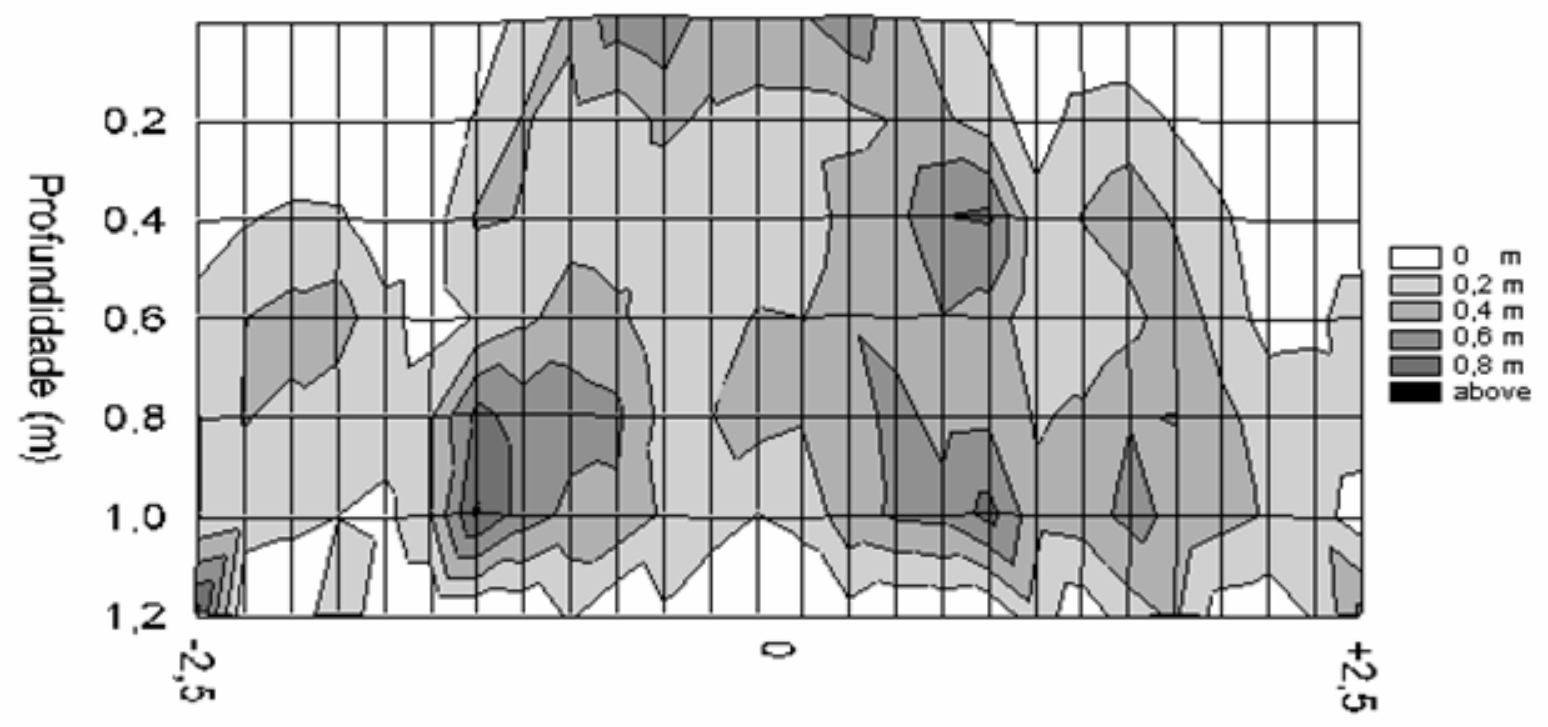

Distância do tronco (m)

Figura 38 - Isolinhas de comprimento de raízes no perfil de solo distante 2,0 m do tronco da goiabeira 


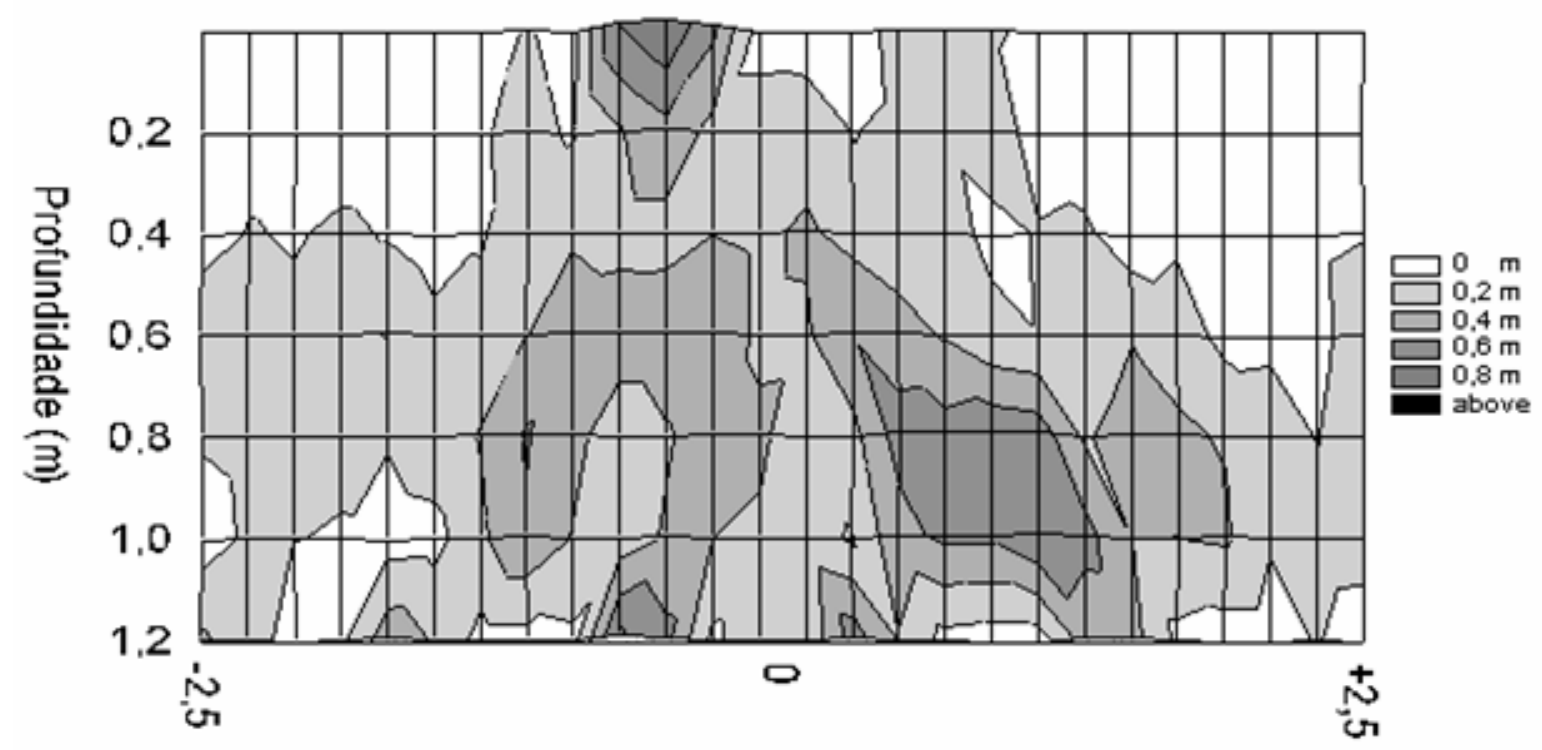

Diståncia da planta (m)

Figura 39 - Isolinhas de comprimento de raízes no perfil de solo distante 2,2 m do tronco da goiabeira

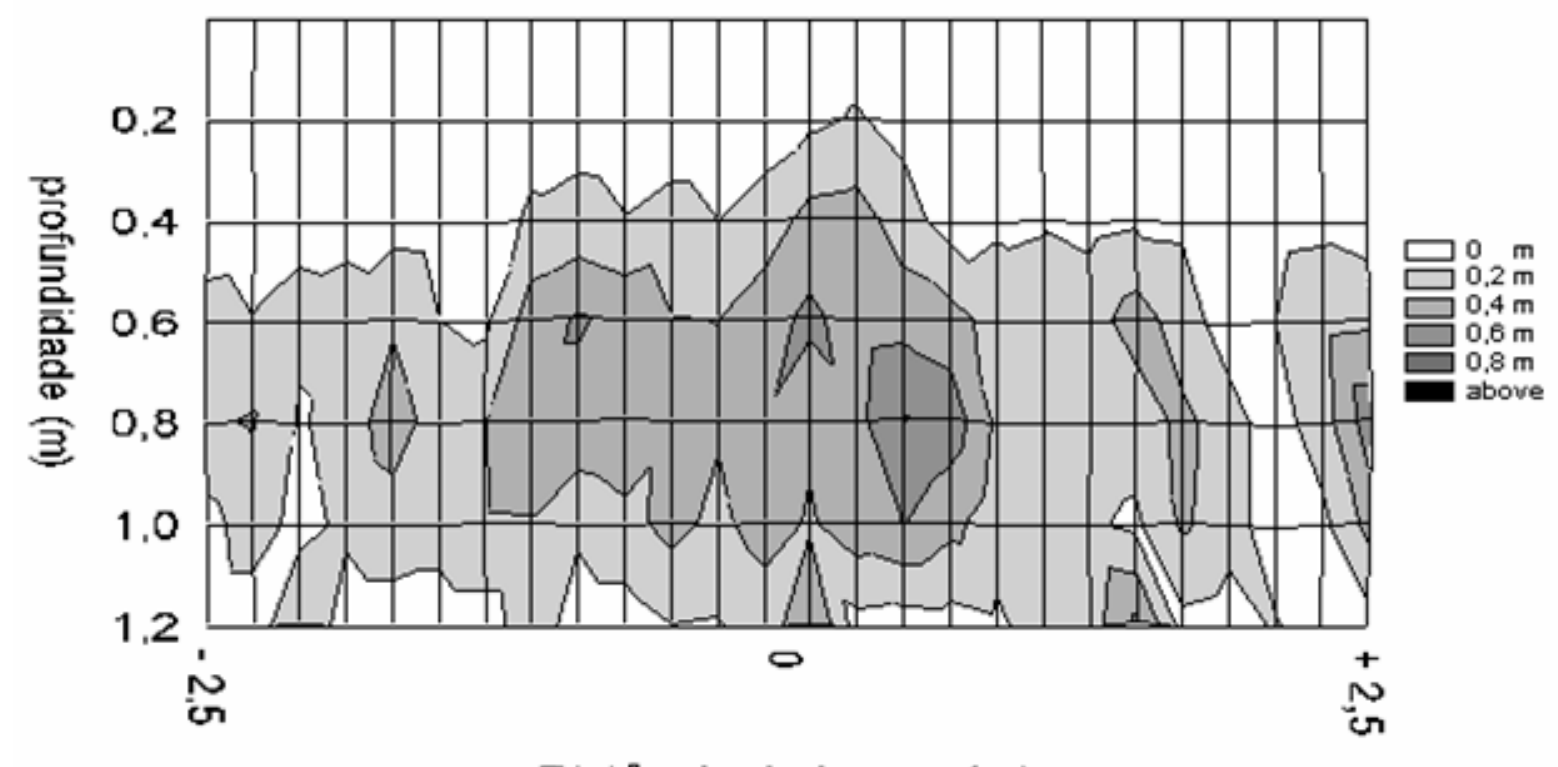

Figura 40 - Isolinhas de comprimento de raízes no perfil de solo distante 2,4 m do tronco da goiabeira 
Na Figura 41 observa-se o perfil de raízes perpendicular a linha de plantas obtido a partir do somatório do comprimento de raízes presentes nos perfis mostrados anteriormente. Por este perfil, observa-se uma maior quantidade de raízes até $0,6 \mathrm{~m}$ distante do tronco e até $0,6 \mathrm{~m}$ de profundidade, mostrando que esse volume de solo seria o mais recomendado para o monitoramento da água no solo e para a aplicação de fertilizantes e matéria orgânica.

$\mathrm{Na}$ Figura 42 observa-se a distribuição percentual média do sistema radicular em função da profundidade do solo, de todos os perfis estudados, onde pode-se constatar que $23,2 \%$ das raízes estão presentes na primeira camada (0-0,2 m). Na segunda camada (0,2-0,4 m) observa-se uma redução de raízes. Devido ao uso intensivo de máquinas e implementos nessa área durante vários anos, uma compactação pode ter ocorrido nessa camada de solo, o que provavelmente contribuiu para essa redução. A partir de 0,6 m observa-se um aumento gradual de raízes até 1,0 m de profundidade e uma redução a 1,2 m de profundidade. Por esta Figura, observa-se ainda que $80 \%$ das raízes das goiabeiras estudadas estão presentes até $0,94 \mathrm{~m}$ de profundidade, parâmetro de grande importância para instalação de drenagem subterrânea e cálculo das lâminas de irrigação.

$\mathrm{Na}$ Figura 43 observa-se a distribuição percentual do sistema radicular em função da distância do tronco, onde 19,5\% das raízes estão distantes 0,2 m do tronco, havendo uma redução gradual de raízes até a distância de 2,4 m, com apenas $1,9 \%$ de raízes. A distância efetiva, correspondendo a $80 \%$ das raízes, foi observada a 1,27 m distante do tronco da planta.

Estudos conduzidos na Índia (Purohit \& Mukheijee, 1974; Ghosh, 1974; Kotur et al, 1998) em pomares não irrigados com 12 a 15 anos de plantio mostraram que o sistema radicular de goiabeiras cultivadas em solos arenoargilosos e silte-argilosos, atingiram de 0,6 a 0,75 m de profundidade, chegando até 2,4 m distante do tronco; porém em solos argilosos (54,6\% de argila) com baixa taxa de infiltração, $100 \%$ das raízes foram encontradas até $0,45 \mathrm{~m}$ de 
profundidade e 2,0 m distante do tronco da planta, mostrando a influência da textura e camadas adensadas no perfil de solo no desenvolvimento do sistema radicular.

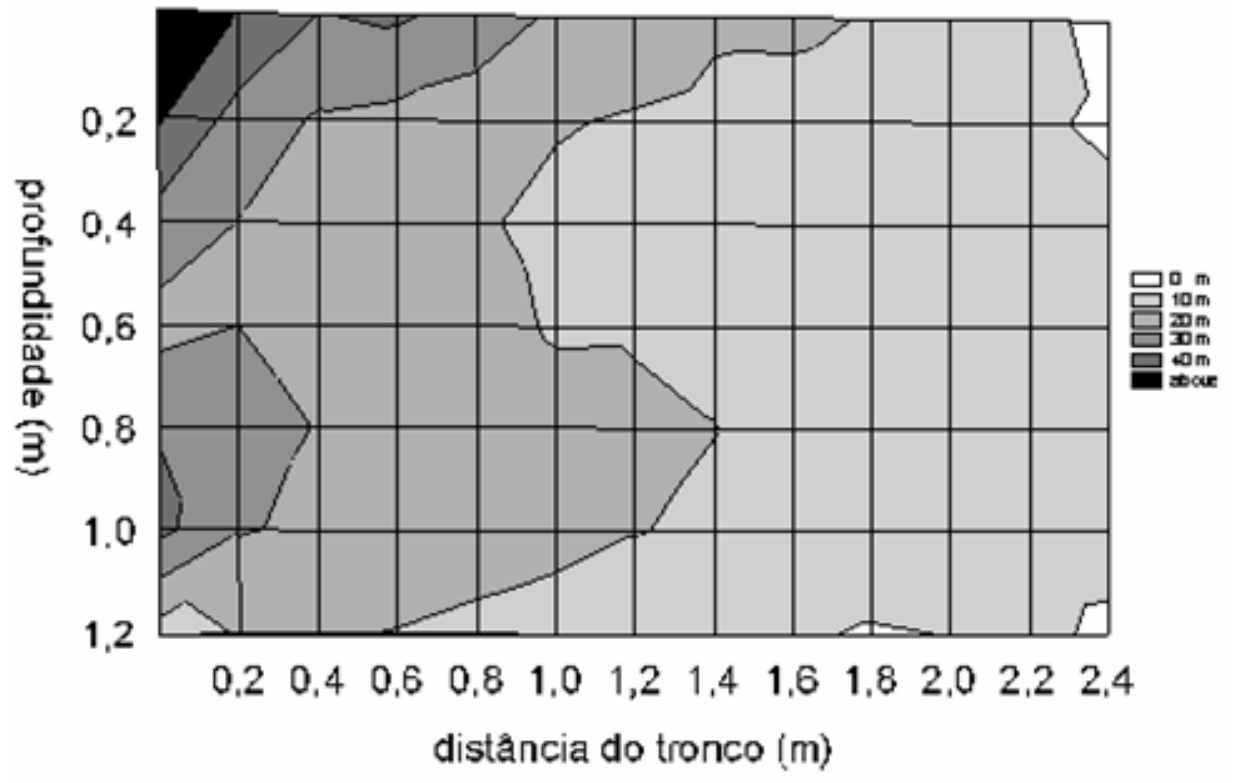

Figura 41 - Isolinhas do comprimento das raízes da goiabeira cv Paluma, na direção perpendicular à linha de plantas (distância do tronco)

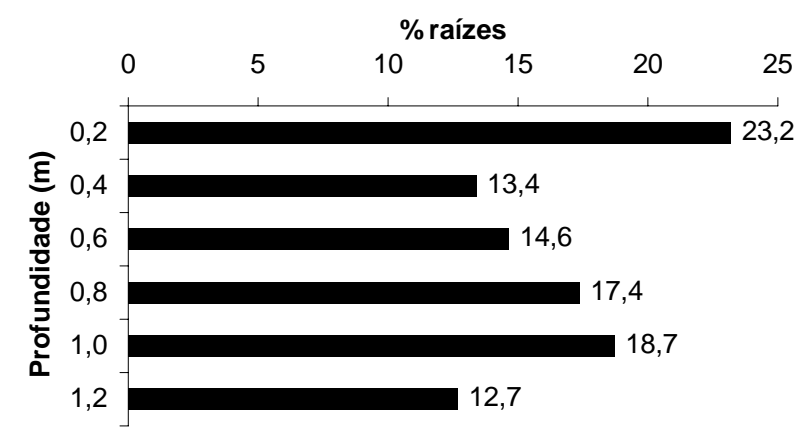

Figura 42 - Distribuição percentual do sistema radicular da goiabeira cv. Paluma em função da profundidade do solo 


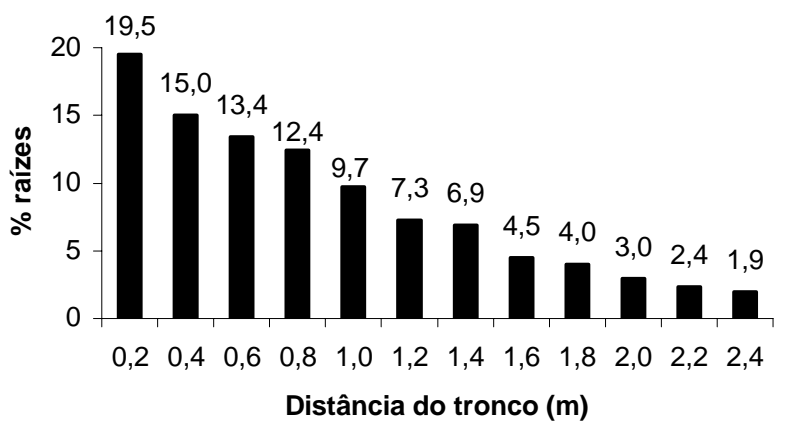

Figura 43 - Distribuição percentual do sistema radicular da goiabeira cv. Paluma em função da distância do tronco

$\mathrm{Na}$ Figura 44 observa-se a distribuição percentual do sistema radicular dos monolitos coletados a 0,6-0,4 m e a 0,4-0,2 m de distância do tronco em função da profundidade do solo. Observa-se uma maior presença de raízes na camada superficial (0-0,2 m), uma presença equilibrada entre 0,2 e 1,0 m de profundidade de solo, e uma redução na camada de solo mais profunda (1,0-1,2 m). Para o mesmo volume de solo, as Figuras 45 a 48 apresentam, respectivamente, a distribuição percentual das raízes em intervalos de diâmetro (d): $\mathrm{d} \leq 2 \mathrm{~mm}, 2<\mathrm{d} \leq 5 \mathrm{~mm}, 5<\mathrm{d} \leq 10 \mathrm{~mm}, \mathrm{~d} \geq 10 \mathrm{~mm}$. Nota-se a maior presença de raízes com diâmetro menor ou igual a $2 \mathrm{~mm}$, distribuída em todo o perfil de solo, e a medida que o diâmetro aumenta, torna-se menor a profundidade alcançada.

A distribuição percentual dos valores médios do comprimento de raízes presentes nos perfis de solo de 0,6 e 0,4 $\mathrm{m}$ e de 0,4 e 0,2 $\mathrm{m}$ distantes do tronco apresentaram uma razoável correlação com a distribuição percentual dos valores do comprimento de raízes presentes nos monolitos a 0,6-0,4 m e 0,40,2 m (Figura 49). Entretanto, ao considerarmos a distribuição acumulada em profundidade, a correlação apresentou-se maior (Figura 50). Resultados semelhantes foram obtidos para as culturas da videira, pupunha, aspargo e 
tamareira (Bassoi et al, 1999; Bassoi et al, 2000; Bassoi et al, 2003), quanto à maior correlação para os valores acumulados.

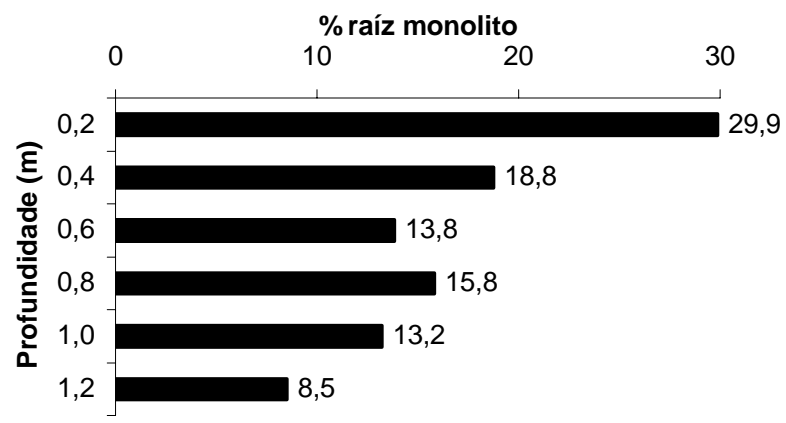

Figura 44 - Distribuição percentual das raízes da goiabeira cv. Paluma coletadas nos monolitos a 0,6-0,4 m e a 0,4-0,2 m de distância do tronco da planta

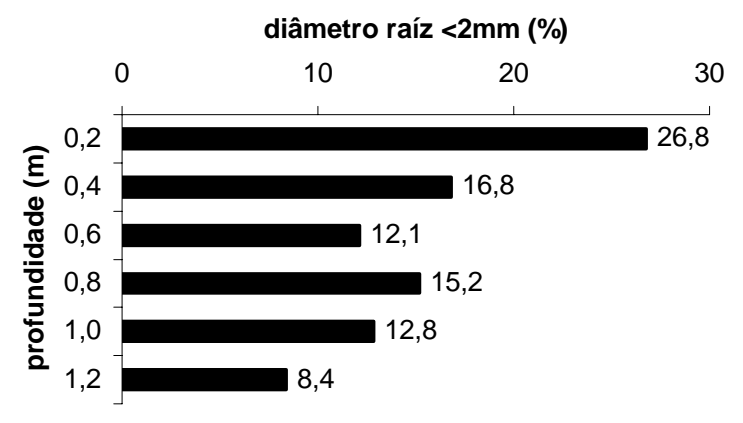

Figura 45 - Distribuição percentual das raízes da goiabeira cv. Paluma, com diâmetro menor ou igual a 2 mm, coletadas nos monolitos a 0,6-0,4 m e a 0,4-0,2 m de distância do tronco da planta 


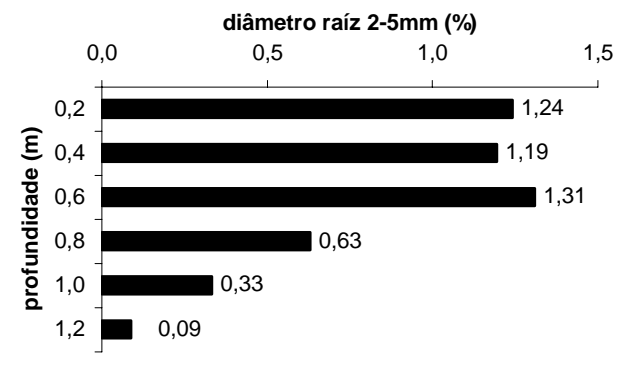

Figura 46 - Distribuição percentual das raízes de goiabeira cv. Paluma, com diâmetro maior que $2 \mathrm{~mm}$ e menor ou igual a $5 \mathrm{~mm}$, coletadas nos monolitos a 0,6-0,4 m e a 0,4-0,2 m de distância do tronco da planta

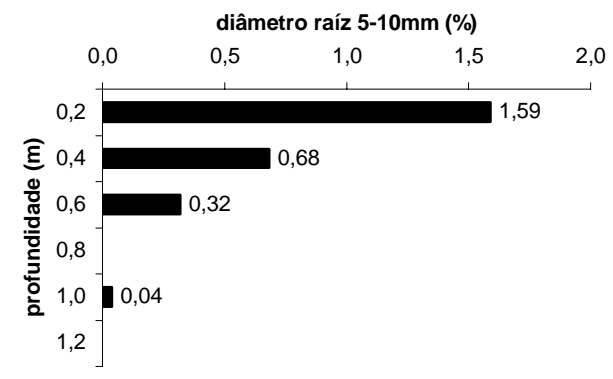

Figura 47 - Distribuição percentual das raízes da goiabeira cv. Paluma, com diâmetro maior que $5 \mathrm{~mm}$ e menor ou igual a $10 \mathrm{~mm}$, coletadas nos monolitos a 0,6-0,4 m e a 0,4-0,2 m de distância do tronco da planta

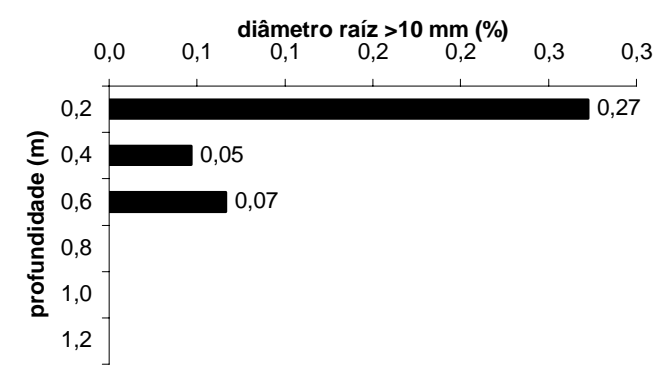

Figura 48 - Distribuição percentual das raízes da goiabeira cv. Paluma, com diâmtero maior que $10 \mathrm{~mm}$, coletadas nos monolitos a 0,6-0,4 m e a 0,4-0,2 m de distância do tronco da planta 


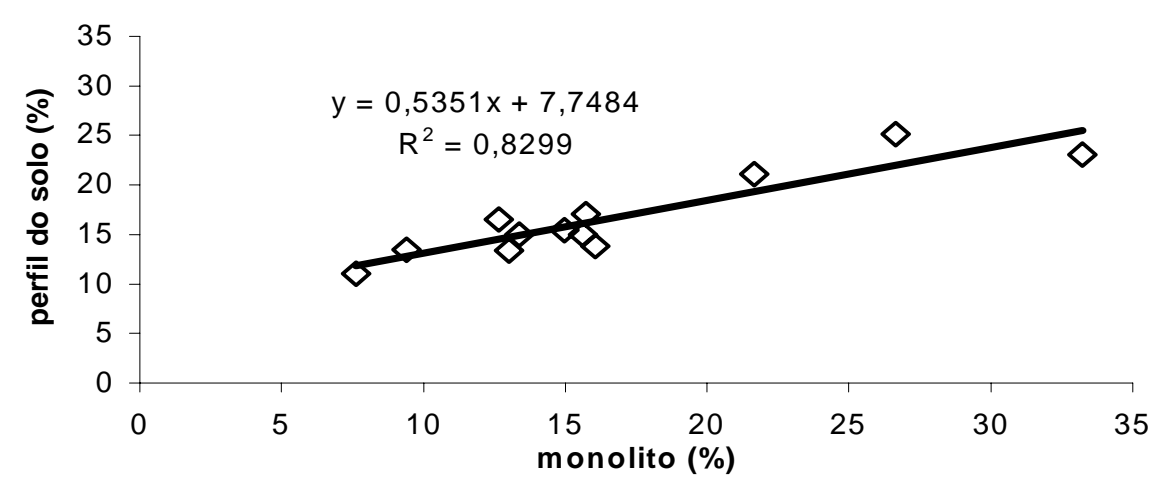

Figura 49 - Correlação da distribuição percentual de raízes da goiabeira cv. Paluma coletadas nos monolitos e medidas nos perfis de solo a 0,6-0,4 m e 0,4-0,2 m de distância do tronco da planta

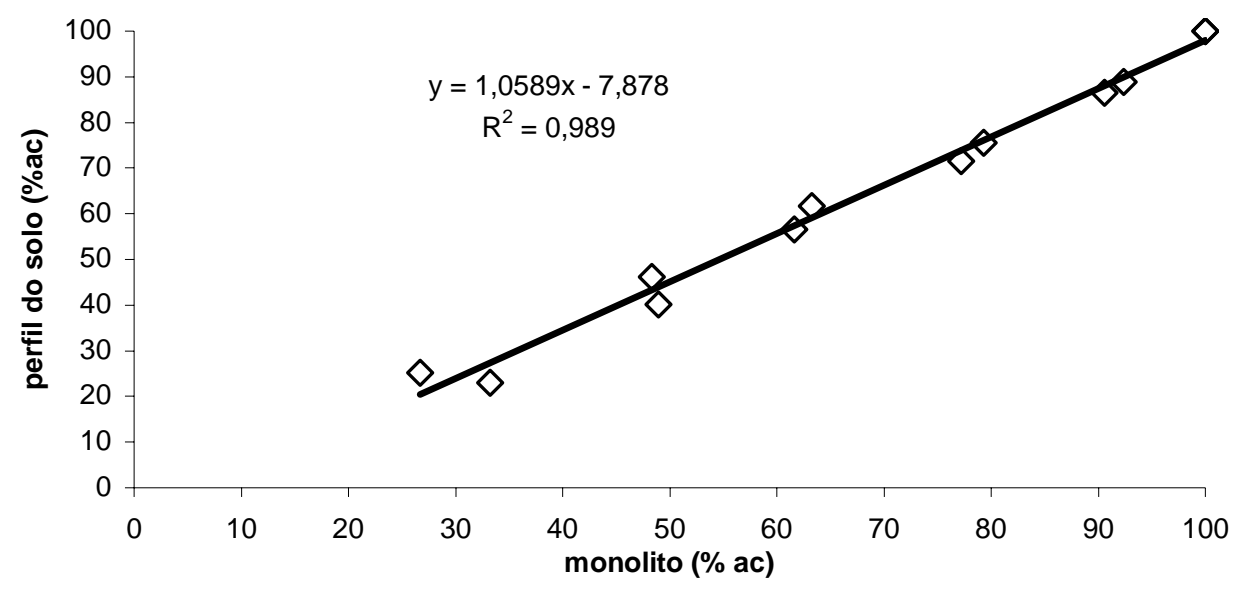

Figura 50 - Correlação da distribuição percentual acumulada das raízes de goiabeira cv. Paluma coletadas nos monolitos e medidas nos perfis de solo a 0,6-0,4 m e 0,4-0,2 m de distância do tronco da planta 
Nas Figuras 51 e 52 observa-se a contribuição percentual das camadas de solo na variação da armazenagem da água, medida com a sonda de nêutrons e com o TDR.

Em conseqüência da presença de raízes em toda a profundidade do solo, todas as camadas contribuíram na variação da armazenagem, porém, observa-se uma contribuição de 54,8\% medido com a sonda de nêutrons e de $56,4 \%$ medido com o TDR na camada de $0-0,2 \mathrm{~m}$, devido a maior contribuição desta camada para a evaporação da água, e a maior presença de raízes. Notase uma redução acentuada da contribuição para a camada subseqüente, e uma redução gradativa desta para as demais camadas de solo. Tal comportamento apresenta correspondência com a distribuição radicular.

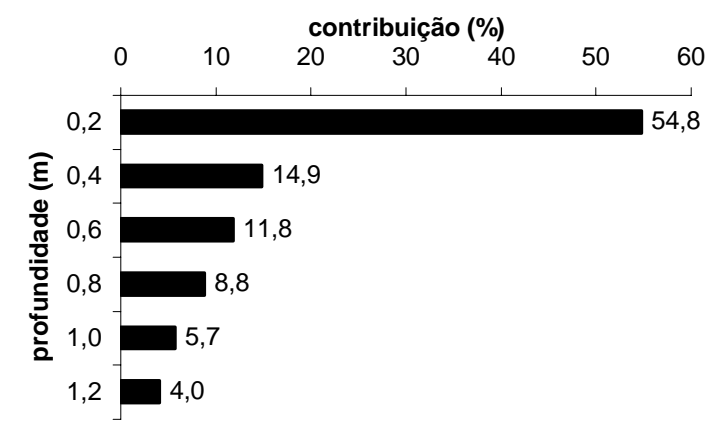

Figura 51 - Contribuição percentual das camadas de solo na variação do armazenamento de água medida com o TDR

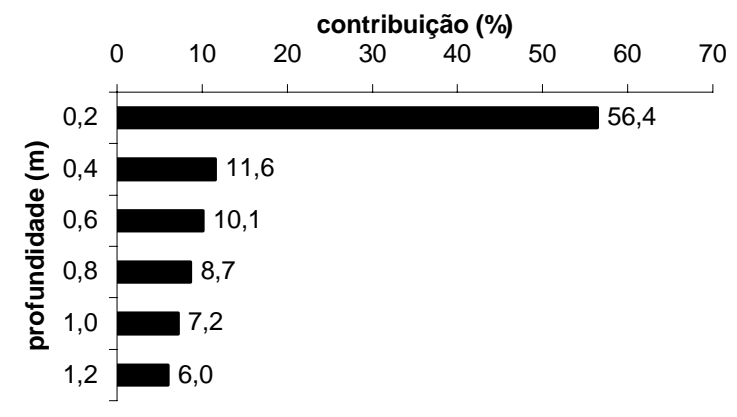

Figura 52 - Contribuição percentual das camadas de solo na variação do armazenamento de água medida com a sonda de nêutrons 
A amplitude dos valores de potencial matricial da água no solo foi maior a 0,2, 0,4 e 0,6 m (Figura 53) em relação às profundidades de 0,8, 1,0 e 1,2 m (Figura 54), pois considerou-se a profundidade de 0,6 $\mathrm{m}$ como aquela que foi manejada devido a maior presença de raízes (Bassoi et al, 2002). Neste volume de solo considerado, procurou-se manter o potencial entre $-10 \mathrm{kPa}$ e $-40 \mathrm{kPa}$, correspondendo à capacidade de campo e o ponto crítico de manejo, respectivamente.

Nas profundidades de 0,8, 1,0 e 1,2 m, observa-se que a variação do potencial matricial ocorreu entre $-10 \mathrm{kPa}$ e $-20 \mathrm{kPa}$, sempre próximo a capacidade de campo, apesar das lâminas de irrigação não terem atingido estas profundidades. Isto ocorreu porque o solo em questão tem uma moderada deficiência de drenagem interna, devido à presença de mosqueado vermelho (plintita) a partir de 1,0 m.

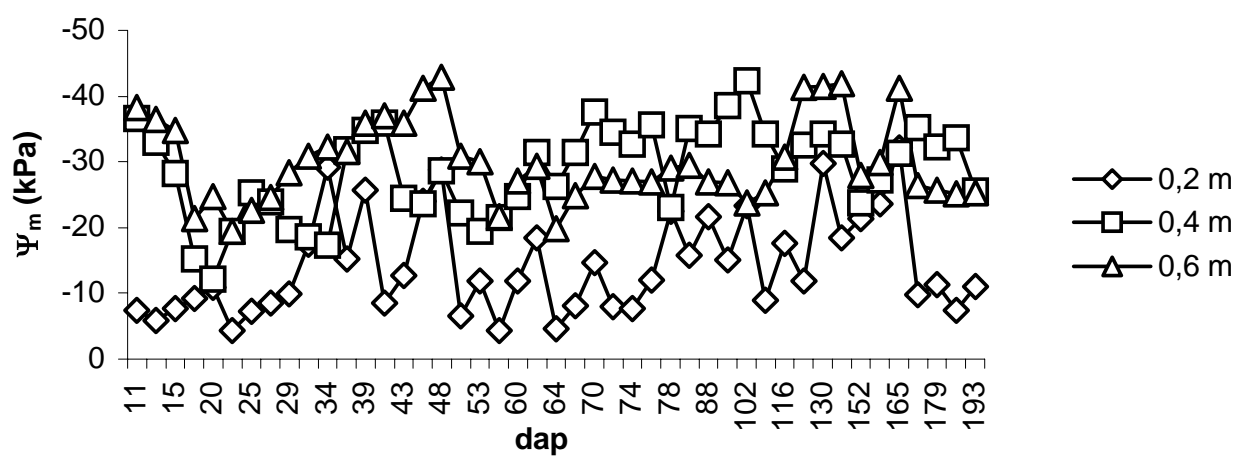

Figura 53 - Potencial matricial médio da água no solo a 0,2, 0,4 e 0,6 m de profundidade em função do número de dias após a poda 


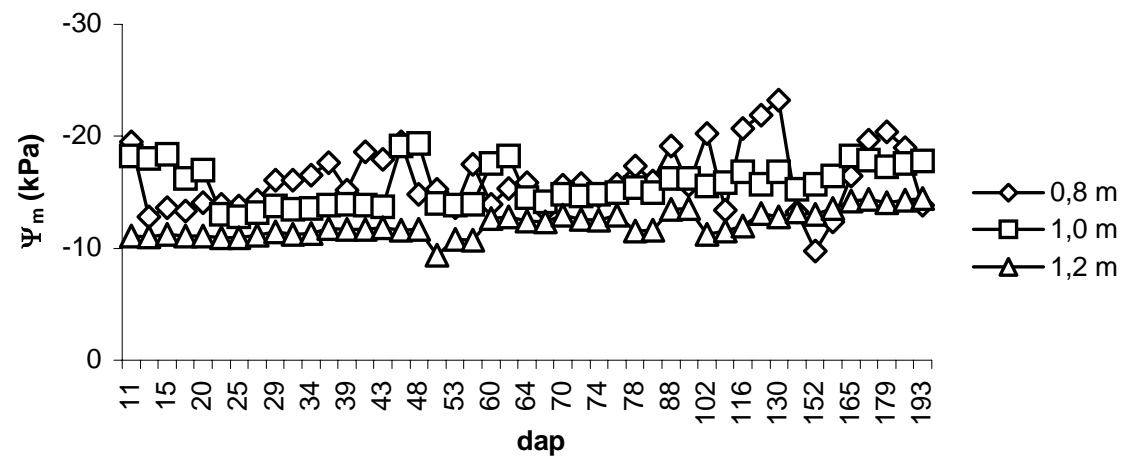

Figura 54 - Potencial matricial médio da água no solo a 0,8, 1,0 e 1,2 m de profundidade em função do número de dias após a poda

Nas Figuras 55 e 56 observa-se o gradiente do potencial total da água no solo em função dos dias após a poda (dap), onde na profundidade de 0,4 m ocorreram valores positivos, indicando fluxos descendentes em função da aplicação de água através da irrigação. Nas profundidades de 0,6, 0,8, 1,0 e 1,2 $m$ ocorreram valores negativos com maior freqüência, indicando fluxos ascendentes e portanto a contribuição das camadas mais profundas do solo no processo de evapotranspiração. Entretanto, os valores negativos de maior magnitude ocorreram até $0,8 \mathrm{~m}$, coincidindo com a maior presença de raízes.

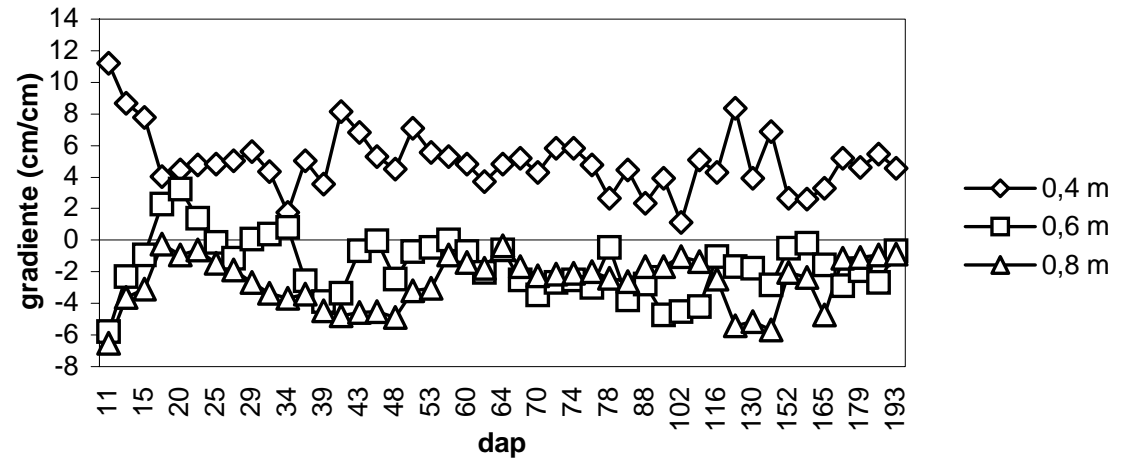

Figura 55 - Gradiente do potencial total médio da água no solo a 0,4, 0,6 e 0,8 $\mathrm{m}$ de profundidade, em função do número de dias após a poda 


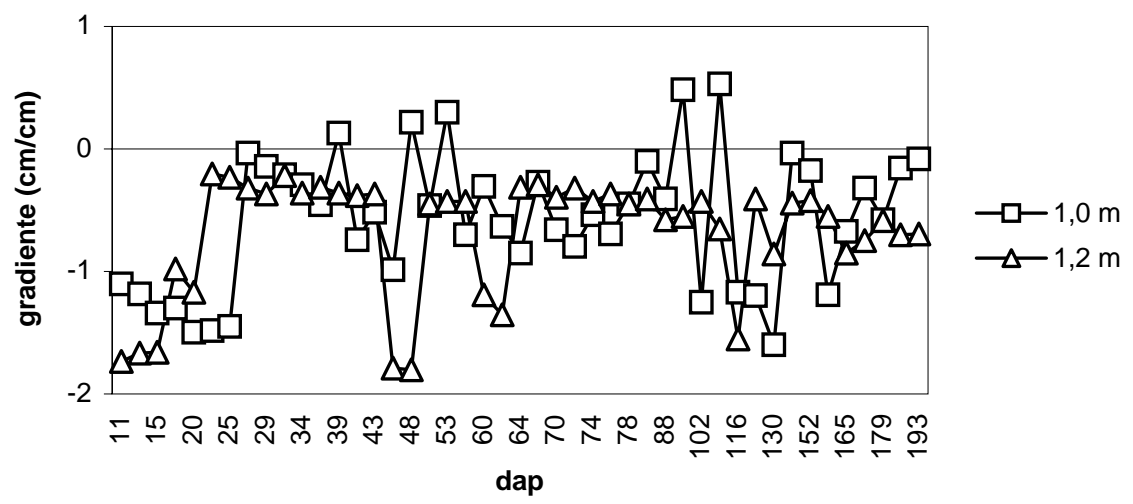

Figura 56 - Gradiente do potencial total médio da água no solo a 1,0 e 1,2 m de profundidade, em função do número de dias após a poda

\subsection{Balanço hídrico no solo}

A poda de frutificação do pomar foi realizada no dia 7 de junho de 2001, após dois meses de repouso das plantas. As fases fenológicas foram definidas de acordo com observações realizadas no campo, sendo caracterizadas quatro fases de desenvolvimento (Tabela 6). O período entre a poda de frutificação e a colheita foi de 200 dias.

Tabela 6. Fases fenológicas da goiabeira, cultivar Paluma, após a poda de frutificação (7 de junho de 2001) em Petrolina-PE

\begin{tabular}{lllll}
\hline Fase & Fase de & Período & \multicolumn{2}{l}{$N^{0}$ de dias } \\
& desenvolvimento & & Parcial & Acumulado \\
\hline F1 & Brotação e crescimento vegetativo & 07/06 a 09/08 & 63 & 63 \\
F2 & Crescimento vegetativo, floração & $10 / 08$ a 23/08 & 14 & 77 \\
& e queda fisiológica dos frutos & $24 / 08$ a 24/09 & 32 & 109 \\
F3 & Crescimento dos frutos & $25 / 09$ a 26/11 & 63 & 172 \\
F4 & Maturação e colheita dos frutos & $26 / 11$ a 24/12 & 28 & 200 \\
\hline
\end{tabular}


A Figura 57 mostra as diferentes fases fenológicas da cultura da goiabeira, cultivar Paluma, no pomar estudado.

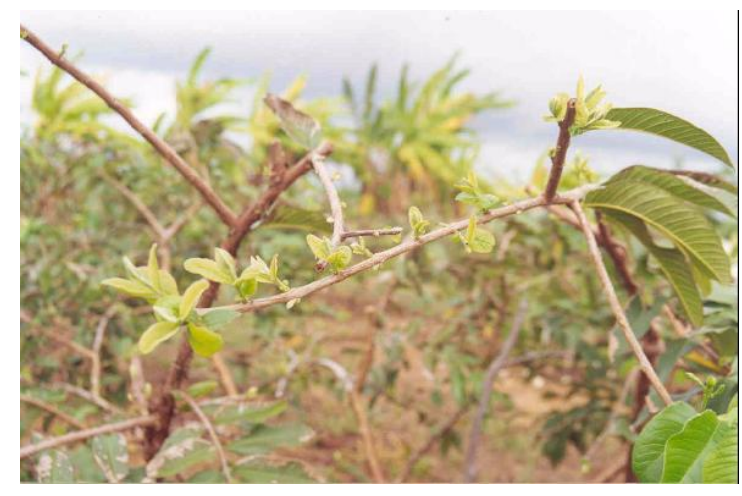

(a)

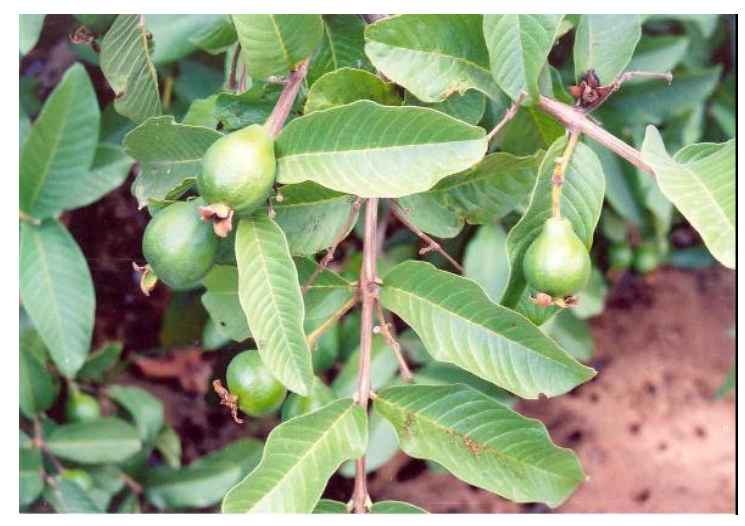

(c)

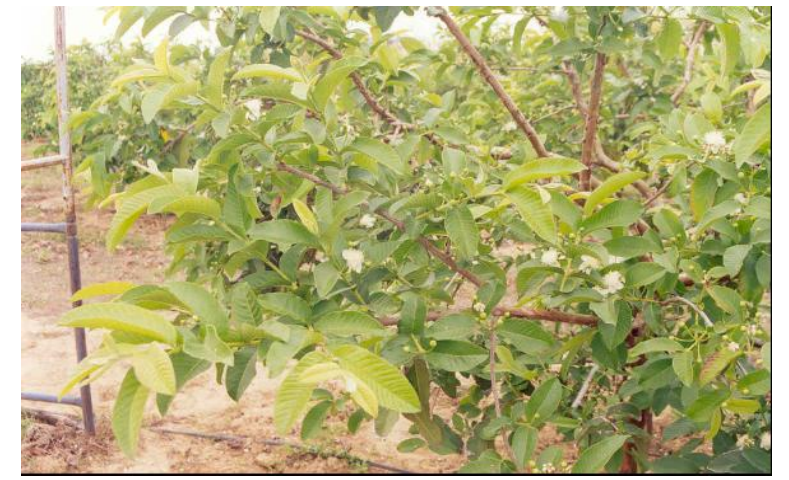

(b)

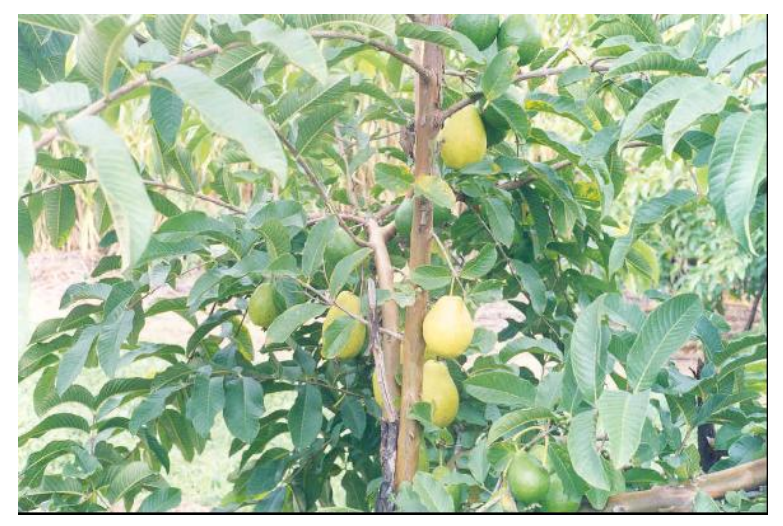

(d)

Figura 57 - Diferentes fases fenológicas da cultura da goiabeira, cultivar Paluma. (a) Fase 1: brotação e crescimento vegetativo, (b) Fase 2: crescimento vegetativo, floração e queda fisiológica dos frutos, (c) Fase 3: crescimento dos frutos, (d) Fase 4: maturação e colheita dos frutos

O diâmetro $(\mathrm{m})$ e a área da copa $\left(\mathrm{m}^{2}\right)$ apresentaram um aumento contínuo. O diâmetro aumentou de 2,98 m aos 10 dap para 4,75 m aos 200 dap 
(Figura 58), enquanto que a área da copa aumentou de 6,96 $\mathrm{m}^{2}$ para 17,72 $\mathrm{m}^{2}$, no mesmo período de tempo (Figura 59) o que correspondem a 23 e $59 \%$ da área ocupada por uma planta, respectivamente.

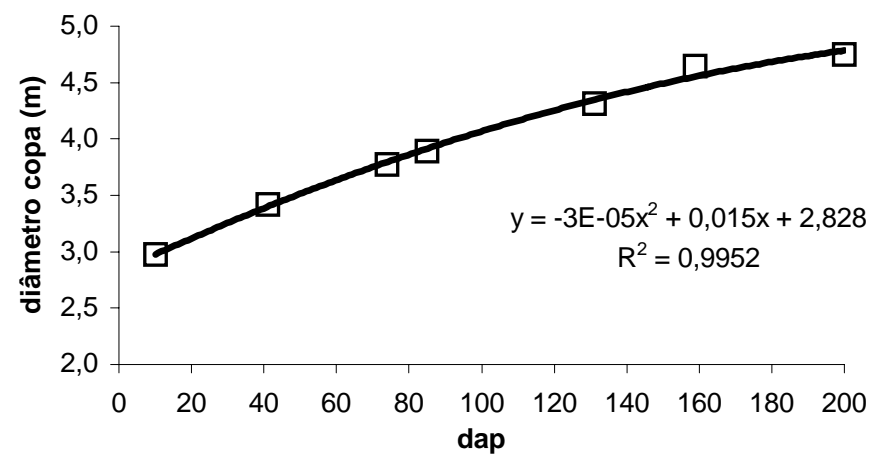

Figura 58 - Diâmetro médio da copa das plantas $(\mathrm{m})$ em função do número de dias após a poda (dap)

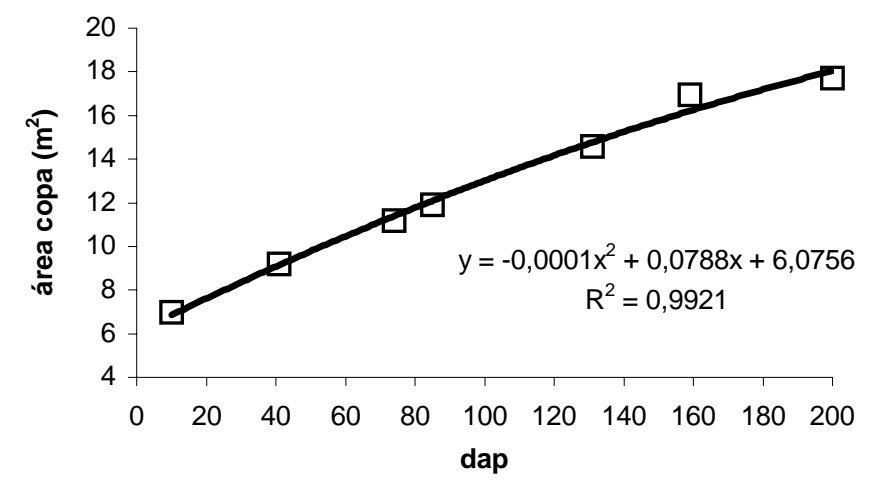

Figura 59 - Área média da copa das plantas $\left(\mathrm{m}^{2}\right)$ em função do número de dias após a poda (dap) 
Na Figura 60 pode-se observar a evapotranspiração de referência (ETo) determinada pelos métodos de Penman-Monteith FAO e do tanque classe A, e a evapotranspiração da cultura (ETc) determinada pelo balanço hídrico com os dados de umidade do solo medidos com a sonda de nêutrons e com o TDR, em função do $n^{0}$ de dias após a poda (dap). Observa-se que a ETo calculada pelo método do tanque classe $A$ foi maior que a ETo calculada pelo método de Penman-Monteith FAO, apresentando um valor médio de $5,22 \mathrm{~mm} /$ dia e 4,68 $\mathrm{mm} / \mathrm{dia}$, respectivamente, durante todo o ciclo de produção. Os valores de evapotranspiração da cultura determinada pelo balanço hídrico a partir de dados de umidade do solo medidos com a sonda de nêutrons e com o TDR, apresentaram a mesma tendência durante todo o ciclo da cultura, com uma média de 3,63 mm/dia e 3,70 mm/dia, respectivamente, com valores mínimo e máximo de $2,27 \mathrm{~mm} /$ dia e $4,92 \mathrm{~mm} /$ dia para os dados da sonda de nêutrons e $2,26 \mathrm{~mm} /$ dia e $5,15 \mathrm{~mm} /$ dia para os dados do TDR, observados nas fases de desenvolvimento F1 e F3.

Moura (2000), determinou a evapotranspiração da cultura de goiabeira em Petrolina-PE pelo método do balanço de energia baseado na razão de Bowen, encontrado valores mínimo e máximo de 2,90 mm/dia e 5,33 mm /dia respectivamente.

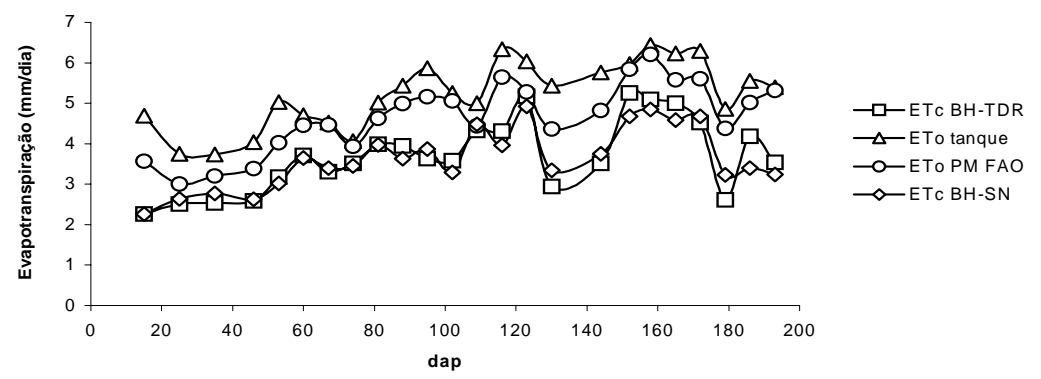

Figura 60 - Comportamento da evapotranspiração de referência obtida pelos métodos do tanque classe $A$ e Penman-Monteith FAO, e da evapotranspiração da cultura obtida pelo balanço hídrico com dados de umidade do solo medidos com a sonda de nêutrons (SN) e com o TDR 
$\mathrm{Na}$ Tabela 7 observa-se os valores de coeficiente de cultivo (Kc) da goiabeira irrigada por microaspersão em Petrolina-PE, onde foram calculados a partir de médias de 7 a 14 dias da evapotranspiração de referência (ETo) determinadas pelos métodos de Penman-Monteith FAO e do tanque classe $A$, e da evapotranspiração da cultura (ETc) obtida do balanço hídrico $(\mathrm{BH})$ no solo a partir de dados de umidade medidos com a sonda de nêutrons e com o TDR. Pode-se observar as flutuações dos valores de coeficiente de cultivo (Kc) durante todo o ciclo produtivo e o valor médio para todo o ciclo.

Nas Figuras 61 e 62 são apresentados os coeficientes de cultivo (Kc) médio para cada fase fenológica (F) estudada durante todo o ciclo produtivo da goiabeira. Por estas Figuras, observa-se que os coeficientes de cultivo apresentam um comportamento crescente da F1 para o ponto intermediário entre a F2 e a F3, verificando um decréscimo até a F4, que corresponde a maturação e colheita. Nas Figuras encontram-se também, as equações para todas as condições estudadas.

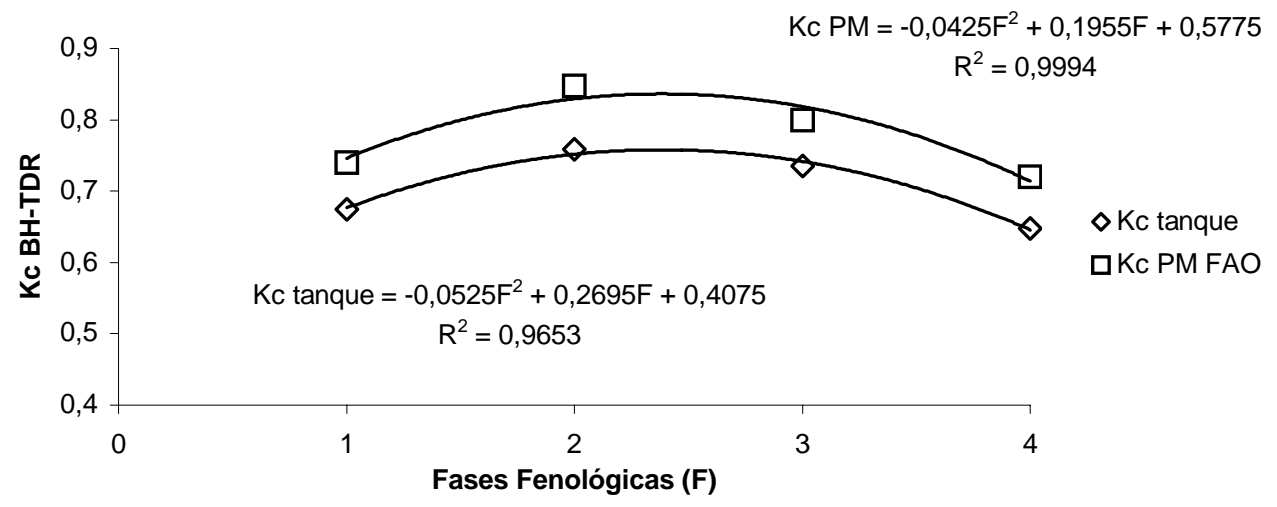

Figura 61 - Comportamento médio dos coeficientes de cultura (Kc) calculados da evapotranspiração de referência por Penman-Monteith FAO e pelo tanque classe $A$, e da evapotranspiração da cultura pelo método do balanço hídrico no solo com os dados de umidade do TDR, ao longo das fases fenológicas da goiabeira em Petrolina-PE 
Tabela 7. Valores de coeficiente de cultura $(\mathrm{Kc})$ para goiabeira irrigada por microaspersão em Petrolina - PE

\begin{tabular}{|c|c|c|c|c|c|c|}
\hline \multirow[t]{2}{*}{ Período } & \multirow[t]{2}{*}{ DAP } & \multirow{2}{*}{$\begin{array}{l}\text { Fases } \\
\text { Fenológicas }\end{array}$} & \multicolumn{2}{|c|}{$\mathrm{Kc} \mathrm{BH}-\mathrm{TDR}$} & \multicolumn{2}{|c|}{$\mathrm{Kc} \mathrm{BH}-\mathrm{SN}$} \\
\hline & & & tanque & PM FAO & tanque & PM FAO \\
\hline $13-22 / 6$ & 15 & F1 & 0,58 & 0,62 & 0,61 & 0,64 \\
\hline $22 / 6-2 / 7$ & 25 & $\mathrm{~F} 1$ & 0,67 & 0,76 & 0,70 & 0,80 \\
\hline $2-12 / 7$ & 35 & $\mathrm{~F} 1$ & 0,68 & 0,78 & 0,73 & 0,79 \\
\hline $12-12 / 7$ & 46 & $\mathrm{~F} 1$ & 0,64 & 0,77 & 0,63 & 0,78 \\
\hline $23-30 / 7$ & 53 & $\mathrm{~F} 1$ & 0,63 & 0,75 & 0,60 & 0,75 \\
\hline $30 / 7-6 / 8$ & 60 & $\mathrm{~F} 1$ & 0,79 & 0,81 & 0,77 & 0,82 \\
\hline $6-13 / 8$ & 67 & F1 & 0,66 & 0,74 & 0,72 & 0,76 \\
\hline $13-20 / 8$ & 74 & $\mathrm{~F} 2$ & 0,86 & 0,90 & 0,85 & 0,87 \\
\hline $20-27 / 8$ & 81 & $\mathrm{~F} 2$ & 0,79 & 0,86 & 0,79 & 0,86 \\
\hline $27 / 8-3 / 9$ & 88 & $\mathrm{~F} 2$ & 0,73 & 0,79 & 0,79 & 0,93 \\
\hline $3-10 / 9$ & 95 & F2 & 0,62 & 0,75 & 0,65 & 0,75 \\
\hline $10-17 / 9$ & 102 & $\mathrm{~F} 2$ & 0,68 & 0,75 & 0,63 & 0,65 \\
\hline $17-24 / 9$ & 109 & $\mathrm{~F} 2$ & 0,86 & 0,97 & 0,84 & 1,03 \\
\hline $24 / 9-1 / 10$ & 116 & F3 & 0,68 & 0,76 & 0,63 & 0,70 \\
\hline $1-8 / 10$ & 123 & F3 & 0,86 & 0,94 & 0,81 & 0,92 \\
\hline $8-15 / 10$ & 130 & F3 & 0,54 & 0,74 & 0,61 & 0,76 \\
\hline $15-29 / 10$ & 144 & F3 & 0,61 & 0,76 & 0,65 & 0,78 \\
\hline 29/10-6/11 & 152 & F3 & 0,88 & 0,90 & 0,78 & 0,80 \\
\hline $6-12 / 11$ & 158 & F3 & 0,79 & 0,82 & 0,75 & 0,78 \\
\hline $12-19 / 11$ & 165 & F3 & 0,80 & 0,90 & 0,73 & 0,81 \\
\hline $19-26 / 11$ & 172 & F3 & 0,72 & 0,81 & 0,74 & 0,83 \\
\hline $26 / 11-3 / 12$ & 179 & F4 & 0,54 & 0,70 & 0,66 & 0,74 \\
\hline $3-10 / 12$ & 186 & $\mathrm{~F} 4$ & 0,75 & 0,80 & 0,61 & 0,67 \\
\hline $10-17 / 12$ & 193 & $\mathrm{~F} 4$ & 0,66 & 0,67 & 0,59 & 0,61 \\
\hline média & & & 0,71 & 0,79 & 0,70 & 0,78 \\
\hline
\end{tabular}




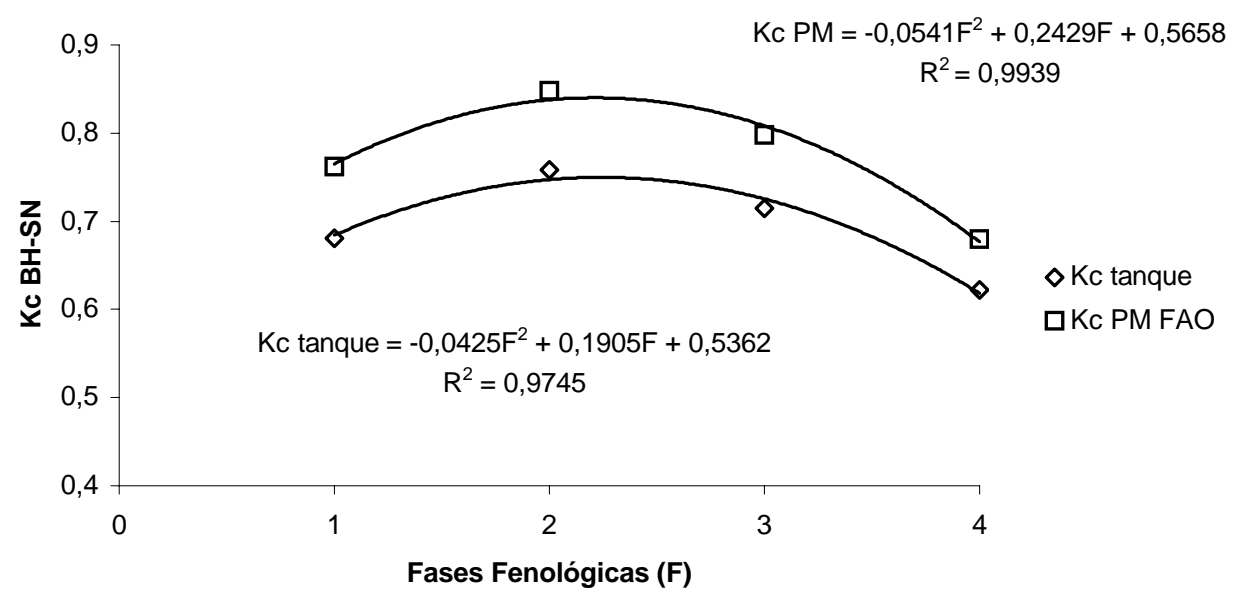

Figura 62 - Comportamento médio dos coeficientes de cultura $(\mathrm{Kc})$ calculados a partir da evapotranspiração de referência por Penman-Monteith FAO e pelo tanque classe $A$, e da evapotranspiração da cultura pelo método do balanço hídrico com os dados de umidade do solo da sonda de nêutrons, ao longo das fases fenológicas da goiabeira em Petrolina-PE

Na Figura 63 estão as lâminas acumuladas do total aplicado através das irrigações+precipitações pluviométricas, ocorridas durante o período, e da evapotranspiração da cultura (ETc) determinada pelo balanço hídrico com os dados de umidade do solo medidos com a sonda de nêutrons e com o TDR, em função do $\mathrm{n}^{\circ}$ de dias após a poda (dap). O total aplicado através das irrigações durante todo o ciclo produtivo foi de $614,54 \mathrm{~mm}$, que somado às precipitações pluviométricas de $50,7 \mathrm{~mm}$, totalizaram $665,24 \mathrm{~mm}$. A lâmina acumulada da evapotranspiração da cultura (ETc) determinada pelo balanço hídrico com os dados de umidade do solo medidos com o TDR foi de $691,38 \mathrm{~mm}$ e com os dados de umidade do solo medidos com a sonda de nêutrons de 679,17 mm.

A diferença entre $\mathrm{P}+\mathrm{I}$ e ETc BH-SN foi de $13,93 \mathrm{~mm}$, enquanto que em relação à ETc BH-TDR, esse valor aumentou para 26,14 mm. Nessa diferença, fazem parte os outros componentes do balanço hídrico no solo, como a 
variação da armazenagem e o fluxo de água no solo (descendente/ascendente), que apresentaram uma menor magnitude na contabilização das entradas e saídas de água no volume de solo considerado no balanço hídrico (Tabela 8). Os pequenos valores de $q$ e $\Delta A$ estão relacionados com o manejo da irrigação, que foi feito até $0,60 \mathrm{~m}$ de profundidade de acordo com as leituras tensiométricas, onde procurou-se aplicar água dentro dos potenciais pré-estabelecidos; e com a presença de plintita observada a partir de 1,0 m de profundidade. Segundo Silva, (2000) a presença de plintita ocorre em extensas áreas de solos da região Nordeste do país, constituindo fator limitante ao uso agrícola por estarem geralmente associadas as condições imperfeitas de drenagem interna e/ou presença de crostas ferruginosas endurecidas.

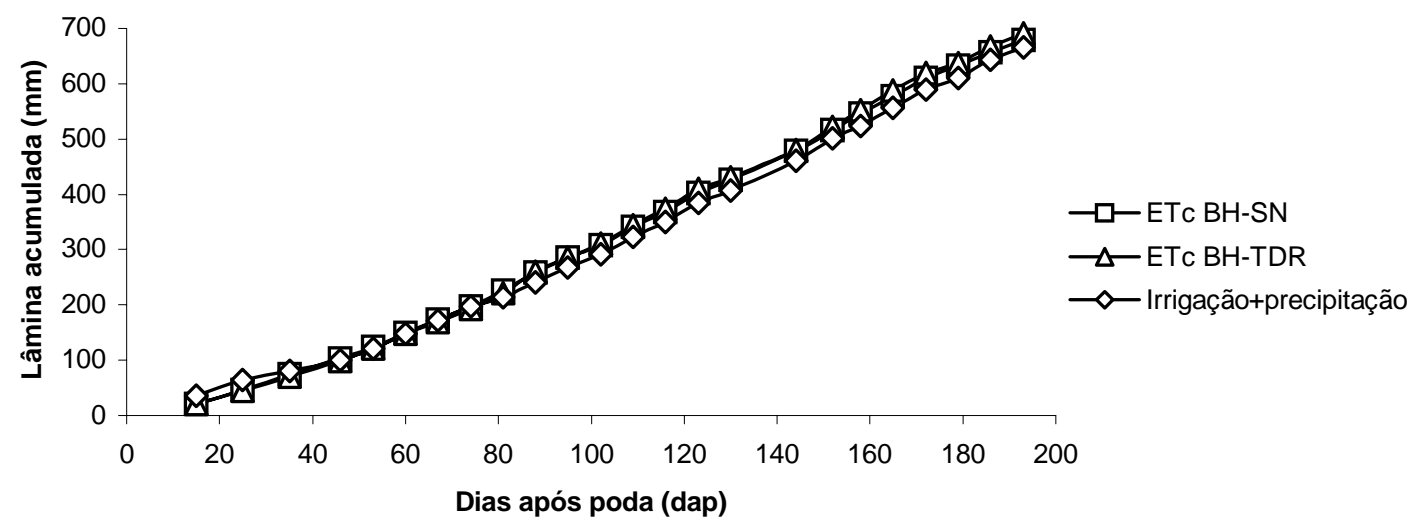

Figura 63 - Lâminas acumuladas do total aplicado (irrigação+precipitação) e evapotranspirado pela cultura de goiabeira (ETc) em Petrolina-PE 
Tabela 8. Componentes do balanço hídrico com os dados de umidade do solo da sonda de nêutron e do TDR para todo o ciclo produtivo de goiabeira em Petrolina-PE

\begin{tabular}{llllllllllll}
\hline & \multicolumn{2}{c}{ Irrigação } & \multicolumn{3}{c}{ Precipitação } & $\Delta \mathrm{A}$ & & $\mathrm{q}$ & \multicolumn{3}{l}{ ETc } \\
$\mathrm{BH}$ & $\mathrm{mm}$ & $\%$ & $\mathrm{~mm}$ & $\%$ & $\mathrm{~mm}$ & $\%$ & $\mathrm{~mm}$ & $\%$ & $\mathrm{~mm}$ & $\%$ \\
\hline BH-SN & 614,54 & 90,5 & 50,7 & 7,4 & 12,87 & 1,9 & 1,06 & 0,2 & 679,17 & 100 \\
BH-TDR & 614,54 & 88,9 & 50,7 & 7,3 & 25,64 & 3,7 & 0,50 & 0,1 & 691,38 & 100 \\
\hline
\end{tabular}

\section{6 - EFICIÊNCIA DO USO DE ÁGUA}

A colheita do pomar de goiabeiras foi realizada em 28 dias, entre 26 de novembro e 24 de dezembro de 2001, onde as plantas apresentaram, em média, 623 frutos colhidos; peso médio dos frutos colhidos de $116 \mathrm{~g}$, variando de $169 \mathrm{~g}$ a $78 \mathrm{~g}$; peso médio dos frutos por planta de $72 \mathrm{Kg}$; e uma produtividade de $24.097 \mathrm{Kg} / \mathrm{ha}$.

Com estes dados, determinou-se a eficiência do uso de água, relacionando a produtividade com a quantidade de água aplicada, que foi de $3,62 \mathrm{Kg} \cdot \mathrm{m}^{-3}$.

Teixeira et al., (2002), determinou a eficiência do uso de água para a bananeira na região de Petrolina-PE encontrando um valor de $1,22 \mathrm{Kg} \cdot \mathrm{m}^{-3}$. Cardoso (2002), trabalhando com o meloeiro rendilhado em ambiente protegido em Piracicaba-SP, encontrou uma eficiência de uso de água de 19,14 Kg.m ${ }^{-3}$.

\subsection{Comparações da umidade do solo medida com a SN e com o TDR}

Nas Figuras 64 a 68 pode-se observar a umidade do solo $\left(\theta, \mathrm{cm}^{3} / \mathrm{cm}^{3}\right)$ medida com o TDR e a sonda de nêutrons (SN) em função dos dias após a 
poda (dap) para as profundidades $0-0,15 \mathrm{~m}, 0,15-0,30 \mathrm{~m}, 0,30-0,60 \mathrm{~m}, 0,60-$ 0,90 m e 0,90-1,2 m, respectivamente, onde nas profundidades de 0-0,15 m e 0,15-0,30 m (Figuras 64 e 65) o TDR apresentou maiores valores de umidade que os da sonda de nêutrons. Na profundidade de 0,30-0,60 m os valores de umidade foram bastante próximos, sendo que no início do ciclo os valores do TDR foram menores que os da sonda de nêutrons, mas no final tornaram-se maiores (Figura 66). Nas profundidades de 0,60-0,90 m e 0,90-1,2 m (Figura 67 e 68) os valores de umidade medidos com o TDR foram menores que os valores da sonda de nêutrons em quase todo o ciclo, observando-se uma igualdade dos valores a partir dos 179 dap.

Tais diferenças de umidade estão relacionadas com os próprios princípios de funcionamento dos equipamentos.

Qualquer método de medida da umidade do solo é dependente da sensitividade espacial da medida, ou seja, do volume de solo que é medido e como a distribuição da sensitividade ocorre dentro desse volume. Para sondas de TDR duplas e paralelas, com 3,175 mm de diâmetro e $300 \mathrm{~mm}$ de comprimento, Baker \& Lascano (1989) verificaram que a sensitividade no ar e na água foi extremamente confinada à uma região transversal de $1000 \mathrm{~mm}^{2}$, podendo estender-se a $3500-4000 \mathrm{~mm}^{2}$, mas com uma menor sensitividade. Devido à desuniforme sensitividade dentro da região do solo que influencia a medida, erros podem ocorrer quando a água encontra-se heterogeneamente distribuída. A largura da região de sensitividade normal ao plano que continha a sonda foi de aproximadamente $30 \mathrm{~mm}$. No sentido longitudinal (ao longo da sonda), a sensitividade não apresentou variações significantes.

A técnica de moderação de nêutrons apresenta um volume esférico relativamente grande, cujo diâmetro pode variar de 10-15 cm, em meios com alto conteúdo de hidrogênio (solo úmido) a $80 \mathrm{~cm}$, em solos muito secos (Bacchi \& Reichardt, 1990). Esse volume pode mascarar consideráveis gradientes de água que ocorrem em um espaço de mesma grandeza, devendose considerar esse fator limitante em estudos que requerem a localização e o 
movimento de uma frente de molhamento. Dentro do volume de solo amostrado com uma determinada umidade, pode-se ter diferentes estimativas da umidade do solo, caso a água esteja distribuída em diversos modos (Willians et al., 1981).

As correlações entre a umidade determinada pelo método gravimétrico com as determinadas pelo TDR e sonda de nêutrons são similares. Na realização do balanço hídrico no solo, as discrepâncias entre as estimativas obtidas com ambos os equipamentos podem ser um reflexo da variabilidade do solo, mesmo em distâncias menores que 1 m (Dasberg \& Dalton, 1985).

Laurent (2000) comparando o uso do TDR com a sonda de nêutrons na medição do conteúdo de água no perfil do solo, obteve uma boa correspondência entre ambos os equipamentos em função do tempo e da profundidade de amostragem. Porém, mudanças rápidas de conteúdo de água próxima a superfície foram detectadas pelo TDR.

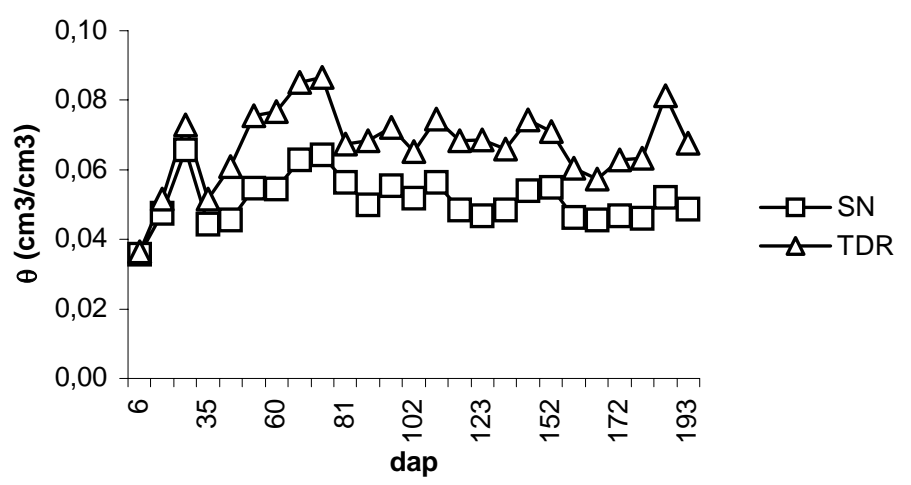

Figura 64 - Umidade do solo medida com o TDR e a sonda de nêutrons na profundidade de 0-0,15 m em função dos dias após a poda (dap) 


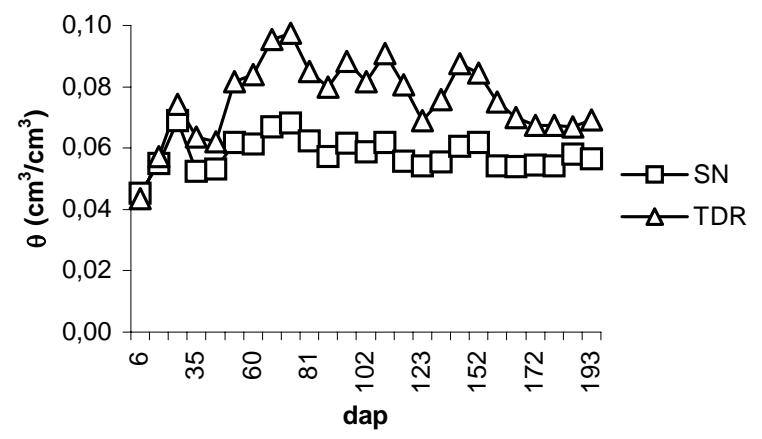

Figura 65 - Umidade do solo medida com o TDR e a sonda de nêutrons na profundidade de 0,15-0,30 m em função dos dias após a poda (dap)

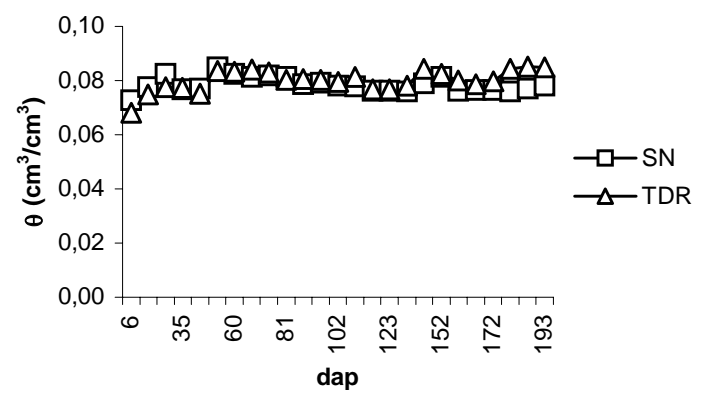

Figura 66 - Umidade do solo medida com o TDR e a sonda de nêutrons na profundidade de 0,30-0,60 m em função dos dias após a poda (dap)

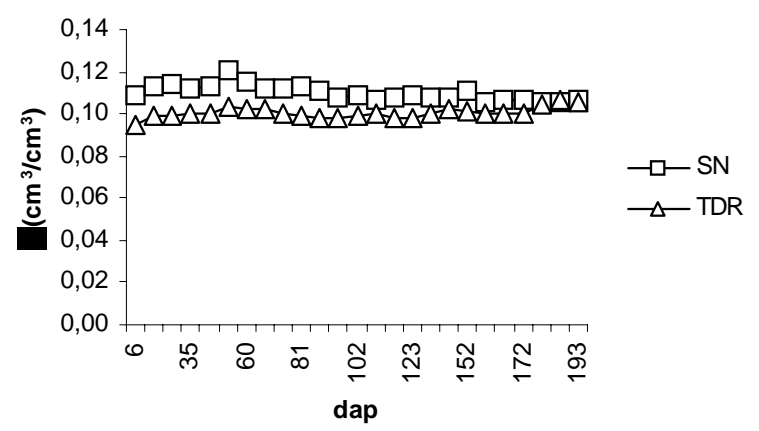

Figura 67 - Umidade do solo medida com o TDR e a sonda de nêutrons na profundidade de 0,6-0,9 m em função dos dias após a poda (dap) 


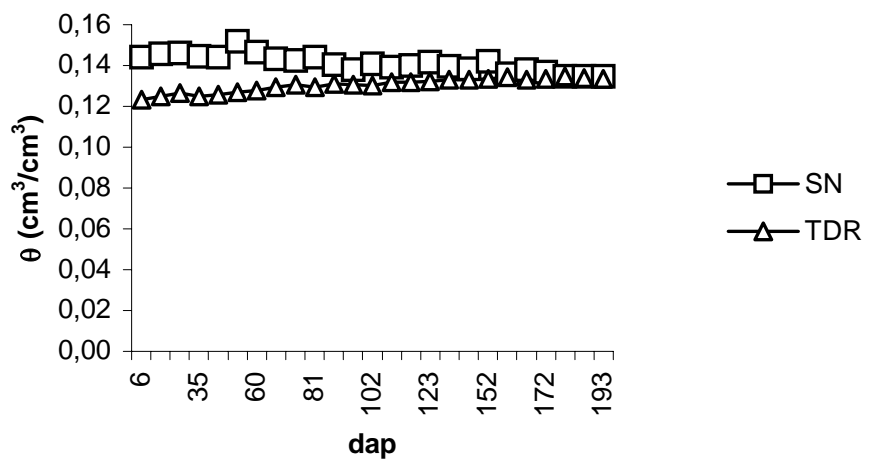

Figura 68 - Umidade do solo medida com o TDR e a sonda de nêutrons na profundidade de 0,90-1,2 m em função dos dias após a poda (dap)

Nas Figuras 69 a 73 pode-se observar as correlações de umidade do solo $\left(\theta, \mathrm{cm}^{3} / \mathrm{cm}^{3}\right)$ medida com o TDR e a sonda de nêutrons para as profundidades 0-0,15 m, 0,15-0,30 m, 0,30-0,60 m, 0,60-0,90 m e 0,90-1,2 m respectivamente, onde nas primeiras camadas de solo os valores de $\theta$-TDR são maiores que $\theta-S N$, havendo uma inversão dos valores nas camadas subseqüentes, e uma diminuição da correlação com o aumento da profundidade do solo.

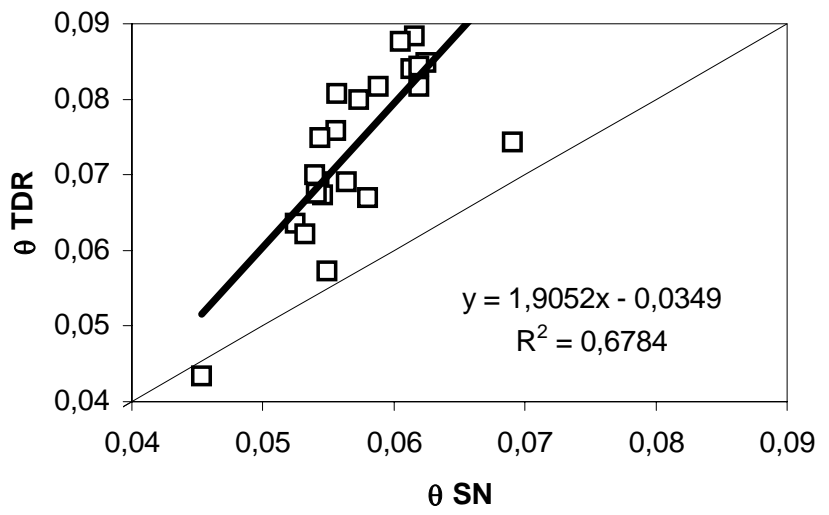

Figura 69 - Correlação da umidade $\left(\theta, \mathrm{cm}^{3} / \mathrm{cm}^{3}\right)$ medida com o TDR e com a sonda de nêutrons na profundidade de 0-0,15 m 


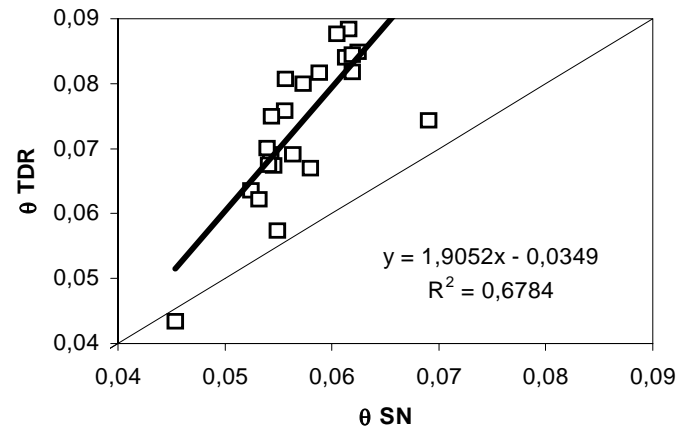

Figura 70 - Correlação da umidade $\left(\theta, \mathrm{cm}^{3} / \mathrm{cm}^{3}\right)$ medida com o TDR e com a sonda de nêutrons na profundidade de 0,15-0,30 m

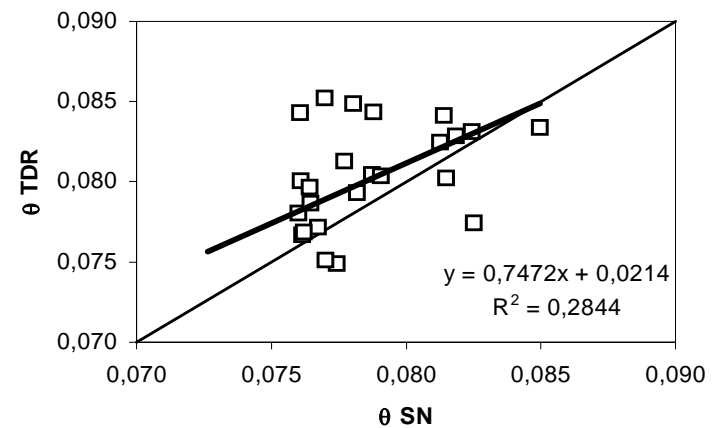

Figura 71 - Correlação da umidade $\left(\theta, \mathrm{cm}^{3} / \mathrm{cm}^{3}\right)$ medida com o TDR e com a sonda de nêutrons na profundidade de 0,30-0,60 m

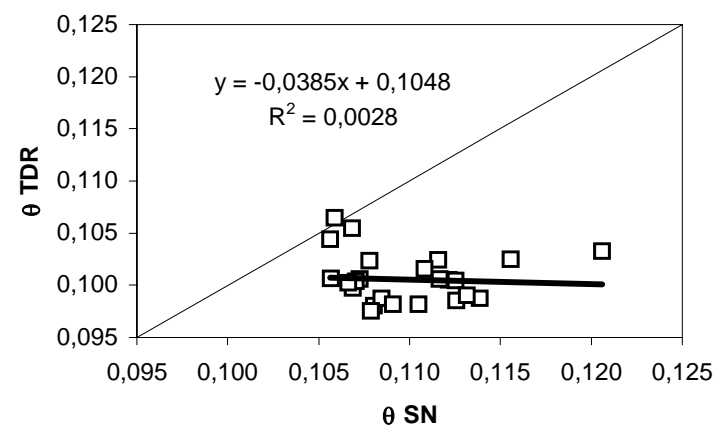

Figura 72 - Correlação da umidade $\left(\theta, \mathrm{cm}^{3} / \mathrm{cm}^{3}\right)$ medida com o TDR e com a sonda de nêutrons na profundidade de 0,60-0,90 m 


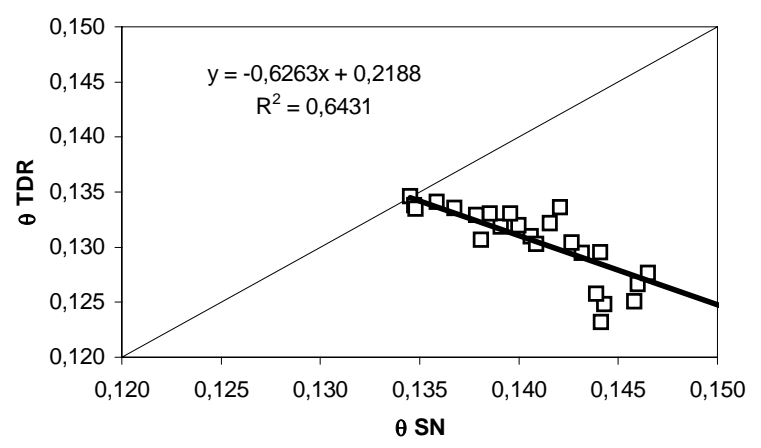

Figura 73 - Correlação da umidade $\left(\theta, \mathrm{cm}^{3} / \mathrm{cm}^{3}\right)$ medida com o TDR e com a sonda de nêutrons na profundidade de 0,90-1,2 m

Na Figura 74 observa-se o armazenamento $(A, \mathrm{~mm})$ a $1,2 \mathrm{~m}$ de profundidade, calculada com os valores de umidade do solo da sonda de nêutrons e do TDR em função dos dias após a poda (dap), onde no início do ciclo até aos 60 dap, o armazenamento calculado a partir dos dados de umidade do TDR apresentou-se menor que a sonda de nêutrons; dos 67 dap aos 123 dap ora apresentou-se maior, ora menor; a partir dos 130 dap até o final do ciclo, o armazenamento estimado com os dados do TDR apresentou-se maior que o da sonda de nêutrons.

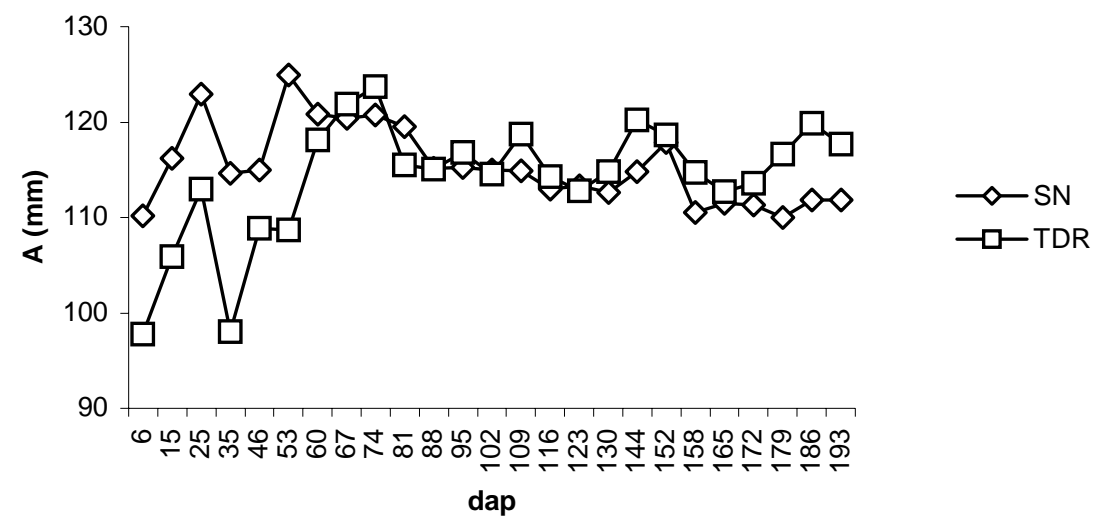

Figura 74 - Armazenamento da água no solo a 1,2 m de profundidade com dados da sonda de nêutrons e do TDR em função dos dias após a poda (dap) 
Com relação à variação do armazenamento $(\Delta \mathrm{A}, \mathrm{mm})$ da água no solo, observa-se uma maior magnitude com os valores calculados a partir do TDR, apresentando um total de $-25,64 \mathrm{~mm}$ durante todo o ciclo, e de $-12,87 \mathrm{~mm}$ para os valores calculados a partir da sonda de nêutrons, representando apenas 1,9 \% e 3,7\%, respectivamente, na contabilização do balanço hídrico no solo (Figura 75).

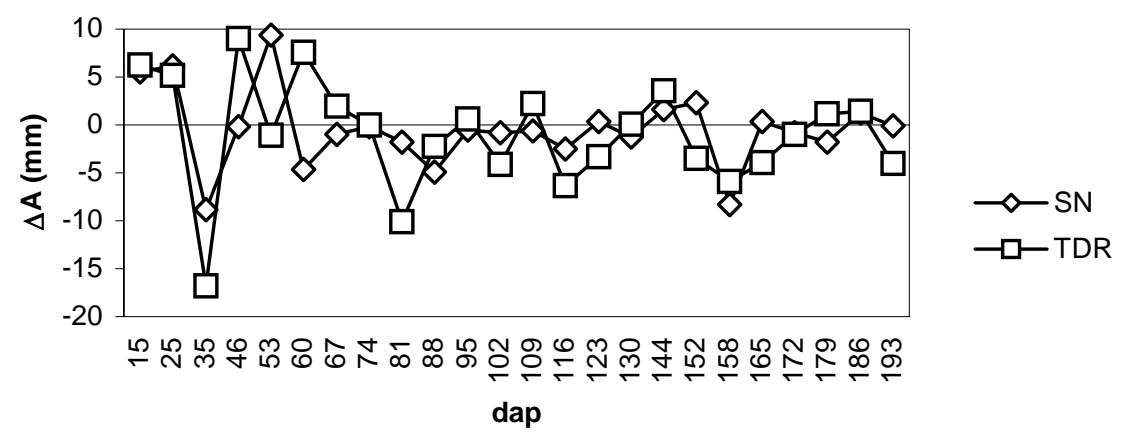

Figura 75 - Variação do armazenamento $(\Delta \mathrm{A}, \mathrm{mm})$ da água no solo com os dados da sonda de nêutrons e do TDR em função dos dias após a poda (dap)

N Figura 76 observa-se a correlação do armazenamento (A, $\mathrm{mm}$ ) calculado até 1,2 $\mathrm{m}$ de profundidade com os valores de umidade do solo obtido a partir do TDR e da sonda de nêutrons, onde constata-se uma baixa correlação. Porém, na Figura 77 observa-se uma maior correlação entre a variação do armazenamento $(\triangle \mathrm{A}, \mathrm{mm})$ obtidas com valores de umidade obtidos pelo TDR e pela sonda de nêutrons. Como o $\Delta \mathrm{A}$ é um dos componentes do balanço hídrico, obteve-se resultados muito próximos de ETC. 


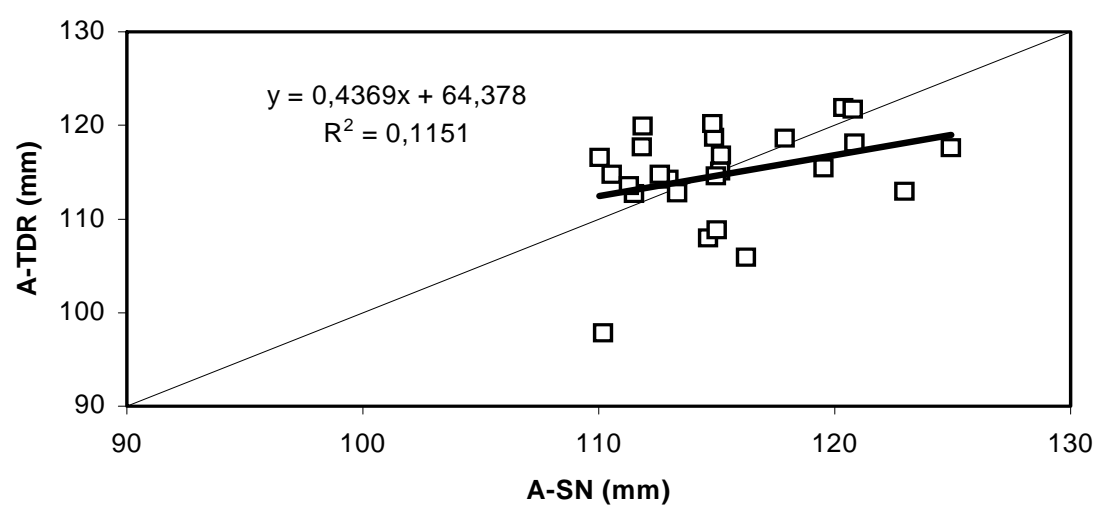

Figura 76 - Correlação do armazenamento (A, mm) calculada até 1,2 m de profundidade com os dados de umidade do TDR e da sonda de nêutrons

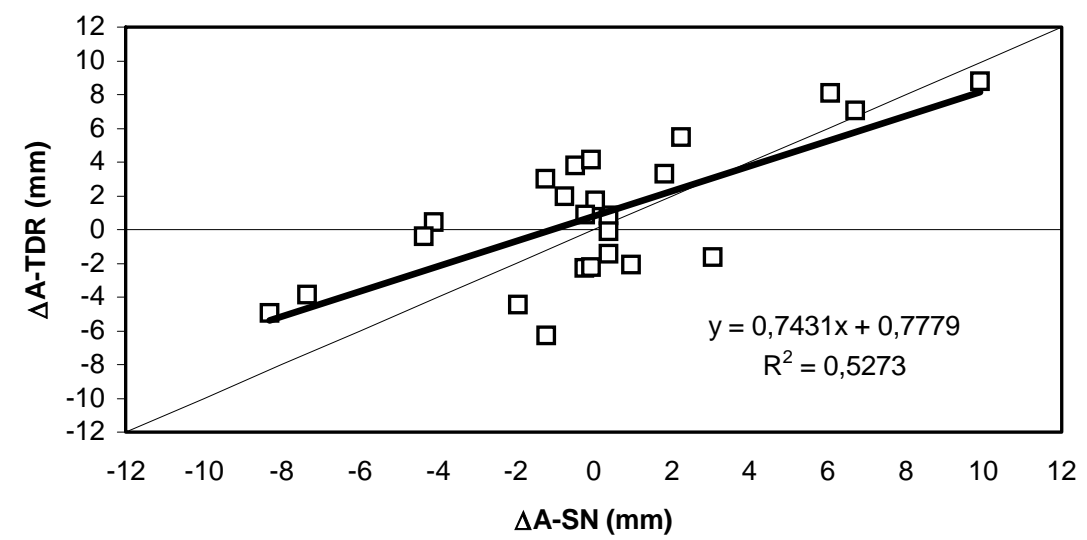

Figura 77 - Correlação da variação do armazenamento $(\Delta \mathrm{A}, \mathrm{mm})$ com os dados de umidade do TDR e da sonda de nêutrons 


\section{CONCLUSÕES}

Os resultados obtidos no pomar de goiabeira irrigada por microaspersão em um Latossolo Vermelho Amarelo textura média, no Perímetro Irrigado de Bebedouro em Petrolina-PE, permitiram as seguintes conclusões:

O sistema radicular dessa cultura atingiu uma profundidade de $1,2 \mathrm{~m}$ e uma distância máxima do tronco de $2,4 \mathrm{~m}$, sendo que a profundidade e distância efetiva encontram-se a 0,94 m e 1,27 m, respectivamente.

Considerando que o maior volume de raízes encontram-se na profundidade e distância do tronco de 0,6 m, recomenda-se esta coordenada para o monitoramento da água no solo e aplicação de fertilizantes e matéria orgânica.

A distribuição percentual dos valores acumulados de comprimento de raízes presentes nos perfis de solo e nos monolitos coletados nas mesmas distâncias do tronco apresentaram uma alta correlação, permitindo recomendar o uso do sistema SIARCS para a quantificação da distribuição espacial do sistema radicular da goiabeira no campo.

A evapotranspiração de referência (ETo) calculada pela metodologia do tanque classe $A$ foi maior que a ETo por Penman-Monteith FAO, durante todo o ciclo da cultura, apresentando um valor médio de 5,22 mm/dia e 4,68 mm/dia, respectivamente. É fato notório que o método Penman Monteith tem apresentado superestimativa da ETo na ordem de 5\% para climas áridos, porém observa-se que para o tanque Classe A o erro de estimativa foi ainda maior para a região de Petrolina-PE.O consumo total de água da cultura foi de 
$679,17 \mathrm{~mm}$ e $691,38 \mathrm{~mm}$, determinado pelo balanço hídrico no solo com a umidade do solo determinada respectivamente pela sonda de nêutrons e pelo TDR, gerando um valor médio de 3,63 mm/dia e 3,70 mm/dia, respectivamente.

O Kc médio determinado pelo balanço hídrico com a umidade do solo medida pelo TDR foi de 0,71 (para ETo segundo o tanque Classe A) e 0,79 (para ETo segundo Penman-Monteith FAO).

O Kc médio determinado pelo balanço hídrico com a umidade do solo medida pela sonda de nêutrons foi de 0,70 (para ETo segundo o tanque classe A) e 0,78 (para ETo segundo Penman-Monteith FAO).

Os conteúdos de água no solo medidos pelo TDR e pela sonda de nêutrons proporcionaram valores similares da variação do armazenamento de água no solo; conseqüentemente, as estimativas de ETc pelo balanço hídrico do solo também foram próximas. 


\section{REFERÊNCIAS BIBLIOGRÁFICAS}

ALLEN, R. G.; PEREIRA, L. S.; RAES, D.; SMITH, M. Crop evapotranspiration: guidelines for computing crop water requirements. Rome: FAO, 1998. 330 p. (FAO. Irrigation and Drainage Paper, 56).

ÁVILA NETO, J. Necessidades hídricas da videira na região do submédio São Francisco. Campina Grande, 1997. 86 p. Dissertação (Mestrado) Universidade Federal da Paraíba.

BAKER, J. M.; LASCANO, R. J. The spatial sensitivity of timedomain reflectometry. Soil Science, v. 127, n. 5, p. 378-384, May, 1989.

BEZERRA, F. M. L.; OLIVEIRA, C. H. C. Evapotranspiração máxima e coeficiente de cultura para o milho em Fortaleza, CE. Engenharia Agrícola, v. 19, n. 1, p. 8-17, set. 1999.

BACCHI, O. O. S.; REICHARDT, K. A sonda de nêutrons e seu uso na pesquisa agronômica. Piracicaba: CENA, 1990. 48 p. (CENA. Boletim Didático, 22). 
BASSOI, L. H. Crescimento e distribuição de raízes de videiras e sua relação com a prática da irrigação. Petrolina, PE: EMBRAPA-CPATSA, 2000. 3 p. (EMBRAPA-CPATSA. Comunicado Técnico, 76).

BASSOI, L. H.; GRANGEIRO, L. C.; SILVA, J. A. M. e; SILVA, E. E. G. da. Distribuição radicular de porta enxertos de videira irrigados em solo de textura arenosa do Vale do São Francisco. Petrolina, PE: Embrapa SemiÁrido, 2001b. 4 p. (Embrapa Semi-Árido. Circular Técnica, 62).

BASSOI, L. H.; FANTE JÚNIOR, L.; JORGE, L. A. C.; CRESTANA, S.; REICHARDT, K. Distribuição do sistema radicular do milho em terra roxa estruturada latossólica: comparação entre cultura irrigada e fertirrigada. Scientia Agrícola, v. 51, p. 541-548, 1994.

BASSOI, L. H.; SILVA, J. A. M.; ALENCAR, C. M.; JORGE, L. A. C.; HOPMANS, J. W. Digital imagem analysis of root distribuition toqards improved water and soil management: grapevine and date palm study cases. (compact disk) In: ASAE INTERNATIONAL ANNUAL MEETING, Milwaukee, 2000. Technical paper St. Joseph: ASAE, 2000.

BASSOI, L. H.; HOPMANS, J. W.; JORGE, L. A. C.; ALENCAR, C. M.; SILVA, J. A. M. Grapevine root distribuition in drip and microsprinkler irrigation. Scientia Agricola, v. 60, n. 2, p. 377-387, 2003.

BASSOI, L. H.; SILVA, J. A. M.; ALENCAR, C. M.; RAMOS, C. M. C.; JORGE, L. A. C.; HOPMANS, J. W. Digital image analysis of root distribuition towards improved irrigation water and soil management. (compact disk) In: ASAE ANNUAL INTERNATIONAL MEETING, Toronto, 1999. Technical paper St. Joseph: ASAE, 1999. 
BASSOI, L. H.; SILVA, J. A. M. e; SILVA, E. E. G. da; RAMOS, C. M. C.; TARGINO, E. de L.; MAIA, J. L. T.; FERREIRA, M. de N. L. Informações sobre a distribuição das raízes da bananeira para o manejo de irrigação. Petrolina, PE: Embrapa Semi-Árido, 2001a. 4 p. (Embrapa Semi-Árido. Comunicado Técnico, 105).

BASSOI, L. H.; TEIXEIRA, A. H. C.; SILVA, J. A. M.; SILVA, E. E. G. da; TARGINO, E. de L.; MAIA, J. L. T.; FERREIRA, M. de N. L. Parâmetros para o manejo de irrigação da goiabeira no Vale do São Francisco. (compact disk) In: CONGRESSO BRASILEIRO DE ENGENHARIA AGRÍCOLA, 31., Salvador, 2002. Anais Salvador: SBEA, UFBA, Embrapa, 2002.

BRASIL. Ministério da Integração Nacional. Secretaria de Infra-Estrutura Hídrica. Departamento de Desenvolvimento Hidroagrícola. Goiaba. Brasília, 2001. 8 p. (MI/SIH-DPE. Pernambuco. Frutiséries, 1).

BOHM, W. Methods of studing root systems. New York: Spriger-Verlag, 1979. 194 p.

BLANEY, H. F.; CRIDDLE. W. D. Determining water requeriments in irrigated areas from climatological and irrigatio data. Washington: USDA, 1950. 48 p.

CARDOSO, S. da S. Doses de $\mathrm{CO}_{2}$ e de potássio aplicadas através da irrigação no meloeiro rendilhado (Cucumis melo L.) cultivado em ambiente protegido. Piracicaba, 2002. 101 p. Tese - (Doutorado) - Escola Superior de Agricultura "Luiz Queiroz", Universidade de São Paulo.

CODEVASF. Cadastro frutícola do Vale do São Francisco (compact disc). Brasília, DF, 2002. 
COELHO, E. F.; ARRUDA, F. B. Aplicações da técnica de TDR: manejo da água no solo. In: WORKSHOP SOBRE APLICAÇÕES DA TÉCNICA DE TDR (REFLECTOMETRIA NO DOMÍNIO DO TEMPO) NA AGRICULTURA, 1., Campinas, 2001, Aplicações da técnica de TDR na agricultura. Campinas: UNICAMP, FEAGRI, 2001. p. 129-145.

CRESTANA, S.; GUIMARÃES, M. F.; JORGE, L. A. C.; RALISH, R.; TOZZI, C. L.; TORRE, A.; VAZ, C. M. P. Avaliação da distribuição de raízes no solo auxiliada por processamento de imagens digitais. Revista Brasileira de Ciências do Solo, v. 18, n. 3, p. 365-371, 1994.

DASBERG, S.; DALTON, F. N. Time daomain reflectometry field measurements of soil water content and electrical conductivity. Soil Science Society of America Journal, v. 49, n. 2, p. 293-297, Mar/Apr, 1985.

DOOREMBOS, J.; KASSAM, A. H. Yeld response to water. Rome: FAO, 1979. 193 p. (FAO. Irrigation and Drainage Paper, 33).

DOOREMBOS, J.; PRUITT, W. O. Guidelines for predicting crop water requirements. Rome: FAO, 1997. 179 p. (FAO. Irrigation and Drainage Paper, 24).

DU PREEZ, R. J. Root growth of guavas. Inligtingsbulletin Institu Vir Tropiense En Subtropiense, n. 271, p. 13-16, 1995.

DALTON, F. N.; HERKELRATH, W. N.; RAWLING, O. S.; RHOADES, J. D. Time domain reflectometry: simultaneous measurement of soil water content and electrical conductivity with a single probe. Science, v. 224, p. 989,1984. 
EMPRESA BRASILEIRA DE PESQUISA AGROPECUÁRIA. Serviço Nacional de Levantamento e Conservação de Solo. Manual de métodos de análise de solo. 2. ed. Rio de Janeiro, 1979. 212 p.

EMPRESA BRASILEIRA DE PESQUISA AGROPECUÁRIA. Centro Nacional de Pesquisa de Solos. Sistema brasileiro de classificação de solos. Brasília: EMBRAPA - SPI, 1999. 412 p.

FELLNER-FELDEGG, H. The measurement of dielectric in the time domain. Journal of Physics and Chemistry, v. 73, p. 616-623, 1969.

FNP CONSULTORIA \& COMÉCIO. Agrianual 2002: Anuário de agricultura brasileira. São Paulo, 2002.

GOMIDE, R. L. Importância da automação nos sistemas agrícolas irrigados, visando a irrigação inteligente e a agricultura de precisão. In: WORKSHOP SOBRE APLICAÇÕES DA TÉCNICA DE TDR (REFLECTOMETRIA NO DOMÍNIO DO TEMPO) NA AGRICULTURA, Campinas, 2001. Aplicações da técnica de TDR na agricultura. Campinas: UNICAMP; FEAGRI, 2001. p. 1-36.

GONZAGA NETO, L.; SOARES, J. M. Goiaba para exportação: aspectos técnicos da produção. Brasília: EMBRAPA-SPI; Petrolina, PE: EMBRAPACPATSA, 1994. 49 p. (FRUPEX. Publicações Técnicas, 5).

GONZAGA NETO, L.; MATTIUS, B. H. Avaliação de genótipos de goiabeira na região do submédio São Francisco. In: SIMPÓSIO BRASILEIRO SOBRE A CULTURA DA GOIABEIRA, 1., Jaboticabal, 1997. Anais Jaboticabal: UNESP-FCAJ, FUNEP, GOIABRAS, 1997. p.162. 
GONZAGA NETO, L.; BEZERRA, J. E. F.; PEDROSA, A. C.; DANTAS, A . P.; SILVA, H. M. Comportamento produtivo da goiabeira sob irrigação no vale do rio Moxotó. I. Variedades industriais: onze anos de produção. Revista Brasileira de Fruticultura, v. 13, n. 3, p. 103-114, 1991.

GHOSH, S. P. Some aspects of root systems of sweet orange, guava and mango. The Punjab Horticultural Journal, v. 14, p. 34-38, 1974.

GOPAL, L. Scheduling and depth of irrigation on growth and yield of guava (Psiduim guajava L.) variety "Sadar". Annals of Biology, v. 12, n. 2, p. 238241, 1996.

HARGREAVES, G. H. Water requeriments manual for irrigated crops and rainfed agriculture. Logan: Utah State University, 1977. 41 p.

HERRMANN JÚNIOR, P. S. de P. Aspectos básicos da reflectometria no domínio do tempo (TDR) e potencialidades de aplicação na física do solo. In: WORKSHOP SOBRE APLICAÇÕES DA TÉCNICA DE TDR (REFLECTOMETRIA NO DOMÍNIO DO TEMPO) NA AGRICULTURA, 1, Campinas, 2001. Aplicações da técnica de TDR na agricultura. Campinas: UNICAMP, FEAGRI, 2001. p. 37-50.

JENSEN, E. M.; HAISE, H. R. Estimating evapotranspiration from solar radiation. Journal of Irrigation and Drainage, v. 89, p. 15-41, 1963.

KLAR, A. E. Irrigação: freqüência e quantidade de irrigação. São Paulo: Nobel, 1991. $153 \mathrm{p}$. 
KOTUR, S. C.; MURTHY, S. V.; IYENGAR, B. R. V. Spatial distribuition of active roots in ÄRKA MRIDULA" guava (Psidium guajava) as influenced by seasons, soil moisture and growth. The Indian Journal of Agricultural Sciences, v. 68, n. 11, p. 744-746, 1998.

LARA RODRIGUES, E. A.; BORYS, M. W. El cultivo del guayabo, Psidium guajava L. Revista Chapingo, v. 8, n. 9, p. 41-45, ago/set, 1983.

LAURENT, J. P. Profiling water content in soils with TDR: comparison with the neutron probe technique. In: COMPARISON OF SOIL WATER MEASUREMENT USING THE NEUTRON SCATTERING, TIME DOMAIN REFLECTOMETRY AND CAPACITANCE METHODS, Vienna, 1998. Results of a consultants meeting Vienna: IAEA, 2000, p. 81-104.

LIBARDI, P. L. A dinâmica da água no solo. Piracicaba: Ed. do autor, 1995. $497 \mathrm{p}$.

LINACRE, E. T. A simple formula for estimating evaporation in various climates using temperature alone. Agricultural Meteorology, v. 18, p. 409-424, 1977.

LOPES, P. M. O. Evapotranspiração da mangueira na região do submédio São Francisco. Campina Grande, 1999. 108 p. Tese (Doutorado) - Universidade Federal da Paraíba.

MARANCA, G. Fruticultura comercial: mamão, goiaba, abacaxi. São Paulo: Nobel, 1978. 1 v. 
MONTEITH, J. L. Evaporation and environmental the state and movement of water in living organisms. In: SYMPOSIUM SOCIETY EXPERIMENTAL BIOLOGY, 19., 1965, Proceedings New York: Academic Press, 1965. p. 205-234.

MOURA, M. S. B. Fenologia e consumo hídrico da goiabeira (Psidium guajava L.) irrigada. Campina Grande, 2000, 124 p., Dissertação (Mestrado) Universidade Federal da Paraíba.

OTTO, S. R. L. Curva de retenção de água no solo: método do TDRtensiômetro. In: CONGRESSO BRASILEIRO DE ENGENHARIA AGRíCOLA, 27., Poços de Caldas, 1998. Anais Lavras: UFLA; SBEA, 1998 , v. 2, p. 70-72.

OTTO, S. R. L. Manejo de irrigação com o TDR. In: CONGRESSO NACIONAL DE IRRIGAÇÃO E DRENAGEM, 11., Fortaleza, 2001. Anais Fortaleza: ABID, 2001. p. 199-203.

PATIL, P. V.; PATIL, V. K. Water use pattern by guava as influenced by irrigatio regimes. Journal of Maharashtra Agricultural Universities, v. 21, n. 2, p. 287-288, 1996.

PATIL, P. V.; PATIL, V. K.; LAWAND, B. T. Effect of different water regimes on yield of guava (Psidium guajava L.). South Indian Horticulture, Lawley, v. 41, n. 6, p 322-332, 1993.

PENMAN, H. L. Natural evaporation from open water, bare soil and grass. Proceedings of Royal Society of London, Série A, v. 193, p. 120-145, 1948. 
PEREIRA, F. M.; MARTINEZ JÚNIOR, M. Goiabas para industrialização. Jaboticabal: Legis Suma, 1986, 142 p.

PEREIRA, A. R.; VILLA NOVA, N. A.; SEDIYAMA, G. C. Evapo(transpi)ração. Piracicaba: FEALQ, 1997. 183 p.

PUROHIT, A .G.; MUKHERJEE, S. K. Characterizing root activity of guava trees by radiotracer technique. The Indian Journal of Agricultural Sciences, v. 44, n. 9, 1974, p. 575-581.

RAMOS, C. M. C. Distribuição do sistema radicular e consumo de água da bananeira irrigada por microaspersão. Viçosa, 2001. 62 p. Dissertação (Mestrado) - Universidade Federal de Viçosa.

REICHARDT, K. Processos de transferência no sistema solo-plantaatmosfera. Campinas: Fundação Cargill, 1985. 445 p.

REICHARDT, K. Dinâmica da matéria e da energia em ecossistemas. Piracicaba: USP/ESALQ, 1996. 505 p.

ROSEMBERG, N. J.; BLAD, B. L.; VERMA, S. B. Microclimate: The biological environment. Jonh Wilei. New York:2.ed., 1983. 495 p.

SEDIYAMA, G. C. Estimativa da evapotranspiração: histórico, evolução e análise crítica. Revista Brasileira de Agrometeorologia, v. 4, n. 1, p. 1-12, 1996. 
SILVA, A. A. G. Maracujá amarelo: aspectos relativos a fenologia, demanda hídrica e conservação pós-colheita. Botucatu, 2002. 98 p. Tese (Doutorado) Universidade Estadual Paulista; Faculdade de Ciências Agrárias, "Júlio de Mesquita Filho".

SILVA, M. S. L. da. Caracterização e gênese do adensamento subsuperficial em solos de tabuleiro do semi-árido do nordeste do Brasil. Porto Alegre, 2000. 126 p. Tese (Doutorado) - Universidade Federal do Rio Grande do Sul.

SILVA, V. P. R. Estimativa das necessidades hídricas da mangueira. Campina Grande, 2000. 129 p. Tese (Doutorado) - Universidade Federal da Paraíba.

SOUZA, E. F.; BERNARDO, S.; COUTO, F. A. A. Influência da irrigação na goiabeira (Psidium guajava L. var. Ogawa III). II: Florescimento e vingamento dos frutos. In: SIMPÓSIO BRASILEIRO SOBRE A CULTURA DA GOIABEIRA, 1., Jaboticabal, 1997, Anais Jaboticabal: UNESP-FCA, FUNEP, GOIABRAS, 1997, p. 17.

SOUZA, C. F.; MATSURA, E. E. Avaliação das sondas de TDR multi-haste segmentadas para a estimativa da umidade do solo. Revista Brasileira de Engenharia Agrícola e Ambiental, v. 6, n. 1, p. 63-68, 2002.

SOUZA, C. F.; MATSURA, E. E. TESTEZLAF, R. Experiência do laboratório de hidráulica, irrigação e drenagem da Faculdade de Engenharia Agrícola / UNICAMP no uso da técnica do TDR. In: WORKSHOP SOBRE APLICAÇÕES DA TÉCNICA DE TDR (REFLECTOMETRIA NO DOMÍNIO DO TEMPO) NA AGRICULTURA, 1., Campinas, 2001. Aplicações da técnica de TDR na agricultura. Campinas: UNICAMP, FEAGRI, 2001. p. 147-176. 
THORNE, D. W. Irrigation and crop production. In. THORNE, D. W.; THORNE, M. D., (Ed). Soil, water and crop production. Westport: Avi Publishing, 1979. cap. 8, p. 96-116.

THORNTHWAITE, C. W. An approach toward a rational classification of climate. Geographical Review, v. 38, n. 1, p. 55-94, 1948.

TOMMASELLI, J. T. G. Influência de algumas características do solo sobre a calibração de um aparelho TDR (Time domain reflectometry). Piracicaba, 1997. 108 p. Tese (Doutorado) - Universidade de São Paulo, Escola Superior de Agricultura "Luiz Queiroz", Universidade de São Paulo.

TOPP, G. C.; DAVIS, J. L.; ANNAN, A. P. Electromagnetic determination of soil water content; measurement in coaxial lines. Water Resources Research, v. 16, n. 3 , p. 574-582, 1980.

TEIXEIRA, A. H. de C. Informações agrometeorológicas do Pólo PetrolinaPE/Juazeiro-BA. Petrolina, PE: Embrapa Semi-Árido, 2002. 48 p. (Embrapa Semi-Árido. Documentos, 168).

TEIXEIRA, A. H. de C.; BASSOI, L. H.; COSTA, W. P. L. B. da; SILVA, J. A. M. e; SILVA, E. E. G. da. Consumo da bananeira no Vale do São Francisco estimado pelo método da razão de Bowen. Revista Brasileira de Agrometeorologia, v. 10, n. 1, p. 45-50, 2002.

WILLIAMS, J.; HOLMES, J. W.; WILLIAMS, B. G.; WINKWORTH, R. E. Application in agriculture, forestry and environment science. In: The neutron method. East Melbourne: CSIRO, 1981. cap. 2, p. 3-15. 
ZAMBÃO, J. C.; BELLINTANI NETO, A. M. Cultura da goiaba. Campinas: Cati, 1998. 23 p. (CATI. Boletim Técnico, 236)

ZANINI, J. R.; PAVANI, L. C. Irrigação da goiabeira. In: SIMPÓSIO BRASILEIRO SOBRE A CULTURA DA GOIABEIRA, 1., Jaboticabal, 1997. Anais Jaboticabal: UNESP, FCAJ, FUNEP, GOIABRAS, 1997, p. 93-115. 